BNL $\quad-46628$

INFORMAL REPORT

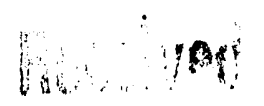

FEBO 109

\title{
AN ORGANIZATIONAL SURVEY OF
}

\section{THE PITTSBURGH ENERGY TECHNOLOGY CENTER}

by

David A. Stock, Deborah A. Shurberg, and Sonja B. Haber

September 1991 
DISCLAIMER

This report was prepared as an account of work sponsored by an agency of the United States Government. Neither the United States Government nor any agency thereof, nor any of their employees, nor any of their contractors, subcontractors, or their esmployees, makes any warranty, express or implied, or assumes any legal liability or responsibility for the accuracy, completeness, or usefulness of any information, apparatus, product, or process disclosed, or represents that its use would not infringe privately owned rights. Reference herein to any specific commercial product, process, or service by trade name, trademark, manufacturer, or otherwise, does not necessarily constitute or imply its endorsement, iecommendation, or favoring by the United States Government or any agency, contractor or subcontractor thereof. The views and opinions of authors expressed herein do not necessarily state or reflect those of the United States Government or any agency, contractor or subcontractor thereof. 


\section{AN ORGANIZATIONAL SURVEY OF}

\section{THE PITTSBURGH ENERGY TECHNOLOGY CENTER}

David A. Stock, Deborah A. Shurberg, and Sonja B. Haber

September 1991

Engineering Technology Division

Department of Nuclear Energy

Brookhaven National Laboratory, Associated Universities, Inc.

Upton, New York 11973

Prepared for:

Office of Environmen ${ }^{\star}$ Safety, and Health

U.S. Department of Energy

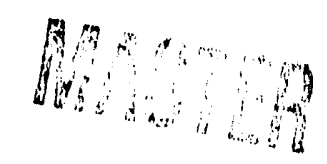




\section{EXECUTIVE SUMMARY}

An Organizational Survey (OS) was administered at the Pittsburgh Energy Technology Center (PETC) that queried employees on the subjects of organizational culture, various aspects of communications, employee commitment, work group cohesion, coordination of work, environmental, safety, and health concerns, hazardous nature of work, safety and overall job satisfaction. The purpose of the $O S$ is to measure in a quantitative and objective way the notion of "culture;" that is, the values, attitudes, and beliefs of the individuals working within the organization. In addition, through the OS, a broad sample of individuals can be reached that would probably not be interviewed or observed during the course of a typical assessment. The OS also provides a descriptive profile of the organization at one point in time that can then be compared to a profile taken at a different point in time to assess changes in the culture of the organization.

The OS administration at PETC was the eighth to occur at a Department of Energy (DOE) facility. It was only the second OS administration to survey both DOE and contractor employees due to the organizational structure of the facility. In the other OS administrations, only contractor employees have been surveyed. Of the 627 employees working at PETC, 565 completed the survey, yielding a response rate of 90.1 percent. Equivalent response rates were obtained from DOE employees ( 89.8 percent), Authorized Systems Inc. (ASI) employees (89.4 percent), and Burns and Roe, Gilbert/Commonwealth, and Science Applications International (TEAM) employees (82.1 percent). The Dynamic Concepts, Inc. (DCI) contractor organization had a 65.0 percent response rate.

Twenty-nine respondents to the survey chose not to categorize themselves by organization. All data from the OS is presented in group summaries, by organization, department within organization, staff classification (both overall and within organization), and supervisory level (both overall and within organization). Statistically significant differences between groups are identified and discussed.

The organizational profile which emerges from the results of the OS PETC sample is that of a constructive and passive/defensive cultural style, as indicated by high mean scores on the Humanistic (C1), Affiliative (C2), Achievement (C11), Conventional (C4), and Dependent (C5) Scales. PETC employees also perceive it: to be important to strive for and succeed in reaching goals, as evidenced by high mean scores on the Perfectionistic (C10) and Self-Actualizing (C12) Scales. Behaviors which might be described as indicative of avoiding responsibility or as being oppositional in nature are not perceived to be important to success within the organization by P'ETC employees.

Four aspec's of the communication process were assessed in the OS: Trust, Accuracy, Desire for Interaction, and General Satisfaction. The mean scores on these scales for the PETC sample indicated a moderate level of trust and satisfaction witk the communication process in the organization. The desire for interaction was slightly higher.

While PETC employees indicated cohesiveness within their working groups, they scored lower on overall commitment to the organization and on work coordination between organizational units. PETC employees also do not generally perceive their jobs to be highly hazardous, as evidenced by the mean score on the Hazard Scale. The mean scores for the questions dealing with the potential for onsite and offsite environmental consequences were also low, suggesting that 
employees do not perceive that poor performance in their working group would result in environmental consequences. However, PETC employees do believe the attributes related to operating in a safe manner are important as evidenced by the high mean score on the Safety Scale. Management emphasis on environmental issues and employee awareness of the risks in their work environment are also perceived to be high by the PETC employees responding to the survey.

Few statistically significant differences were obtained between the four organizations at PETC. Those that were obtained included a difference on perceived accuracy of communication, with DOE employees perceiving the information they receive to be more accurate than DCI employees do. Differences were also ubtained on the Hazard Scale, with TEAM and DCI employees indicating a greater perception of the hazardous nature of their work, than DOE and ASI employees. A similar result was obtained on the Onsite Environmental Consequences Question with ASI respondents having a significantly lower mean score on this question than both DCI and TEAM employees.

Analyses within the organizations, by department, yielded few statistically significant differences and only for the DOE, DCI and TEAM organizations. The majority of the differences obtained involved environmental, safety, and health issues. Similarly, differences obtained across staff classifications were on similar scales and questions. The only differences obtained across supervisory levels at PETC involved satisfaction with communication, with supervisors being more satisfied with the communication process, than non-supervisors.

In summary, the few differences obtained between groups at PETC is indicative of an organization with a homogeneous culture. The very few differences obtained on the questions dealing with organizational culture is further support for this notion. This homogeneity is unique from other DOE facilities at which multiple organizations are represented. Where differences were obtained in the PETC sample, they were related to environment, safety and health issues, and they appeared to be consistent with work function. 


\section{CONTENTS}

Page

EXECUTIVE SUMMARY $\ldots \ldots \ldots \ldots \ldots \ldots \ldots \ldots \ldots \ldots \ldots \ldots \ldots$ iii

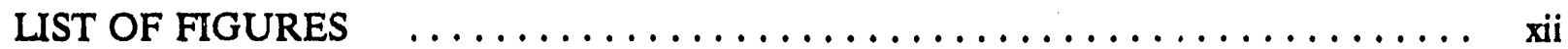

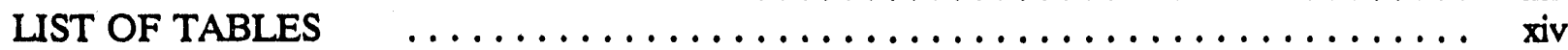

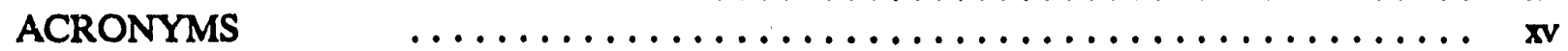

ACKNOWLEDGEMENT $\ldots \ldots \ldots \ldots \ldots \ldots \ldots \ldots \ldots \ldots \ldots \ldots \ldots \ldots$ svii

1. INTRODUCTION $\ldots \ldots \ldots \ldots \ldots \ldots \ldots \ldots \ldots \ldots \ldots \ldots \ldots \ldots \ldots \ldots$

2. METHODOLOGY $\ldots \ldots \ldots \ldots \ldots \ldots \ldots \ldots \ldots \ldots \ldots \ldots \ldots \ldots \ldots$

3. ORGANIZATIONAL DESCRIPTION $\ldots \ldots \ldots \ldots \ldots \ldots \ldots \ldots \ldots \ldots$ 3-1

4. ORGANIZATIONAL SURVEY SCALES AND RESULTS . . . . . . . . . . 4-1

4.1 Organizational Culture Inventory $\ldots \ldots \ldots \ldots \ldots \ldots \ldots \ldots \ldots \ldots$

4.1.1 Description ......................... 4-1

4.1 .2 Overall Profile ....................... 4-3

4.1.3 Differences Between Organizations on the OCI .......... 4.4

4.1.4 Differences Between DOE Departments on the OCI ......... 4. 4

4.1.5 Differences Between TEAM Departments on the OCI ........ 4-4

4.1.6 Differences Between ASI Departments on the OCI ......... 4. 4

4.1.7 Differences Between DCI Departments on the OCI ......... 4-5

4.1.8 Differences Between. Staff Classifications on the OCI ....... 4. 4-5

4.1.9 Differences Between Supervisory Levels on the OCI ........ . . 4-6

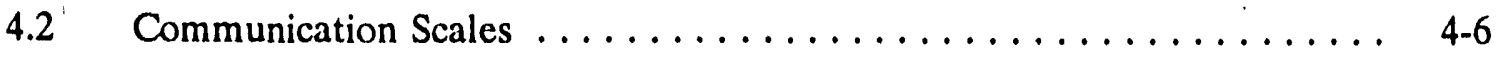

4.2.1 Description ........................ 4-6

4.2 .2 Overall PETC Results ...................... 4-7

4.2.3 Differences Between Organizations on the Communication Scales . 4-8

4.2.4 Differences Between DOE Departments on the Communication

Scales ... . . . . . . . . . . . . . . . . . . . . . 4-9

4.2.5 Differences Between TEAM Departments on the Communication

Scales ................................ 4-9

4.2.6 Differences Between ASI Departments on the Communication

Scales ............................... 4-9

4.2.7 Differences Between DCI Departments on the Communication

Scales ... . . . . . . . . . . . . . . . . . . . . . . . 4-9

4.2.8 Differences Between Staff Classifications on the Communication Scales . . . . . . . . . . . . . . . . . . 4-9

4.2.9 Differences Between Supervisory Levels on the

Communication Scales . . . . . . . . . . . . . . . . . . 4-10 
$4.3 \quad$ Commitment Scale $\ldots \ldots \ldots \ldots \ldots \ldots \ldots \ldots \ldots \ldots \ldots \ldots, 4-13$

4.3.1 Scale Description ......................... 4-13

4.3.2 Overall PETC Results .................... 4-13

4.3.3 Differences Between Organizations on the Commitment Scale ... 4-13

4.3.4 Differences Between DOE Departments on the Commitment Scale 4-14

4.3.5 Differences Between TEAM Departments on the Commitment

4.3.6 Differences Between ASI Departments on the Commitment

4.3.7 Differences Between DCI Departments on the Commitment Scale

4.3.8 Differences Between Staff Classifications on the Commitment

4.3.9 Differences Between Supervisory Levels on the Commitment

Scale .................................

4.4 Cohesion Scale $\ldots \ldots \ldots \ldots \ldots \ldots \ldots \ldots \ldots \ldots \ldots \ldots \ldots, 4-15$

4.4.1 Scale Description ........................ 4-15

4.4.2 Overall PETC Results ...................... 4-15

4.4.3 Differences Between Organizations on the Cohesion Scale ..... 4-15

4.4.4 Differences Between DOE Departments on the Cohesion Scale .. 4-15

4.4.5 Differences Between TEAM Departments on the Cohesion Scale . 4-15

4.4.6 Differences Between ASI Departments on the Cohesion Scale ... 4-15

4.4.7 Differences Between DCI Departments on the Cohesion Scale ... 4-15

4.4.8 Differences Between Staff Classifications on the Cohesion Scale ............................... 4-16

4.4.9 Differences Between Supervisory Levels on the Cohesion Scale .. 4-16

4.5 Coordination Scale $\ldots \ldots \ldots \ldots \ldots \ldots \ldots \ldots \ldots \ldots \ldots \ldots, 4-16$

4.5.1 Scale Description $\ldots \ldots \ldots \ldots \ldots \ldots \ldots \ldots \ldots \ldots \ldots, 4,16$

4.5.2 Overall PETC Results ...................... 4-16

4.5.3 Differences Between Organizations on the Coordination Scale ... 4-17

4.5.4 Differences Between DOE Departr ents on the Coordination Scale 4-17

4.5.5 Differences Between TEAM Departments on the Coordination Scale ............................ 4-17

4.5.6 Differences Between ASI Departments on the Coordination Scale ............................ 4-17

4.5.7 Differences Between DCI Departments on the Coordination Scale ............................. $4-27$ 


\section{CONTENTS (Continued)}

Page

4.5.8 Differences Between Staff Classifications on the Coordination

4.5.9 Differences Between Supervisory Levels on the Coordination

4.6.1 Description of Scale

4.6.2 Overall PETC Results

Differences Between Organizations on the Job Satisfaction

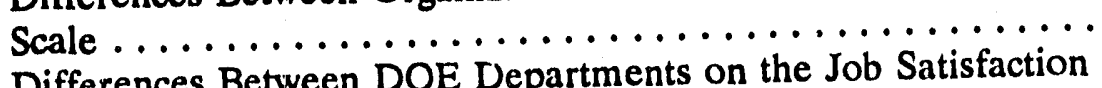

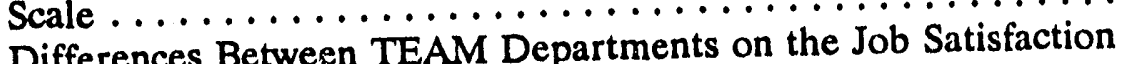

4.6.6 Differences Between ASI Departments on the Job Satisfaction

4.6.7 Differences Between DCI Departments on the Job Satisfaction

4.6.8 Differences Between Staff Classifications on the Job

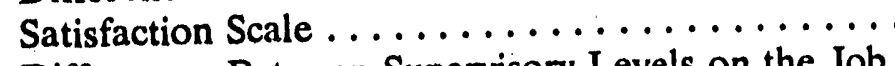

Satisfaction Scale

4.7.1 Scale Description

4.7 .2 Overall PETC Results ....................

4.7.3 Differences Between Organizations on the Hazard Scale ........

4.7.4 Differences Between DOE Departments on the Hazard Scale ....

4.7.6 Differences Between ASI Departments on the Hazard Scale . . . . .

4.7.7 Differences Between DCI Departments on the Hazard Scale ....

4.7.8 Differences Between Staff Classifications on the Hazard Scale ...

4.81 Scale Description ........................ 4-23

4.8 .2 Overall PETC Results . . . . . . . . . . . . . . . . . . 4-23

4.8.3 Differences Between Organizations on the Safety Scale ...... 4. 4-23

4.8.4 Differences Between DOE Departments on the Safety Scale ... . 4 4-23

4.8.5 Differences Between TEAM Departments on the Safety Scale ... 4-23

4.8.6 Differences Between ASI Departments on the Safety Scale . . . . . 4-24 
4.8.7 Differences Between DCI Departments on the Safety Scale . . . . 4- 4-24

4.8.8 Differences Between Staff Classifications on the Safety Scale . . . 4 4-24

4.8.9 Differences Between Supervisory Levels on the Safety Scale . . . . 4-24

4.9 Environment, Safety, and Health Questions $\ldots \ldots \ldots \ldots \ldots \ldots \ldots$. . . . . . . .

4.9.1 Question Descriptions . . . . . . . . . . . . . . . . . . . . . 4-24

4.9.2 Overall PETC Results . . . . . . . . . . . . . . . . . . . . . . . 4 4-24

4.9.3 Differences Between Organizations on the Environment, Safety, and Health Questions ...................... 4-25

4.9.4 Differences Between DOE Departments on the Environment, Safety, and Health Questions ................... 4-25

4.9.5 Differences Between TEAM Departments on the Environment, Safety, and Health Questions . . . . . . . . . . . . . . . 4-27

4.9.6 Differences Between ASI Departments on the Environment, Safety, and Health Questions . . . . . . . . . . . . . . . 4 4-29

4.9.7 Differences Between DCI Departments on the Environment, Safety, and Health Questions . . . . . . . . . . . . . . . . 4-29

4.9.8 Differences Between Staff Classifications on the Environment, Safety, and Health Questions . . . . . . . . . . . . . . . . . . 4-29

4.9.9 Differences Between Supervisory Levels on the Environment, Safety, and Health Questions ................. 4-32

5. CONCLUSIONS $\ldots \ldots \ldots \ldots \ldots \ldots \ldots \ldots \ldots \ldots \ldots \ldots \ldots \ldots \ldots \ldots \ldots \ldots$

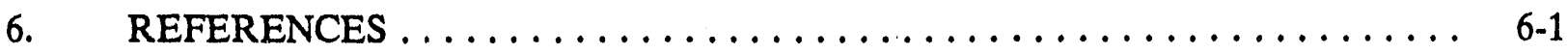

APPENDIX A: SIGNIFICANT DIFFERENCES BETWEEN ORGANIZATIONS

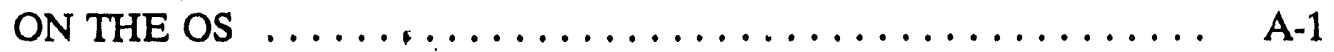

APPENDIX B: SIGNIFICANT DIFFERENCES BETWEEN DOE DEPARTMENTS

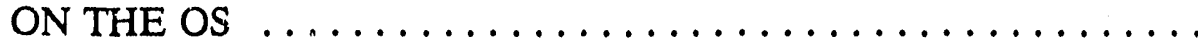

APPENDIX C: SIGNIFICANT DIFFERENCES BETWEEN TEAM DEPARTMENTS ON THE OS

APPENDIX D: SIGNIFICANT DIFFERENCES BETWEEN ASI DEPARTMENTS ON THE OS

APPENDIX E: SIGNIFICANT DIFFERENCES BETWEEN DCI DEPARTMENTS ON THE OS

APPENDIX F: SIGNIFICANT DIFFERENCES BETWEEN STAFF CLASSIFICATIONS ON THE OS $\ldots \ldots \ldots \ldots \ldots \ldots \ldots \ldots \ldots$ 
CONTENTS (Continued)

Page

APPENDIX G: SIGNIFICANT DIFFERENCES BETWEEN DOE STAFF CLASSI-

FICATIONS ON THE OS $\ldots \ldots \ldots \ldots \ldots \ldots \ldots \ldots$ G-1

APPENDIX H: SIGNIFICANT DIFFERENCES BETWEEN TEAM STAFF CLASSI-

FICATIONS ON THE OS $\ldots \ldots \ldots \ldots \ldots \ldots \ldots \ldots \ldots \ldots \ldots$ H-1

APPENDIX I: SIGNIFICANT DIFFERENCES BETWEEN ASI STAFF CLASSI-

FICATIONS ON THE OS $\ldots \ldots \ldots \ldots \ldots \ldots \ldots \ldots \ldots$ I-1

APPENDIX J: SIGNIFICANT DIFFERENCES BETWEEN SUPERVISORY

LEVELS ON THE OS .................... J-1

APPENDIX K: SIGNIFICANT DIFFERENCES BETWEEN DOE SUPERVISORY

LEVELS ON THE OS .................... K-1

APPENDIX L: SIGNIFICANT DIFFERENCES BETWEEN TEAM SUPERVISORY

LEVELS ON THE OS .................... L-1

APPENDIX M: SIGNIFICANT DIFFERENCES BETWEEN SUPERVISORS AND

NON-SUPERVISORS ON THE OS ................ M-1

APPENDIX N: SIGNIFICANT DIFFERENCES BETWEEN DOE SUPERVISORS

AND NON SUPERVISORS ON THE OS ............ N-1

APPENDIX O: SIGNIFICANT DIFFER้ENCES BETWEEN TEAM SUPER-

VISORS ANL NON-SUPERVISORS ON THE OS ......... O-1

APPENDIX P: SIGNIFICANT DIFFERENCES BETWEEN ASI SUPERVISORS AND NON-SUPERV!SORS ON THE OS $\ldots \ldots \ldots \ldots \ldots$ P-1

APPENDIX Q: SIGNIFICANT DIFFERENCES BETWEEN DCI SUPERVISORS AND NON-SUPERVISORS ON THE OS ............ Q

APPENDIX R: COMPARISON OF PETC ORGANIZATIONS TO OVERALL PETC MEAN VALUES ON THE OCI SCALES $\ldots \ldots \ldots \ldots \ldots \ldots$ R-1

APPENDIX S: COMPARISON OF PETC ORGANIZATIONS TO OVERALL PETC MEAN VALUES ON THE COMMUNICATIONS SCALES . S-1

APPENDIX T: COMPARISON OF PETC ORGANIZATIONS TO OVERALL PETC MEAN VALUES ON THE ADDITIONAL SCALES . . . . . T T-1 
CONTENTS (Continued)

Page

APPENDIX U: COMPARISON OF PETC ORGANIZATIONS TO OVERALL PETC MEAN VALUES ON THE ENVIRONMENT, SAFETY, AND HEALTH QUESTIONS $\ldots \ldots \ldots \ldots \ldots \ldots \ldots \ldots$

APPENDIX V: COMPARISON OF DOE DEPARTMENTS TO THE OVERALL DOE MEAN VALUES ON THE OS $\ldots \ldots \ldots \ldots \ldots \ldots \ldots, \quad$ V-1

APPENDIX W: COMPARISON OF TEAM DEPARTMENTS TO THE OVERALI TEAM MEAN VALUES ON THE OS $\ldots \ldots \ldots \ldots \ldots \ldots \ldots, W-1$

APPENDIX X: COMPARISON OF ASI DEPARTMENTS TO THE OVERALL ASI MEAN VALUES ON THE OS $\ldots \ldots \ldots \ldots \ldots \ldots \ldots \ldots, \mathrm{X}-1$

APPENDIX Y: COMPARISON OF DCI DEPARTMENTS TO THE OVERALL DCI MEAN VALUES ON THE OS ................. Y.1

APPENDIX Z: COMPARISON OF DOE DEPARTMENTS TO THE OVERALL DOE MEAN VALUES ON THE COMMUNICATION SCALES . .

APPENDIX AA: COMPARISON OF TEAM DEPARTMENTS TO THE OVERALL TEAM MEAN VALUES ON THE COMMUNICATION SCALES .

APPENDIX BB: COMPARISON OF ASI DEPARTMENTS TO THE OVERALL ASI MEAN VALUES ON THE COMMUNICATION SCALES ...

BB-1

APPENDIX CC: COMPARISON OF DCI DEPARTMENTS TO THE OVERALL DCI MEAN VALUES ON THE COMMUNICATION SCALES ... CC-1

APPENDIX DD: COMPARISON OF DOE DEPARTMENTS TO THE OVERALL DOE MEAN VALUES ON THE ADDITIONAL SCALES ...... DD-1

APPENDIX EE: COMPARISON OF TEAM DEPARTMENTS TO THE OVERALL TEAM MEAN VALUES ON THE ADDITIONAL SCALES .....

EE-1

APPENDIX FF: COMPARISON OF ASI DEPARTMENTS TO THE OVERALL ASI MEAN VALIUES ON THE ADDITIONAL SCALES ....... FF-1

APPENDIX GG: COMPARISON OF DCI DEPARTMENTS TO THE OVERALL DCI MEAN VALUES ON THE ADDITIONAL SCALES ....... GG-1 APPENDIX HH: COMPARISON OF DOE DEPARTMENTS TO THE OVERALL DOE MEAN VALUES ON THE ENVIRONMENT, SAFETY, AND HEALTH QUESTIONS 
CONTENTS (Continued)

APPENDIX II: COMPARISON OF TEAM DEPARTMENTS TO THE OVERALL TEAM MEAN VALUES ON THE ENVIRONMENT, SAFETY, AND HEALTH QUESTIONS

APPENDIX JJ: COMPARISON OF ASI DEPARTMENTS TO THE OVERALL ASI MEAN VALUES ON THE ENVIRONMENT, SAFETY, AND HEALTH QUESTIONS

APPENDIX KK: COMPARISON OF DCI DEPARTMENTS TO THE OVERALL DCI MEAN VALUES ON THE ENVIRONMENT, SAFETY, AND HEALTH QUESTIONS 


\section{LIST OF FIGURES}

Page

4.1 Overall mean values on OCI for PETC $\ldots \ldots \ldots \ldots \ldots \ldots \ldots \ldots \ldots \ldots$

4.2 Significant differences between staff classifications on the perfectionistic scale . . . 4-5

4.3 Significant differences between DCI supervisors and non-supervisors on the perfectionistic scale . . . . . . . . . . . . . . . . . . . . . $4-7$

4.4 Overall mean values on communication scales for PETC $\ldots \ldots \ldots \ldots \ldots \ldots \ldots$

4.5 Significant differences between organizations on the communication-accuracy scale $\quad \ldots \ldots \ldots \ldots \ldots \ldots \ldots \ldots \ldots \ldots \ldots \ldots \ldots \ldots \ldots . \ldots \ldots$. . . . . . . . . .

4.6 Significant differences between DCI departments on the communication-trust

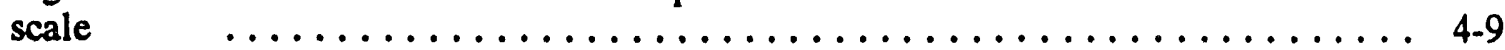

4.7 Significant differences between DCI departments on the communicationinteraction scale $\ldots \ldots \ldots \ldots \ldots \ldots \ldots \ldots \ldots \ldots \ldots \ldots \ldots \ldots \ldots \ldots$. . . . . . . . . . . .

4.8 Significant differences between supervisory levels on the communication-

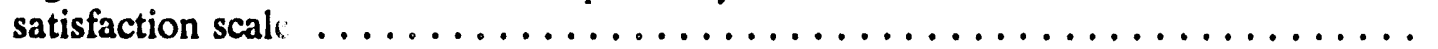

4.9 Significant differences between supervisory levels at the TEAM organization on

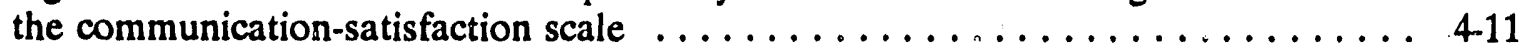

4.10 Significant differences between supervisors and non-supervisors on the communication-satisfaction scale $\ldots \ldots \ldots \ldots \ldots \ldots \ldots \ldots \ldots \ldots \ldots \ldots \ldots \ldots$. $\ldots \ldots \ldots$

4.11 Significant differences between TEAM supervisors and non-supervisors on the

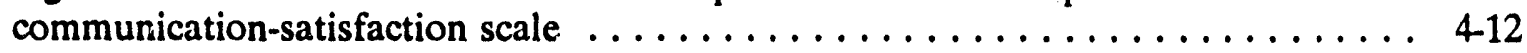

4.12 Overall mean values on additional scales for PETC . . . . . . . . . . . . 4-13

4.13 Significant differences between DCI departments on the cohesion scale ...... 4-16

4.14 Significant differences between PETC organizations on the hazard scale . . . . . 4 4-20

4.15 Significant differences between DOE departments on the hazard scale . . . . . . 420

4.16 Signiticant differences between TEAM departments on the hazard scale . . . . . 4 421

4.17 Significant differences between staff classifications on the hazard scale . . . . . . 4-22

4.18 Significant differences between TEAM staff classifications on the hazard scale . . . 4-22

4.19 Overall means on environment, safety, and health questions . . . . . . . . . . 4-25

4.20 Significant differences between organizations on the onsite environment, safety, and health question $\ldots \ldots \ldots \ldots \ldots \ldots \ldots \ldots \ldots \ldots \ldots \ldots \ldots \ldots$. $\ldots \ldots \ldots$

4.21 Significant differences between DOE departments on the management emphasis

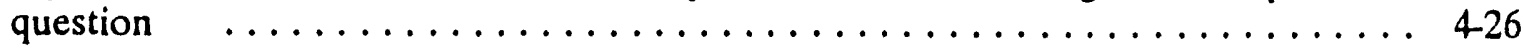

4.22 Significant differences between DOE departments on the employee awareness

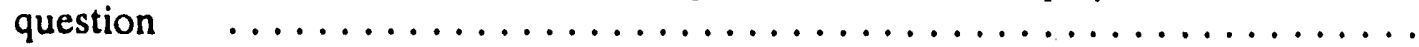

4.23 Significant differences between TEAM departments on the offsite consequences

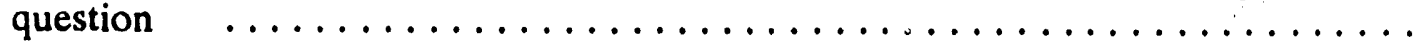

4.24 Significant differences between TEAM departments on onsite consequences

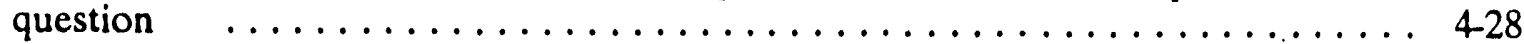

4.25 Significant differences between TEAM departments on the employee awareness

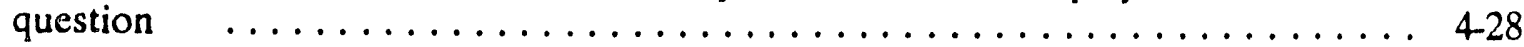

4.26 Significant differences between staff classifications on the offsite consequences

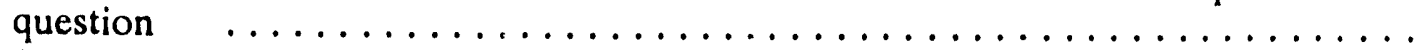

4.27 Significant differences between staff classifications on the onsite consequences

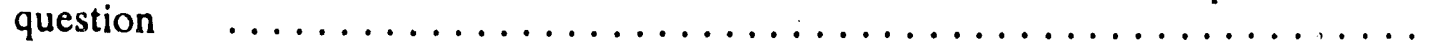




\section{LIST OF FIGURES (Continued)}

Page

4.28 Significant differences between staff classifications on the employee awareness

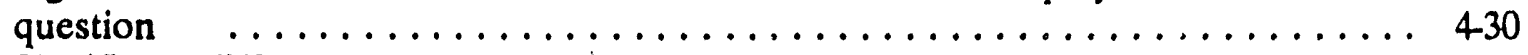

4.29 Significant differences between TEAM staff classifications on the offsite

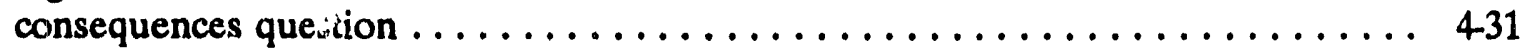

4.30 Significant differences between TEAM staff classifications on the onsite

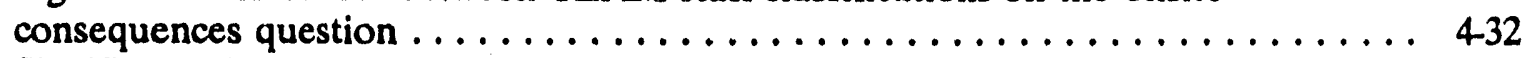

4.31 Significant differences between TEAM staff classifications on the employee

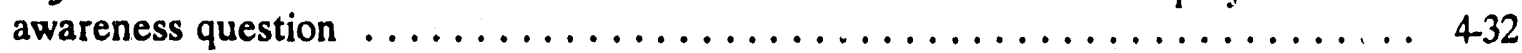




\section{LIST OF TABLES}

3.1 Response Rate by Organization for PETC . . . . . . . . . . . . . . $3-1$

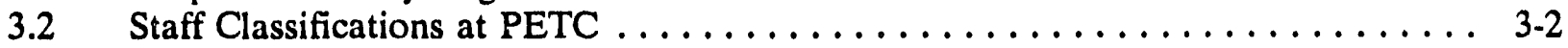

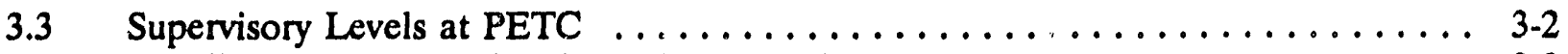

3.4 Distribution of Educational Levels at PETC $\ldots \ldots \ldots \ldots \ldots \ldots \ldots \ldots \ldots$

3.5 Distribution of Number of Years at PETC $\ldots \ldots \ldots \ldots \ldots \ldots \ldots \ldots \ldots$

3.6 Modal Educational Level and Mean Number of Years at

PETC Overill and for Each Department 


\section{ACRONYMS}

\section{Organization}

ASI

DCI

DOE

TEAM

ADS

ADP

PMS

ESH

MNT

SEC

$A D$

CCT

DI

PM

R\&D

Authorized Systems, Inc.

Dynamic Concepts, Inc.

U.S. Department of Energy

BRSC (Burns \& Roe Services Corporation),

GCI (Gilbert/Commonwealth, Inc.), and

SAIC (Science Ap: lications International Corp.)

\section{ASI Departments}

Administrative Support

ADP Support

Project Management \& Support Services (Project Support, Project Management, Research Support)

\section{Departmerts}

Environment, Sarety, and Health

Maintenance/Janitorial

Security

\section{DOE Departments}

Administration

Clean Coal Technology

Directors Office

Project Management

Research \& Development

\section{TEAM Departments}

ADM

ESH

MIS

PRO

R\&D

RPM

TEK

Administrative Services

Environment, Safety, and Health Services

Management and Information Serrices

Project Support

Research \& Development

Real Property Management Services

Technical Management Services

\section{$\underline{\text { Staff Classifications }}$}

ADM Administration

ENG

Engineering/Scientific Staff

ESH Environment, Safety, and Health

LAB Laboratory Research 
ACRONYMS FOR PETC (Cont'd.)

Staff Classifications (cont'd.)

$\begin{array}{ll}\text { MNT } & \text { Maintenance/Janitorial } \\ \text { OFF } & \text { Office/Clerical } \\ \text { PRO } & \text { Program Management } \\ \text { PUB } & \text { Public Affairs } \\ \text { R\&D } & \text { Research and Development } \\ \text { SYS } & \text { Systems Staff } \\ \text { OTH } & \text { Other }\end{array}$

Supervisory Levels

ADS

NSU

SES

SUP

Administrative Supervisor

Non-Supervisor

Scientific/Engineering Supervisor

Supervisor

\section{Survey Scales}

C1 Humanistic-Encouraging

C2 Affiliative

C3 Approval

C4 Conventional

C5 Dependent

C6 Avoidance

C7 Oppositional

C3 Power

C9 Competition

C10 Perfectionistic

C11 Achievement

C12 Self-Actualizing

ACCURACY (CMA)

AWARENESS (EMA)

COHESION (COH)

COMMITMT (COT)

COORE (COD)

EMPHASIS (MGE)

HAZARD (HAZ)

INTERACT (CMI)

JOBSAT (JOB)

OFFSITE (OFF)

ONSITE (ONS)

SAFETY (SAF)

SATISFAC (CMS)

TRUST (CMT)
Perceived Accuracy of Communications

Employee Awareness of Workplace Hazards

Cohesion of Work Group

Organizational Commitment

Coordination

Management Emphasis of Environmental Issues

Perceived Hazardous Nature of Work

Desirability of Interaction with Others

Overall Job Satisfaction

Consequence to Offsite Environment

Consequence to Onsite Environment

Attention to Safety

Satisfaction with Communications

Trust in Communications 


\section{ACKNOWLEDGEMENT}

The authors wish to thank the Department of Energy (DOE) staff that have been supportive and facilitative of this work, Mark Gilbertson and Larry Weiner, and George Bellows and Laura Brletich of the Pittsburgh Energy Technology Center (PETC) for their cooperation in this effort, in particular, for help in arranging the logistics and details of the survey administration.

We also extend our appreciation to the efforts of our Brookhaven National Laboratory colleague, Kathleen Nasta, for her help in administering the survey and in preparing this manuscript, and Sonja Santos for her proficiency in graph production. In addition, the review, comments, and insights provided by James Higgins were also very much appreciated. 


\section{INTRODUCTION}

An Organizational Survey (OS) was administered at the Pittsburgh Energy Technology Center (PETC) that queried employees on the subjects of organizational culture, various aspects of communication, employee commitment, work group cohesion, coordination of work, environmental concerns, hazardous nature of work, safety, and overall job satisfaction. A description of each of the scales used to address these subjects is discussed in Section 4.1.

The primary purpose of administering the survey was to attempt to measure, in a quantitative and objective way the notion of "organizational culture," that is, the values, attitudes, and beliefs of the individuals working within the organization. In particular, those aspects of the working environment which are believed to be important influences on the operations of a facility and on the safety issues relevant to the organization were assessed.

In addition, by conducting a survey, a broad sampling of the individuals in the organization can be obtained. This is especially important when the survey is utilized in conjunction with an assessment or inspection team which typically has only a limited amount of resources to address many issues. The OS provides a broad, but comprehensive picture of the organization by querying a much larger number of individuals than could be reached through the assessment team alone.

Finally, the OS provides a descriptive profile of the organization at one point in time. This profile can then be used as a baseline point against which comparisons of other points in time can be made. Such comparisons may prove valuable and would help to measure changes in the organizational culture. Comparisons of the profiles can also be made across similar facilities. 


\section{METHODOLOGY}

The Organizational Survey (OS) was administered to the employees of the Pittsburgh Energy Technology Center (PETC) in large groups. The surveys were administered on August 6, 1991. Included with the survey was a cover letter explaining the purpose for the survey administration. Prior to the survey administration, a memorandum from the Director of PETC was circulated. This memorandum encouraged employees to complete the survey and contained the times at which various groups of employees were to take the survey. A background sheet attached to the survey requested information pertaining to the organization and department in which the respondent was located, the number of years they have been working at PETC, their staff classification, supervisory, and educational levels.

Two subject matter experts familiar with the survey were at PETC during the survey administration in order to distribute the surveys and to answer any questions which employees may have had while taking the questionnaire. A total of 565 surveys were completed, for a response rate of 90.1 percent. The surveys were taken from PETC for data entry and analysis.

Overall means, standard errors, and standard deviations were computed for each scale assessed in the OS. A one-way analysis of variance was also performed on each OS scale using the scale score as the dependent variable, and separate analyses using organization, department within organization, staff classification (both overall and within organizations), and supervisory level (both overall and within organizations) as the independent variables. In order to control the false positive rate (Type I error rate), the Bonferroni correction was applied to all the analyses of variance performed for each independent variable. Since there were 26 one-way analyses of variance for each independent variable, the significance level for each analysis of variance was reduced to $.05 / 26=.0019$. Where the analysis of variance showed a significant difference among the group means at the .0019 level, a Tukey HSD (Honestly Significant Difference) (Hays, 1988) procedure was applied to identify those means that were statistically significantly different from each other. Consequentl:; the results that are reported to be significantly different from each other represent a very conservative approach in the interpretation of the data analyses performed.

Included in this report are the overall results for PETC on each of the scales used in the OS. In addition, any statistically significant differences between organizations, departments within organizations, staff classifications and supervisory levels, both overall and within organizations, are also presented. 


\section{ORGANIZATIONAL DESCRIPTION}

The Pittsburgh Energy Technology Center (PETC) is unique from most of the other U.S. Department of Energy (DOE) facilities which have taken the Organizational Survey (OS). A large number of DOE employees are involved in the primary work flow of the organization. The three groups of contractors at PETC, Authorized Systems, Inc. (ASI), Dynamic Concepts, Inc. (DCI), and TEAM (comprised of Burns and Roe Services Corporation, Gilbert/Commonwealth, Inc., and Science Applications International Corporation), perform mainly support functions (e.g., Environment, Safety, and Health Services, Management and Information Services, Maintenance/Janitorial). Within each organizatiol, the organizational units are identified as departments. The demographics sheet used in the administration of the OS included five departments for DOE, three departments for ASI, three departments for DCI, and seven departments for TEAM. The four organizations, as used in this report are presented in Table 3.1. Also presented in this table are the response rates for each organization. The response rate is computed by dividing the number of surveys returned by the number of employees in that organization.

Table 3.1. Response Rate by Organization for PETC

\begin{tabular}{||r|r|r|r||}
\hline \multicolumn{1}{|c|}{ Organization/Department } & No. Responses & No. Employees & Response Rate \\
\hline \hline Department of Energy (DOE) & 289 & 322 & 89.8 \\
\hline Authorized Systems Inc. (ASI) & 42 & 47 & 89.4 \\
\hline Dynamic Cr,ncepts Inc. (DCI) & 26 & 40 & 65.0 \\
\hline BRSC, GCI, SAIC (TEAM) & 179 & 218 & 82.1 \\
\hline Unknown & 29 & -- & - \\
\hline & 565 & 627 & 90.1 \\
\hline
\end{tabular}

Both DOE and ASI had comparablc response rates ( 89.8 and 89.4 percent, respectively). The TEAM Organization had a somewhat lower, although still high, response rate of 82.1 percent. Of the four organizations at PETC, the DCI Organization had the lowest response rate, 65.0 percent.

PETC employees were also given fifteen staff classifications in which to categorize themselves. These fifteen staff classifications were later condensed into the eleven staff classifications presented in Table 3.2. This was a result of the fact that some of the staff classifications which were specific to an organization did not have a large enough number of respondents to allow statistical analysis. In some instances, another organization had a staff classification similar in function, but with a different title. The similarly functioning classifications were grouped together to form the list presented. Also presented in Table 3.2 are the number of respondents who placed themselves into each category and the percent of the total sample that number represents.

The Research and Development Staff Classification had the largest percentage of the total sample (21.2 percent). The Administration, Engineering/Scientific Staff and Other/Unknown Staff Classifications accounted for $15.2,12,0$, and 11.5 percent of the sample, respectively. The Public Affairs Staff Classification comprised the smallest percent of the total sample ( 2.0 percent). 
Table 3.2. Staff Classifications at PETC

\begin{tabular}{|l|c|c|}
\hline \multicolumn{1}{|c|}{ Staff Classification } & No. Responses & $\begin{array}{c}\text { Percent of } \\
\text { Total Sample }\end{array}$ \\
\hline \hline Administration & 86 & 15.2 \\
\hline Engineering/Scientific Staff & 68 & 12.0 \\
\hline ES\&H & 27 & 4.8 \\
\hline Laboratory Research & 31 & 5.5 \\
\hline Maintenance/Janitorial & 33 & 5.8 \\
\hline Office, Clerical & 47 & 8.3 \\
\hline Program Management & 52 & 9.2 \\
\hline Public Affairs & 11 & 2.0 \\
\hline Research and Development & 120 & 21.2 \\
\hline Systems Staff & 25 & 4.4 \\
\hline Other and Unknown & 65 & 11.5 \\
\hline & 565 & 100.0 \\
\hline
\end{tabular}

The OS demographics questions used at PETC also provided three categories of supervisory levels by which an employee could identify him/herself. Table 3.3 presents the three supervisory levels used, as well as the total number of respondents in each category and the percentage of the total sample that number represents.

Table 3.3. Supervisory Levels at PETC

\begin{tabular}{||l|c|c|}
\hline \multicolumn{1}{|c|}{ Supervisory Level } & No. Responses & $\begin{array}{c}\text { Percent of } \\
\text { Total Sample }\end{array}$ \\
\hline \hline Administrative Supervisor & 65 & 11.5 \\
\hline Scientific/Engineering Supervisor & 70 & 12.4 \\
\hline Non-Supervisor & 399 & 70.6 \\
\hline Unknown & 31 & 5.5 \\
\hline
\end{tabular}

Table 3.4 depicts the number of responses and the percent of the total sample by educational level for PETC. The majority of respondents at PF TC indicated they had a college degree or higher educational level, and in fact, the largest percentage of the sample have a graduate degree (26.7 percent). 
Table 3.4. Distribution of Educational Levels at PETC

\begin{tabular}{||l|c|c||}
\hline \multicolumn{1}{|c|}{ Educational Level } & No. Responses & $\begin{array}{c}\text { Percent of } \\
\text { Total Sampie }\end{array}$ \\
\hline \hline Some High School & 4 & 0.7 \\
\hline High School Degree & 65 & 11.5 \\
\hline Some Technical School & 13 & 2.3 \\
\hline 2-Year Technical Degree & 33 & 5.9 \\
\hline Some College & 94 & 16.6 \\
\hline 2-Year College Degree & 25 & 4.4 \\
\hline 4-Year College Degree & 109 & 19.3 \\
\hline Some Graduate Work & 41 & 7.3 \\
\hline Graduate Degree & 151 & 26.7 \\
\hline Unknown & 30 & 5.3 \\
\hline
\end{tabular}

Table 3.5 presents information on the number of years the respondents have been at PETC. The majority of survey respondents, 41.6 percent, reported that they had been at PETC between one and five years. Only 30 individuals, or 5.3 percent of the sample, chose not to indicate the number of years they had been at PETC.

Table 3.6 presents the modal educational level and mean number of years at PETC for the survey respondents, overall in each organization, and in each department. Overall, the modal educational level was a Graduate Degree and the mean number of years at PETC was 9.1.

Overall, for the DOE Organization, the modal educational level was a Graduate Degree and the mean number of years at PETC was 8.6. In the DOE Departments, three of the five departments included on the demographics sheet had modal educational levels of a Graduate Degree. The Director's Office had the lowest modal educational level of Some College. The Research and Development Department had the longest tenure at PETC of the DOE departments, 12.7 years. The DOE department with the lowest mean number of years at PETC was the Administration Department, with an average number of years at PETC of 8.4.

Within the ASI Organization, the modal educational level was a Four-Year College Degree and an average number of years at PETC of 5.9 years. Two of the three departments included on the demographics sheet for DCI also had modal educational levels of a Four-Year College Degree. The third department, Project Management and Support Services, had a modal educational level of a High School Degree. Both the Administrative Support and Project Management and Support Services Departments had equivalent average tenure at PETC, 6.6 and 6.2 years respectively. The ADP Support Department had the shortest average length of tenure at PETC, 4.9 years. 
Table 3.5. Distribution of Number of Years at PETC

\begin{tabular}{||l|c|r|}
\hline \multicolumn{1}{|c|}{ No. Years } & No. Respondents & $\begin{array}{c}\text { Percent of } \\
\text { Total Sample }\end{array}$ \\
\hline \hline $1-5$ years & 235 & 41.6 \\
\hline $6-10$ years & 91 & 16.1 \\
\hline $11-15$ years & 100 & 17.7 \\
\hline $16-20$ years & 70 & 12.4 \\
\hline $21-25$ years & 20 & 3.5 \\
\hline $26-30$ years & 9 & 1.6 \\
\hline$>30$ years & 10 & 1.8 \\
\hline Unknown & 30 & 5.3 \\
\hline
\end{tabular}

The DCI Organization had a modal educational level of a High School Degree and a mean number of years at PETC of 6.1 years. Two of the three DCI Departments also had modal educational levels of High School Degrees. The third DCI Department, Environment, Safety, and Health, had a modal educational level of Some College. The Environment, Safety and Health Department had a mean number of years at PETC of 9.2, the longest of the three DCI Organizations. The Security Department had the shortest tenure at PETC 4.4 years.

The modal educational level for the TEAM Organization was a Four-Year College Degree and the mean length of time at PETC for those TEAM employees who responded to the survey was 7.0 years. Four of the seven TEAM departments had a modal educational level of a Four-Year College Degree. The Technical Management Services Department had the highest mod: i educational level of a Graduate Degree. The Real Property Maintenance Services Department ha. a modal educational level of a High School Degree. The Real Property Maintenance Services Department also had the greatest length of time at PETC, 11.1 years. The TEAM department with the shortest average tenure at PETC was the Administrative Services Department, with an average of 3.9 years. 
Table 3.6. Modal Educational Level and Mean Number of Years at PETC Overall and for Each Department

\begin{tabular}{|c|c|c|}
\hline Department & $\begin{array}{c}\text { Educational } \\
\text { Level }^{1}\end{array}$ & $\begin{array}{l}\text { Years at } \\
\text { PETC }\end{array}$ \\
\hline Overall: & 9 & 9.1 \\
\hline DOE & 9 & 8.6 \\
\hline Directors Office & 5 & 11.6 \\
\hline Clean Coal Technology & 9 & 9.4 \\
\hline Project Management & 9 & 10.4 \\
\hline Research and Development & 9 & 12.7 \\
\hline Administration & 7 & 8.4 \\
\hline ASI & 7 & 5.9 \\
\hline Project Management \& Support Services & 2 & 6.2 \\
\hline Administrative Support & 7 & 6.6 \\
\hline ADP Support & 7 & 4.9 \\
\hline DCI & 2 & 6.1 \\
\hline Security & 2 & 4.4 \\
\hline Maintenance/Janitorial & 2 & 5.4 \\
\hline Environment, Safety, and Health & 5 & 9.2 \\
\hline TEAM & 7 & 7.0 \\
\hline Project Support & 7 & 6.7 \\
\hline Administrative Services & 7 & 3.9 \\
\hline Real Property Maintenance Services & 2 & 11.1 \\
\hline Research and Development & 7 & 8.4 \\
\hline Environment, Safety, and Health Services & 8 & 4.1 \\
\hline Technical Management Services & 9 & 4.8 \\
\hline Management and Information Services & 7 & 4.0 \\
\hline
\end{tabular}

Note:

For educational level: 2 = High School Degree, 5 = Some College, $6=2$-Ycar College Degree, 7 = 4-Year College Degree $8=$ Some Graduate Work, $9=$ Graduate Degree. 


\section{ORGANIZATIONAL SURVEY SCALES AND RESULTS}

The Organizational Survey (OS) administered at the Pittsburgh Energy Technology Center (PETC) was comprised of the Organizational Culture Inventory (OCI) (Human Synergistics, 1987), consisting of 12 scales describing different organizational cultural styles, and scales assessing communication processes, commitment to the organization, cohesiveness of work group, coordination of work, overall job satisfaction, perceived hazardous nature of work, attention to safety, and questions concerning environmental, safety, and health issues. The results from each of these scales are discussed in the sections that follow. Each section presents the overall results for PETC on that scale(s), the results by organization, by department within organization, by staff classification (both overall and within organization), and by supervisory level (both overall and within organization).

\subsection{Organizational Culture Inventory}

\subsubsection{Description}

The philosophy of management, the mission of the organization, and the strategic chcices management makes determine the culture of the organization (Cooke and Burack, 1987). The aspect of culture most immediately affected by these factors is what is valued by the organization. The extent to which these values are recognized and shared reflects the strength of the organization's culture. Organizational factors, along with these shared values, influence the operating structures of the organization, its human resource management practices, and the styles of its managers and supervisors. To the extent that these shared values and behavioral norms can be measured and evaluated, data collection of this type is important in understanding the organizational factors that influence perfermance.

The Organizational Culture Inventory (OCl) (Human Synergistics, 1987) is a paper-and-pencil diagnostic system for measuring the aspects of organizational culture that have the greatest impact on the activities of members and the functioning of the organization. Respondents are asked to review 120 statements which describe some of the thinking and behavioral styles that members of an organization may be expected to adopt in carrying out their work and in interacting with others. These statements measure 12 different cultural styles, some of which are indicative of a positive and supportive environment, while others are useful in identifying potentially dysfunctional environments. All of the styles measured by the $\mathrm{OCI}$ are related to, and result from, organizational structural variables, reward systems, managerial styles and philosophies, and other factors that can be changed, at least to some extent, by those in leadership positions.

The 12 organizational culture styles, with examples of the items used to assess each one, are described below.

C1: HUMANISTIC-ENCOURAGING: Organizations which are managed in a participative and personcentered way. Members are expected to be supportive, constructive, and open to influence in their dealings with one another.

- Involving subordinates in decisions;

- Showing concern for the needs of others.

C2: AFFILIATIVE: Organizations which place high priority on constructive personal relations. The members are expected to be friendly, open, and sensitive to the satisfaction of their work group. 
- Thinking in terms of the group satisfaction;

- Using good human relations skills.

C3: APPROVAL: Organizations in which conflicts are avoided and personal relations are pleasant, at least superficially. Members feel they should agree with and gain approval of others.

- Staying on the good side of superiors;

- Making sure people accept you.

C4: CONVENTIONAL: Organizations that are conservative, traditional, and bureaucratically controlled. Members are expected to conform, follow rules, and make a good impression.

- Always following policies and practices;

- Avoiding confrontations.

C5: DEPENDENT: Organizations that are hierarchically controlled and non-participative. Centralized decision-making leads members to do only what they are told and to clear all decisions with superiors.

- Accepting goals without questioning them;

- Never challenging superiors.

C6: AVOIDANCE: Organizations that do not reward success but punish failures. Negative rewards leads members to shift responsibility to others and avoid being blamed fo mistakes.

- Taking few chances;

- Laying "low" when things get tough.

C7: OPPOSITIONAL: Organizations in which confrontation prevails and negativism is rewarded. Members gain status and influence by being critical and are encouraged to oppose the ideas of others.

- Pointing out flaws;

- Remaining aloof from the situation.

C8: POWER: Non-participative organizations which are structured on the basis of authority in members' positions. Members expect to take charge, control subordinates, and respond to demands of superiors.

- Demanding loyalty;

- Acting forceful.

C9: COMPETITION: Organizations where winning is valued and rewards are given for out-performing others. Members operate in a "win-lose" framework and work against their peers to be noticed.

- Always trying to be right;

- Out-performing one's peers.

C10: PERFECTIONISTIC: Organizations in which persistence, hard work, and perfectionism are highly valued. Members feel they must avoid all mistakes, keep track of everything, and work long hours to attain specific objectives. 
- Setting unrealistically high goals;

- Viewing work as more important than anything else.

C11: ACHIEVEMENT: Organizations that do things well and value members who set and accomplish their own goals. Members set challenging, but realistic goals, and plan and pursue them with enthusiasm.

- Exploring alternatives before acting;

- Pursuing a standard of excellence.

C12: SELF-ACTUALIZING: Organizations that value creativity, quality over quantity, tasks, and individual growth. Members are encouraged to gain satisfaction from their work, develop themselves, and take on new activities.

- Thinking in unique and independent ways;

- Communicating ideas.

From these twelve scales, three cultural styles are described. The first style is comprised of the Humanistic-Encouraging Scale (C1), the Affiliative Scale (C2), the Achievement Scale (C11), and the Self-Actualizing Scale (C12). These scales are considered "Constructive;" in other words, organizations which score high on these four scales tend to promote behaviors which are conducive to the satisfaction of the organizational members.

The second cultural style is the "Passive/Defensive Style." This style is made up of the Approval Scale (C3), the Conventional Scale (C4), the Dependent Scale (C5), and the Avoidance Scale (C6). In organizations which score high on these scales, a culture exists which leads employees of the organization to act and react in a defensive way and at the same time, act in a way which does not pose a threat to one's own security within that organization.

A third cultural style is made up of the Oppositional Scale (C7), the Power Scale (C8), the Competitive Scale (C9), and the Perfectionistic Scale (C10). Organizations which score high on these scales often expect members to act in a way that is both forceful and which protects one's position and status. In other words, members adopt an "Aggressive/Defensive Style" in order to be successful within the organization.

\subsubsection{Overall Profile}

The overall mean scores on the OCI scales for the entire sample of PETC employees who responded to the Organizational Survey (OS) are depicted in Figure 4.1. The scales are identified by number and are described in the preceding section. The scores represent the mean score for the entire sample where the score 1 equals not at all and the score 5 equals to a great extent.

Based on the sample of PETC employees who responded to the OS, the organizational profile reflected on the $\mathrm{OCI}$ is best described by the constructive and passive/defensive cultural styles. The constructive style is comprised of the Humanistic (C1), Affiliative (C2), Achievement (C11), and SelfActualizing (C12) scales. The passive/defensive style is comprised of the Approval (C3), Conventional (C4), Dependent (C5), and Avoidance (C6) Scales. The style for PETC is best exemplified by the high mean scores on the Humanistic, Affiliative, Achievement, Conventional, and Dependent Scales. This indicates that respondents believe that the behaviors which are important to success in the organization 
are those which are constructive and defensive (i.e., "Using good human relations skills," "Pursuing a standard of excellence," "Never challenging superiors"). The mean score obtained on the Perfectionistic (C10) Scale indicates that employees believe persistence, hard work, and perfectionism are also valued by the PETC organization.

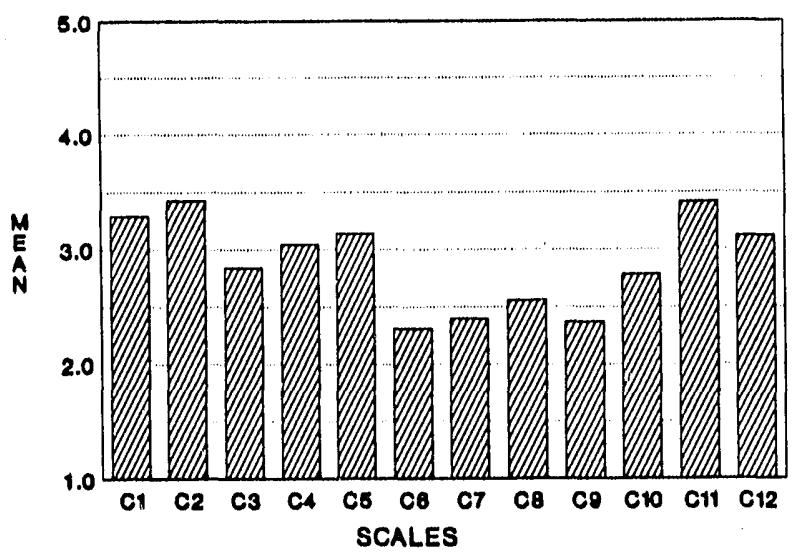

Figure 4.1. Overall mean values on OCI for PETC

\subsubsection{Differences Between Organizations on the $\mathrm{OCI}$}

There were no statistically significant differences obtained between the DOE, TEAM, ASI and DCI Organizations on the $\mathrm{OCI}$ scales. The mean scores for each organization on each scale are presented in Appendix A.

Appendix $Q$ contains figures which compare each organization to the overall mean value of the PETC sample on each of the OCI scales.

\subsubsection{Differences Between DOE Departments on the OCI}

Statistically significant differences between DOE Departments were not obtained on any of the scales of the OCl. Appendix B presents the mean values for each DOE Department on each scale. Appendix $\mathrm{V}$ contains figures which compare the mean scores for each DOE Department to the overall DOE Organization means on the OCI scales.

\subsubsection{Differences Between TEAM Departments on the OCI}

Statistically significant differences between TEAM Departments were not obtained on any of the OCI scales. Appendix $\mathrm{C}$ presents the mean values for each TEAM Department on each scale. Appendix W contains figures which compare the mean scores for each TEAM Department to the overall TEAM Organization means on the OCI scales.

\subsubsection{Differences Between ASI Departments on the OCI}

Statistically significant differences between ASI Departments were not obtained on any of the scales of the OCI. Appendix D presents the mean values for each ASI Department on each scale. 
Figures in Appendix X compare the mean scores for each ASI Department to the overall ASI Organization means on the $\mathrm{OCI}$ scales.

\subsubsection{Differences Between DCI Departments on the OCI}

Statistically significant differences between DCI Departments were not obtained on any of the OCI scales. Appendix E presents the mean values for each DCI Department on each scale. Appendix $Y$ contains figures which compare the mean scores for each DCI Department to the overall DCI Organization means on each of the $\mathrm{OCI}$ scales.

\subsubsection{Differences Between Staff Classifications on the OCI}

Fifteen levels of staff classifications were originally listed on the demographics sheet. Due to the fact that some staff classifications had only a few respondents, four of the nriginal categories were combined with other categories for data analysis. The remaining eleven staff classifications are Administration, Engineering/Scientific Staff, ES\&H, Laboratory Research, Maintenance Janitorial, Office/Clerical, Program Management, Public Affairs, Research and Development, Systems Staff, and Other. The four categories which were collapsed were Engineering Research, which was combined with and called Engineering/Scientific Staff; Quality Assurance/Quality Control, which was combined with and called Program Management; Security, which was combined with and called ES\&H; and Facility/Crafts Staff which was combined with and called Other.

Analyses by staff classifications were conducted across the entire PETC sample. Although there are four separate organizations at PETC, the DCI Organization did not have enough employees in many of the staff classification categories to allow meaningful analyses to be conducted. Therefore, analyses by staff classifications within organizations were conducted only for the DOE, ASI, and TEAM Organizations.

Over the entire PETC sample, only one significant difference was found between staff classifications on the OCI scales. This difference was on the Perfectionistic (C10) Scale, with the Administration and ES\&H groups having statistically significantly higher mean scores than the Systems Staff Classification (Figure 4.2). Appendix $F$ presents the mean values obtained for each staff classification on each of the scales on the OCI. Appendices G, H, and I present the mean values obtained for each staff classification within the DOE, TEAM, and ASI Organications.

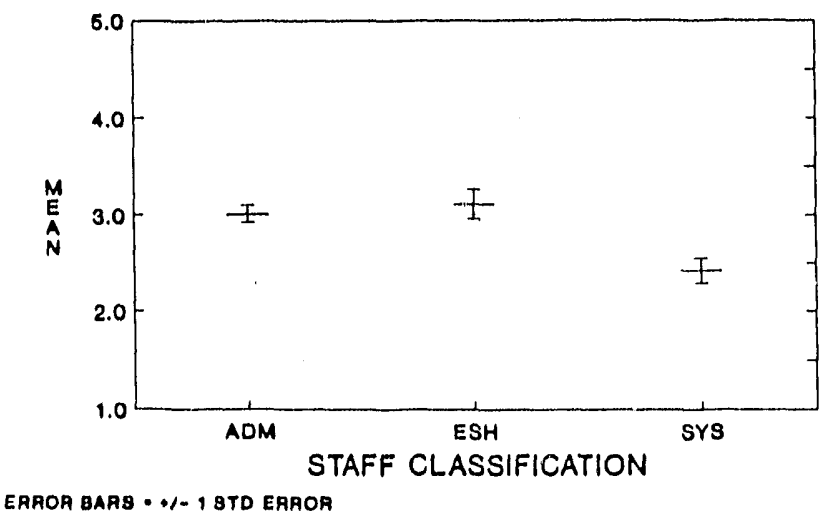

Figure 4.2. Significant differences between staff classifications on the perfectionistic scale 
No significant differences were found between staff classifications on the $\mathrm{OCl}$ scales when the analysis was performed within the DOE, ASI, and TEAM organizations.

\subsubsection{Differences Between Supervisory Levels on the OCI}

Significant differences between supervisory levels were assessed in three ways. The first way utilized the three supervisory levels listed on the demographics sheet: Non-Supervisors, Administrative Supervisors, and Scientific/Engineering Supervisors. The second way involved analyses of all supervisors verstis non-supervisors. Supervisors were defined as those individuals who selected either Administrative Supervisors or Scientific/Engineering Supervisors on the background information sheet, and NonSupervisors are those who classified themselves as such. In addition, analyses were conducted which compared Supervisors and Non-Supervisors within each of the four organizations.

No statistically significant differences between the three supervisory levels were found for the overall PETC organization on any of the OCI scales. Nor were any statistically significant differences found at PETC when the two supervisory levels were combined into one group and compared to the non-supervisors. Appendix J presents the mean values for each of the three supervisory levels on the scales used in the OCA. Appendix M presents the means for supervisors and non-supervisors on these same scales.

The three levels of supervisors were not compared within the ASI and DCI organizations. Within ASI, no Scientific/Engineering Supervisors responded to the survey, making this analysis identical to the supervisor versus non-supervisor analysis for the ASI Organization. The analysis was not conducted within the DCI Organization because only one Scientific/Engineering Supervisor from DCI respondea' to the survey. Therefore, conducting this analysis within the DCI Organization would compromise the anonymity guaranteed to the survey respondents. While these analyses were conducted within the DOE and TEAM Organizations, no statistically significant differences between supervisory levels were obtained on the $O C I$ scales. Appendices $K$ and $L$ present the mean values obtained for the three supervisory levels for the DOE and TEAM Organizations on each of the scales used on the OCA.

When the supervisor/non-supervisor analyses were conducted within each of the four organizations at PETC, only one statistically significant difference emerged on the OCI scales. Within the DCI Organization, supervisors scored statistically significantly higher than non-supervisors on the Perfectionistic (C10) Scale (Figure 4.3). The mean values for supervisors and non-supervisors within the DOE, TEAM, ASI, and DCI Drganizations on the scales used in the OCA are presented in Appendices $\mathrm{N}$ through $\mathrm{Q}$, respectively.

\subsection{Communication Scales}

\subsubsection{Description}

Communication is a critical process for effective operations in any organization. However, because it is a process rather than a variable, it is very difficult to measure. The scales used in the questionnaire administered at PETC were developed by Roberts and O'Reilly (1974). They have been administered to various organizations with good reliability and success in analyzing several facets of the communication process. 


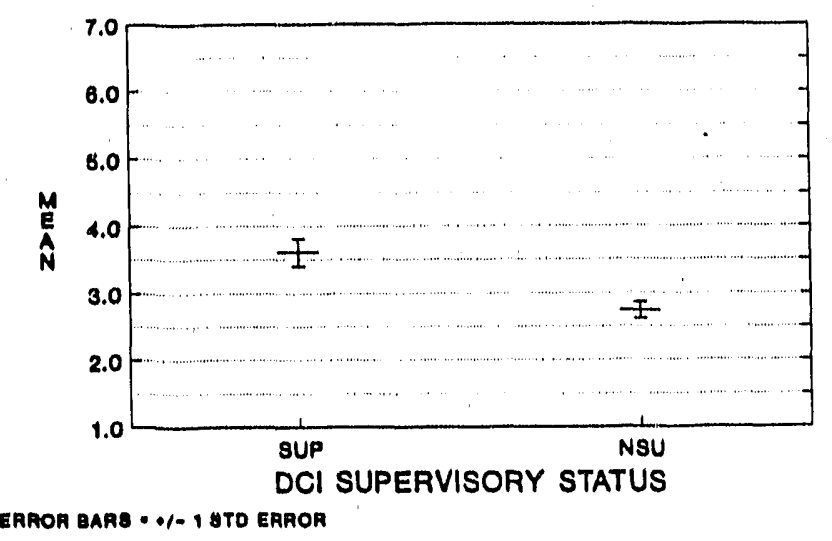

Figure 4.3. Significant differences between DCI supervisors and non-supervisors on the perfectionistic scale

Four communication scales were administered and are described below. The range on each scale is from a low score of 1 to a high score of 7 .

TRUST: $\quad$ Freedom to discuss the problems and difficulties in the job with an immediate supervisor without jeopardy.

ACCURACY: Perception of the accuracy of information received from other organizational levels (superior, same, and subordinate levels).

INTERACT: Desirability of frequent contact with others in the organization (superiors, same, and subordinate).

SATISFAC: $\quad$ Overall satisfaction with the communication process in the organization.

\subsubsection{Overall PETC Results}

The overall means for PETC on each of the communication scales described above are presented in Figure 4.4. For the Trust in Communication and Overall Satisfaction with Communication Scales, moderate mean values were obtained for the PETC sample. The mean value on the Perceived Accuracy of Communication Scale was slightly higher. Employees aiso desire a moderately high amount of interaction with others in the organization, as evidenced by the mean score on the Desire for Interaction Communication Scale.

Appendix $\mathrm{R}$ contains figures which compare each organization's means to the overall mean value of the PETC sample on each of the communications scales. Appendices Z, AA, BB, and CC contain figures which compare the mean scores for each department within DOE, TEAM, ASI and DCI to the overall mean for their respective organizations on each of the communications scales. 


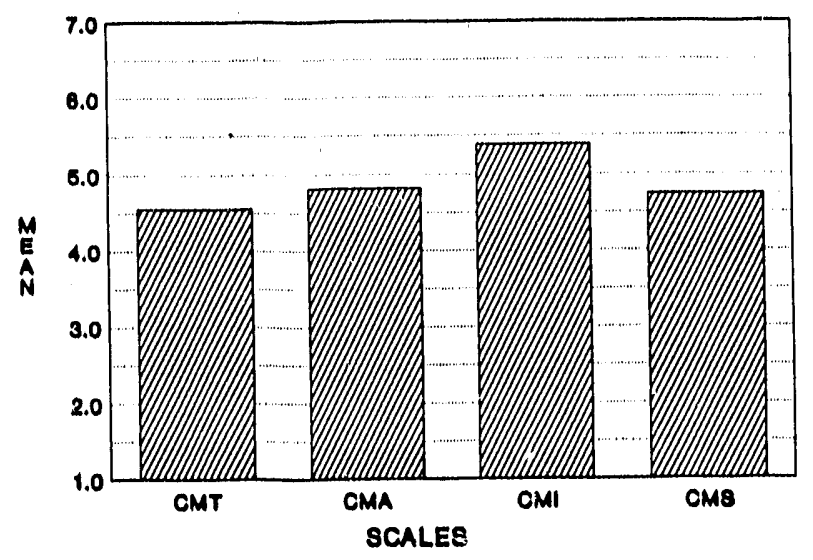

Figure 4.4. Overall mean values on communication scales for PETC

\subsubsection{Differences Between Organizations on the Communication Scales}

Statistically significant differences between organizations occurred on one of the communication scales. Appendix A contains the mean values for each organization on each of the communication scales.

Figure 4.5 depicts the statistically significant difference between organizations at PETC on the Communication - Accuracy Scale. The DOE Organization had the highest mean value on this scale and was statistically significantly different from the DCI Organization.

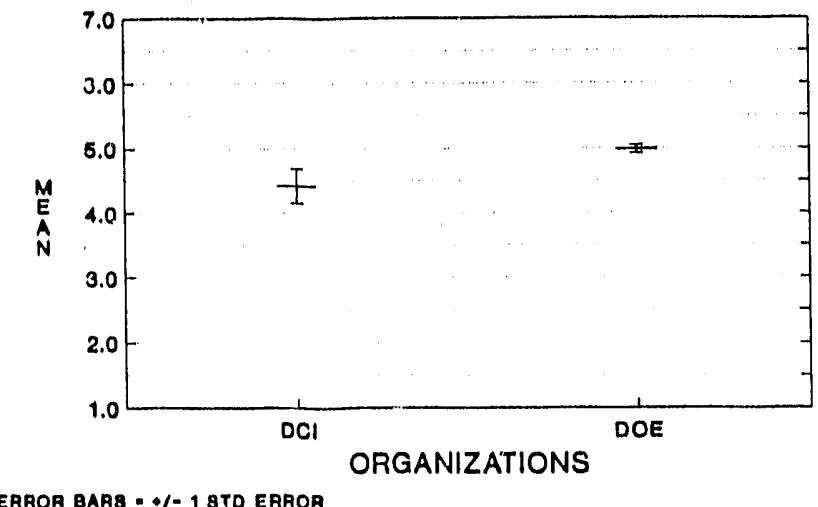

Figure 4.5. Significant differences between organizations on the communication-accuracy scale 


\subsubsection{Differences Between DOE Departments on the Communication Scales}

No statistically significant differences between DOE Departments on the communication scales were obtained in the PETC sample. Appendix B presents the mean values for each DOE Department on each of the communication scales.

\subsubsection{Differences Between TEAM Departments on the Communication Scales}

No statistically significant differences between TEAM Departments on the communication scales occurred in the PETC sample. Appendix $C$ presents the mean values for each TEAM Department on each of the communication scales.

\subsubsection{Differences Between ASI Departments on the Communication Scales}

No statistically significant differences between ASI Departments on the communication scales occurred in the PETC sample. Appendix C presents the mean values for each ASI Department on each of the communication scales.

\subsubsection{Differences Between DCI Departments on the Communication Scales}

Within DCI, statistically significant differences were obtained on the Communications - Trust Scale and on the Communications - Interaction Scale. On both of these scales, the Environment, Safety, and Health Department scored statistically significantly higher than both the Maintenance/Janitorial and Security Departments. Figure 4.6 illustrates the difference on the Communications Trust Scale, and Figure 4.7 depicts the differences on the Communications - Interaction Scale. Appendix D presents the mean values for each DCI Department on each of the communication scales.

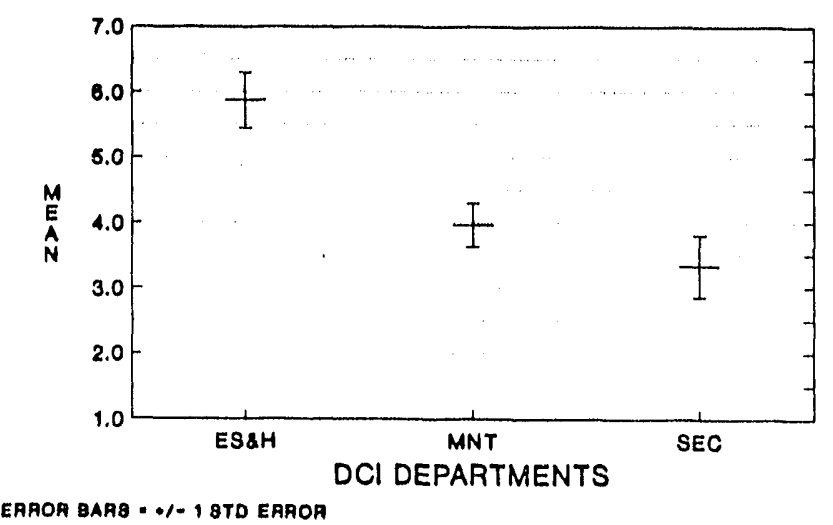

Figure 4.6. Significant differences between DCI departments on the communication-trust scale

\subsubsection{Differences Between Staff Classifications on the Communication Scales}

Statistically significant differences between staff classifications were assessed for the overall PETC sample, as well as within each organization. Significant differences between staff classifications were not obtained on any of the communication scales. Appendix F presents the mean values for each staff classification on these scales. 


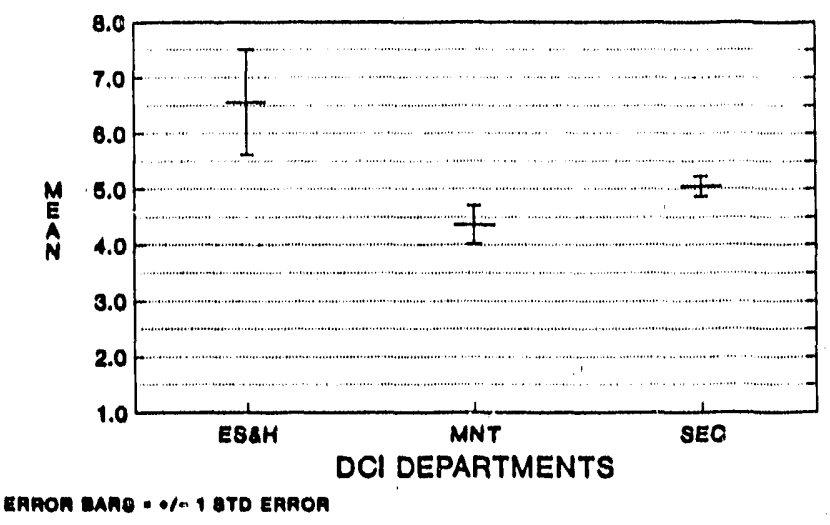

Figure 4.7. Significant differences between DCI departments on the communication-interaction scale

No statistically significant differences between staff classifications were found in the DOE, TEAM, or ASI Organizations on any of the communication scales. Appendices G, H, and I present the mean values for each staff classification within the DOE, TEAM, and ASI Organization on the communication scales. As mentioned previously, there were not enough respondents in the DCI organization to conduct a meaningful analysis by staff classification.

\subsubsection{Differences Between Supervisory Levels on the Communication Scales}

It will be recalled that supervisory level was analyzed in three different ways. The first involved utilizing those categories included on the demographics sheet of Non-Supervisors, Scientific/Engineering Supervisors, and Administrative Supervisors. The second analysis consisted of combining Scientific/Engineering and Administrative Supervisors into one group called Supervisors and comparing this group to the Non-Supervisors. In addition, analyses were conducted w/hich compared Supervisors and Non-Supervisors within each of the four organizations.

Statistically significant differences between supervisory levels for the overall PETC sample were obtained on one of the communication scales. Figure 4.8 depicts the statistically significant differences between the supervisory levels nn the Communication - Satisfaction Scale for the overall PETC sample. The Administrative Supervisors had the highest mean value on this scale and were statistically significantly different from the Non-Supervisors.

As previously discussed, analyses of the three supervisory levels were only conducted within the DOE and TEAM organizations. Within both ASI and DCI, the analyses were nonmeaningful as they were identical, in the case of ASI, or virtually identical, in the case of DCI, to the supervisor versus nonsupervisor analyses conducted within these same organizations. No statistically significant differences between supervisory levels in the DOE Organization were obtained on the communication scales. Appendix $\mathrm{K}$ contains the mean values on each scale for each supervisory level in the DOE Organization. 


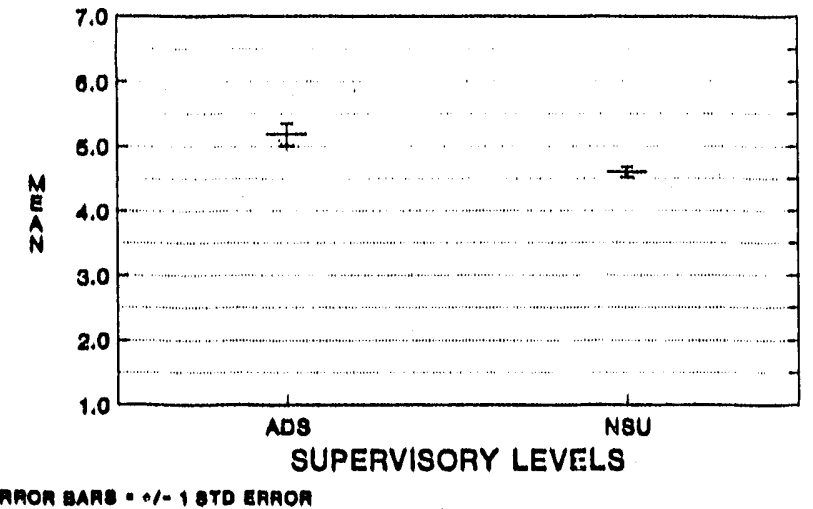

Figure 4.8. Significant differences between supervisory levels on the communication-satisfaction scale

Within the TEAM Organization, one statistically significant difference between supervisory levels was found on the communication scales. The Administrative Supervisors had a statistically significantly higher mean value on the Communication-Satisfaction Scale than the Non-Supervisors (Figure 4.9). The mean values for each supervisory level within the TEAM organization on the communication scales are contained in Appendix L.

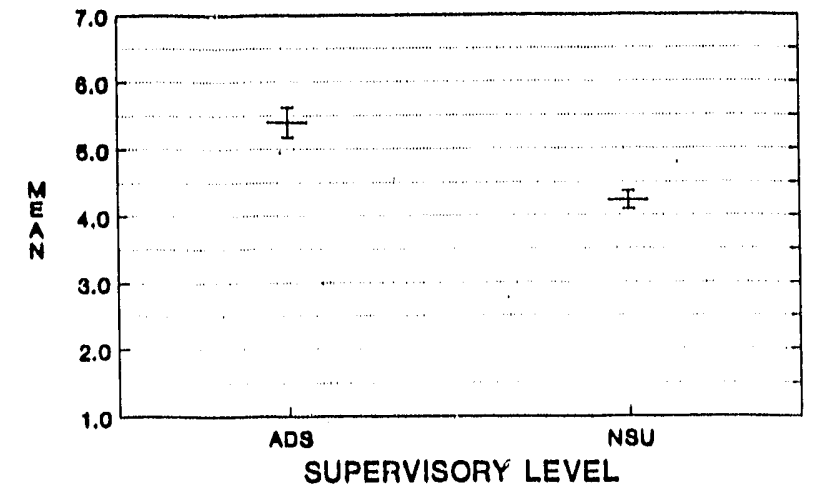

ERROR BARS * * 1 - BTD EFROA

Figure 4.9. Significant differences between supervisory levels at the TEAM organization on the communication-satisfaction scale

When the two types of supervisors were combined into one group for the overall PETC sample and compared to non-supervisors, statistically significant differences were also obtained on the Communication-Satisfaction Scale. Supervisors had a statistically significantly higher mean value on this scale than did the Non-Supervisors (Figure 4.10). 


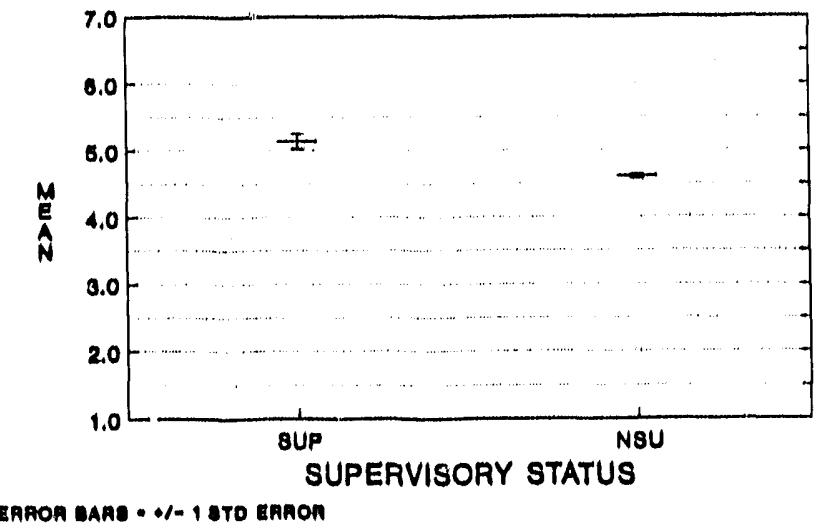

Figure 4.10. Significant differences between supervisors and non-supervisors on the communication-satisfaction scale

Differences between supervisors and non-supervisors were also analyzed within each organization at PETC. Figure 4.11 depicts the statistically significant differences between supervisory levels on the Communication-Satisfaction Scale for the TEAM Organization. The Supervisors had the highest mean value on this scale, and were statistically significantly different from the Non-Supervisors. Appendix $O$ contains the mean values for the TEAM Organization's supervisors and non-supervisors on each communication scale.

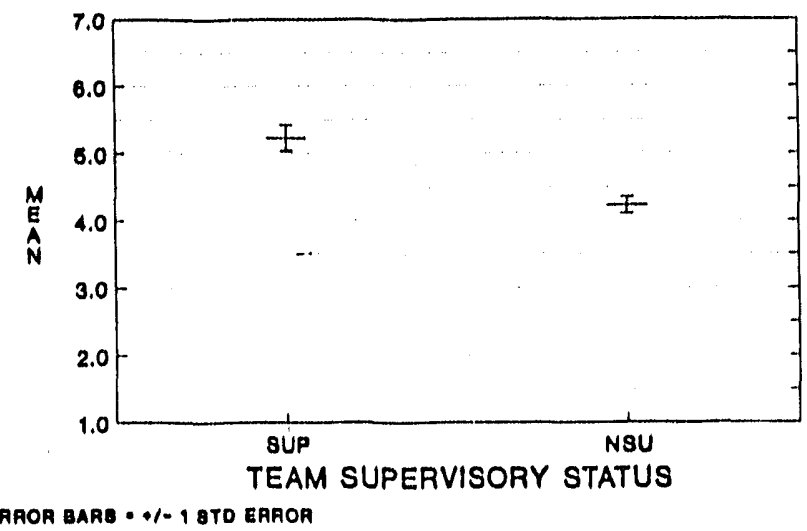

Figure 4.11. Significant differences between TEAM supervisors and non-supervisors on the communication-satisfaction scale

No other statistically significant differences between supervisory levels within organizations were obtained on the communication scales. The mean values for supervisors and non-supervisors in the DOE, ASI, and DCI Organizations on the Communication Scales are contained in Appendices N, P, and $Q$, respectively. 


\section{$4.3 \quad$ Commitment Scale}

\subsubsection{Scale Description}

The Commitment Scale is defined as the relative strength of an individual's identification with and involvement in a particular organization (Mowday \& Steers, 1979). This commitment extends to the goals of the organization and the desire to maintain membership in the organization to facilitate these goals. The range on this scale is from a low score of 1 (low commitment) to a high score of 7 (high commitment).

\subsubsection{Overall PETC Results}

The mean score for the PETC sample on the Commitment Scale (COT) was 4.45, as shown in Figure 4.12. It appears that PETC employees who completed the survey have a moderate level of commitment to the PETC organization. Mean scores for additional scales are also shown in this figure and will be discussed later.

Appendix I contains figures which compare each organization to the overall mean value of the PETC sample on each of the scales shown in Figure 4.12. Appendices DD, EE, FF, and GG contain figures which compare the mean scores for each department within DOE, TEAM, ASI and DCI to the overall mean for their respective organizations on each of the scales shown in Figure 4.12. Statistically significant differences between organizations on this scale are discussed below.

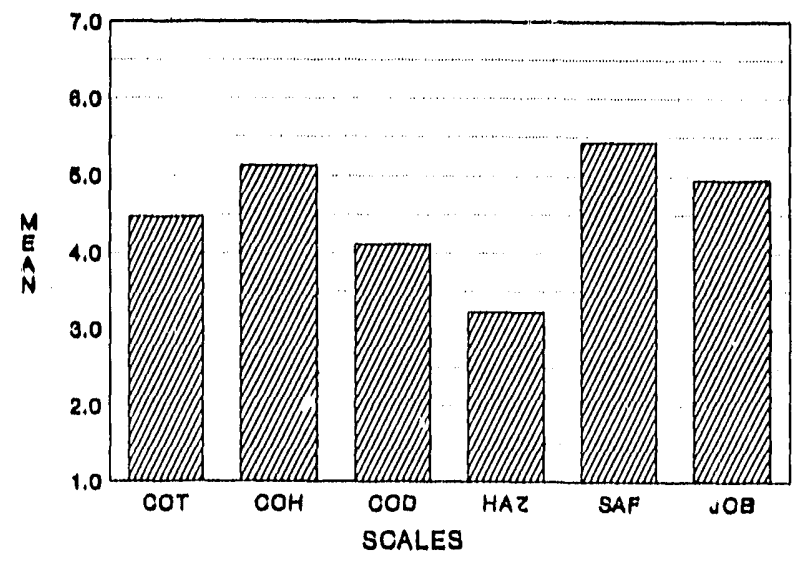

Figure 4.12. Overall mean values on additional scales for PETC

\subsubsection{Differences Between Organizations on the Commitment Scale}

The four organizations at PETC were not statistically significantly different from each other on the Commitment Scale. Appendix A presents the mean values for each organization on the Commitment Scale. 


\subsubsection{Differences Between DOE Departments on the Commitment Scale}

No statistically significant differences between DOE Departments were obtained on the Commitment Scale. Appendix B presents the mean values for $x$ h of the DOE Departments on the Commitment Scale.

\subsubsection{Differences Between TEAM Departments on the Commitment Scale}

No statistically significant differences between TEAM Departments were obtained on the Commitment Scale. Appendix C presents the mean values for each of the TEAM Departments on the Commitment Scale.

\subsubsection{Differences Between ASI Departments on the Commitment Scale}

No statistically significant differences between ASI Departments were obtained on the Commitment Scale. Appendix D presents the mean values for each of the ASI Departments on the Commitment Scale.

\subsubsection{Differences Between DCI Departments on the Commitment Scale}

No statistically significant differences between $\mathrm{DCl}$ Departments were obtained on the Commitment Scale. Appendix E presents the mean values for each of the DCI Departments on the Commitment Scale.

\subsubsection{Differences Between Staff Classifications on the Commitment Scale}

When staff classifications were compared, regardless of organizational affiliation, no statistically significant differences between classifications were found on the Commitment Scale. The mean values for each staff classification on the Commitment Scale, are presented in Appendix F.

No statistically significant differences between staff classifications were found for either the DOE, TEAM, or ASI Organizations on the Commitment Scale. Appendices G, $H$, and I present the mean values for each staff classification within the DOE, TEAM, and ASI Organizations, respectively, on the Commitment Scale. It wili be recalled that there were not enough respondents in the DCI Organization to conduct a mearingful analysis by staff classification and assure that anonymity would be protected within each staff classification.

\subsubsection{Differences Between Supervisory Levels on the Commitment Scale}

No statistically significant differences between any supervisory levels were obtained on the Commitment Scale. Appendix J contains the mean values for the three supervisory levels across all organizations at PETC on this scale, and Appendix M presents the mean values for supervisors and nonsupervisors overall at PETC on this scale. In addition, analyses conducted comparing the three supervisory levels within organizations yielded no statistically significant differences (mean values for the DOE and TEAM supervisory levels are contained in Appendices $K$ and $L$, respectively). Nor were statistically significant differences found when supervisors were compared to nonsupervisors within each organization. Mean values for these two groups within the DOE, TEAM, ASI, and DCI Organizations are contained in Appendices $\mathrm{N}$ through $\mathrm{Q}$, respectively. 
Appendix I contains figures which compare each organization to the overall mean value of the PETC sample on the Coordination Scale. Appendices DD, EE, FF, and GG contain figures which compare the mean scores for each department within DOE, TEAM, ASI and DCI to the overall mean for their respective organizations on the Coordination Scale. No statistically significant differences were obtained between any groups at PETC on this scale.

\subsubsection{Differences Between Organizations on the Coordination Scale}

No statistically significant differences between organizations were obtained on the Coordination Scale for the PETC sample. Appeidix A contains the mean values for each organization on this scale.

\subsubsection{Differences Between DOE Departments on the Coordination Scale}

No statistically significant differences were obtained between departments within the DOE Organization on the Coordination Scale. Appendix B contains the mean values for each DOE Department on this scale.

\subsubsection{Differences Between TEAM Departments on the Coordination Scale}

No statistically significant differences between departments within the TEAM Organization were obtained on the Coordination Scale. The mean values for each TEAM Department on this scale are contained in Appendix C.

\subsubsection{Differences Between ASI Departments on the Coordination Scale}

No statistically significant differences were obtained between departments within the ASI Organization on the Coordination Scale. Appendix D contains the mean values for each ASI Department on this scale.

\subsubsection{Differences Between DCl Departments on the Coordination Scale}

No statistically significant differences between departments within the DCI Organization were obtained on the Coordination Scale. The mean values for each DCI Department on this scale are contained in Appendix E.

\subsubsection{Differences Between Staff Classifications on the Coordination Scale}

No statistically significant differences between staff classifications for the overall PETC sample, or within organizations, were obtained on the Coordination Scale. Mean values for each staff classification for the overall PETC sample on this scale are contained in Appendix F. Appendices G through I contain the mean values for each staff classification on this scale for the DOE, TEAM, and ASI Organizations, respectively.

\subsubsection{Differences Between Supervisory Levels on the Coordination Scale}

No statistically significant differences between supervisory levels were obtained on the Coordination Scale regardless of the way in which supervisory levels were analyzed, and whether the analyses were over the entire PETC sample or within one of the organizations. The mean values for each analyses conducted on this scale are contained in Appendices $\mathrm{J}$ through $\mathrm{Q}$. 


\subsection{Job Satisfaction}

\subsubsection{Description of Scale}

The Job Satisfaction Scale (Kunin, 1955) refers to employees' overall satisfaction with their jobs. While it is not able to point to specific aspects of the working environment which people are satisfied or dissatisfied with, it can help to determine if employee satisfaction is something which needs further consideration by management. The scale ranges from a low score of 1 (very dissatisfied) to a high score of 7 (very satisfied).

\subsubsection{Overall PETC Results}

Overall, PETC employees were moderately satisfied with their jobs. The mean value for the PETC sample on this scale was 4.95 (see Figure 4.12). No statistically significant differences between the organizations, beiween departments within organizations or between staff classifications or supervisory levels, either overall or within organizations, were obtained on this scale.

\subsubsection{Differences Between Organizations on the Job Satisfaction Scale}

No statistically significant differences on the Job Satisfaction Scale were obtained between organizations in the PETC sample. Appendix A contains the mean values for each organization on this scale.

\subsubsection{Differences Between DOE Departments on the Job Satisfaction Scale}

No statistically significant differences on the Job Satisfaction Scale were obtained between DOE Departments in the PETC sample. Appendix B contains the mean values for each DOE Department on this scale.

\subsubsection{Differences Between TEAM Departments on the Job Satisfaction Scale}

No statistically significant differences between TEAM Departments on the Job Satisfaction Scale were obtained. The mean values for each TEAM Department on this scale are contained in Appendix C.

\subsubsection{Differences Between ASI Departments on the Job Satisfaction Scale}

No statistically significant differences on the Job Satisfaction Scale were obtained between ASI Departments in the PETC sample. The mean values for each ASI Department on this scale are contained in Appendix D.

\subsubsection{Differences Between DCI Departments on the Job Satisfaction Scale}

No statistically significant differences between DCI Departments on the Job Satisfaction Scale were obtained. Appendix E contains the mean values for each DCI Department on this scale. 


\subsubsection{Differences Between Staff Classifications on the Job Satisfaction Scale}

Whether staff classifications were analyzed over the entire PETC sample or within organizations, no statistically significant differences were obtained on the Job Satisfaction Scale. The mean value for each of these analyses are contained in Appendices $\mathrm{F}$ through I, respectively.

\subsubsection{Differences Between Supervisory Levels on the Job Satisfaction Scale}

No statistically significant differences between supervisory levels were obtained on the Job Satisfaction Scale, regardless of the way in which the supervisory levels were analyzed, and whether the analyses were over the entire PETC sample or within one of the organizations. Appendices J through $Q$ contain the mean values for this scale for each group on which an analysis was conducted.

\subsection{Hazard Scale}

\subsubsection{Scale Description}

The Hazard Scale is used to identify people's perception of the hazardous nature of their work (K.H. Roberts, 1990, personal communication). The scale ranges from a low score of 1 (not hazardous) to a high score of 7 (very hazardous).

\subsubsection{Overall PETC Results}

The overall PETC mean score on this scale was 3.23 (see Figure 4.12). PETC employees do not perceive there to be a gre't amount of hazard in their work.

Appendix $\mathrm{T}$ contain. figures which compare each organization to the overall mean value of the PETC sample on the Hazard Scale. Appendices DD, EE, FF, and GG contain figures which compare the mean scores for each department within DOE, TEAM, ASI and DCI to the overall mean for their respective organizations on the Hazard Scale.

\subsubsection{Differences Between Organizations on the Hazard Scale}

Statistically significant differences between PETC Organizations on the Hazard Scale are depicted in Figure 4.14. The ASI organization had the lowest mean value on this scale and was statistically significantly different from both the DCI and TEAM Organizations. The DCI Organization had the highest mean score on the Hazard Scale.

\subsubsection{Differences Between DOE Departments on the Hazard Scale}

Statistically significant differences between DOE Departments on the Hazard Scale are depicted in Figure 4.15. The Research and Development Department had the highest mean value on this scale and was statistically significantly different from every other department. The Clean Coal Technology Department had the lowest mean value on this scale. 


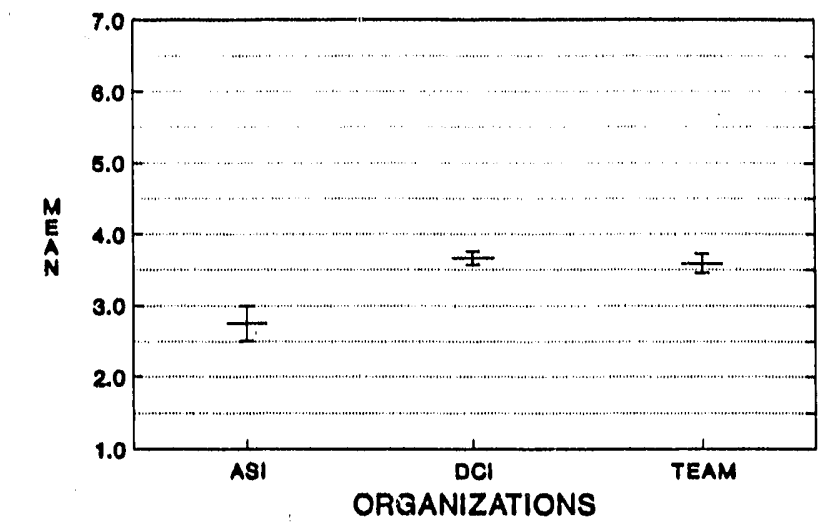

ERAON QARE $* \bullet / * 1$ STO EAROA

Figure 4.14. Significant differences between PETC organizations on the hazard scale

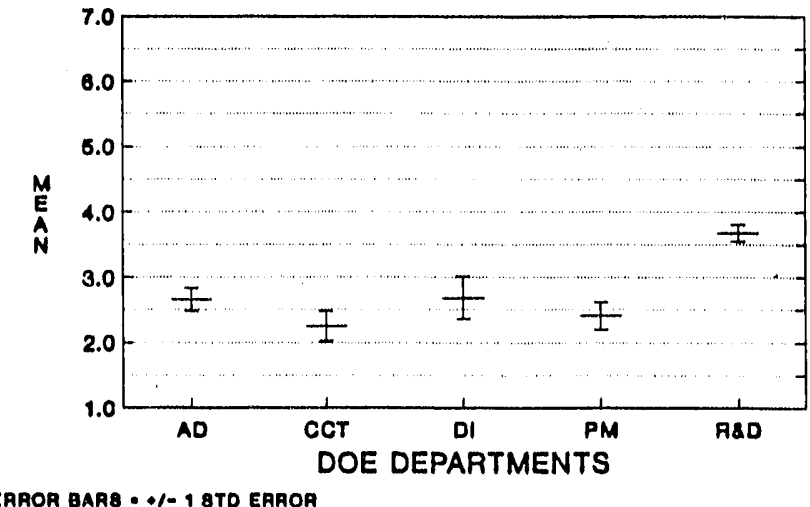

Figure 4.15. Significant differences between DOE departments on the hazard scale

\subsubsection{Differences Between TEAM Departments on the Hazard Scale}

Statistically significant differences between TEAM Departments on the Hazard Scale are depicted in Figure 4.16. The Real Property Management Services Department had the highest mean score on the Hazard Scale, and was statistically significantly different than the Administrative Services, Management Information Services, Project Support, and Technical Management Services Departments. The Research and Development and Environment, Safety, and Health Services Departments had the second and third highest mean scores on the Hazard Scale and were statistically significantly different from the Administrative Services, Management Information Services, and Technical Management Services Departments. The Administrative Services Department had the lowest mean value on this scale. No other statistically significant differences between TEAM Departments were found on the Hazard Scale. Appendix C contains the mean values for each of these departments on this scale. 


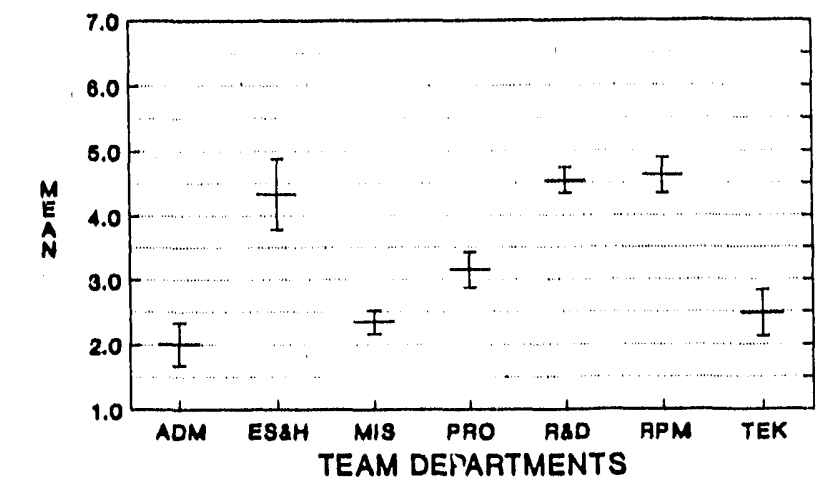

ERAOR BAME - $/-1$ BTO EARON

Figure 4.16. Significant differences between TEAM departments on the hazard scale

\subsubsection{Differences Between ASI Departments on the Hazard Scale}

No statistically significant differences between ASI Departments were obtained on the Hazard Scale. Appendix D presents the mean value for each ASI Department on this scale.

\subsubsection{Differences Between DCI Departments on the Hazard Scale}

No statisticaliv significant differences between DCI Departments were obtained on the Hazard Scale. Appendix E prtsents the mean value for each DCI Department on this scale.

\subsubsection{Differences Betwe?n Staff Classifications on the Hazard Scale}

Statistically signific ınt differences between staff classifications across the entire PETC sample are depicted in Figure 4.17. The Environment, Safety, and Health Staff Classification had the highest mean value on this scale and was statistically significantly greater than the Other, Systems Staff, Engineering/Scientific Sta/f, Program Management, Office/Clerical; Public Affairs and Administration Staff Classifications. The Research and Development, Maintenance/Janitorial, and Lab Research Staff Classifications had the second, third and fourth highest scores. These three groups all had mean scores which were statistically significantly greater than the Program Management, Office/Clerical, Public Affairs and Administration Staff Classifications. The Administration Staff Classification had the lowest mean value on this scale.

Other statistically significant differences between staff classifications on the Hazard Scale for the entire PETC sample are presented in Appendix F.

Statistically significant differences between staff classifications on the Hazard Scale within the TEAM Organization are presented in Figure 4.18. The Research and Development Staff Classification had the highest mean score on the Hazard Scale and was statistically significantly different from the Systems Staff, Program Management, Office/Clerical, Administration, and Public Affairs Staff Classifications. The Maintenance/Janitorial Staff Classification had the second highest mean on the Hazard Scale, and was statistically significantly different from the Program Management, Office/Clerical, 
Administration, and Public Affairs Staff Classifications. The Environment, Safety, and Health Staff. Classification had the third highest mean on the Hazard Scale, and was statistically significantly different from the Administration, and Public Affairs Staff Classifications. The Laboratory Research Staff Classification had the fourth highest mean on the Hazard Scale, and was statistically significantly greater than the Public Affairs Staff Classifications, which had the lowest mean value on this scale of all the TEAM Staff Classifications. No other statistically significant differences between the TEAM Staff Classifications existed on this scale. Appendix $\mathrm{H}$ contains the mean value for each TEAM Staff Classification on this scale.

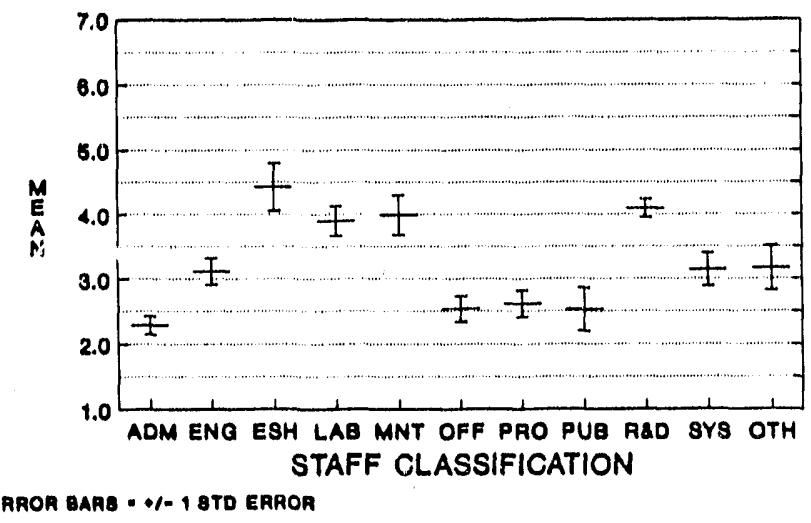

Figure 4.17. Significant differences between staff classifications on the hazard scale

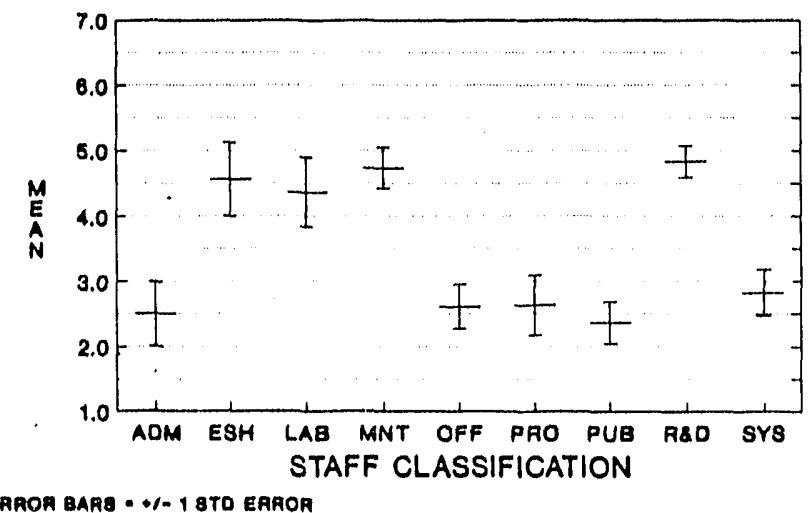

Figure 4.18. Significant differences between TEAM staff classifications on the hazard scale

No statistically significant differences between staff classifications occurred within the ASI Organization. Appendix I contains the mean value for each ASI Staff Classification on the Hazard Scale. As discussed earlier, analyses of staff classifications within the DCI Organization were not conducted due to the low number of individuals in some of the groups. 


\subsubsection{Differences Between Supervisory Levels on the Hazard Scale}

No statistically significant differences between supervisory levels across PETC on the Hazard Scale were obtained regardless of the way in which supervisory level was analyzed. Additionally, no statistically significant differences were found between supervisory levels within any of the PETC organizations, regardless of the way in which supervisory level was analyzed. Appendices $J$ through $Q$ contain the mean values for each group for each analysis conducted.

\subsection{Safety Scale}

\subsubsection{Scale Description}

The Safety Scale, developed by researchers at the University of California at Berkeley (K. H. Roberts, 1989, personal communication), is used to assess an individual's perception of the importance of safety to success in an organization. Safety is defined as operating in a manner to ensure that the probability of making a mistake is low, because the consequences of making a mistake are high. Organizations typically viewed as operating in this manner are nuclear reactors, naval aircraft carriers and air traffic control centers. The Safety Scale consists of 40 items which range from a low score of 1 (does not help at all) to a high score of 7 (helps a great deal).

\subsubsection{Overall PETC Results}

The overall mean score for the PETC sample on the Safety Scale was 5.42 (see Figure 4.12). Thus, it appears that the employees of PETC do understand those behaviors which are important to safe operations.

Appendix $\mathrm{T}$ contains figures which compare each organization to the overall mean value of the PETC sample on the Safety Scale. Appendices DD, EE, FF, and GG contain figures which compare the mean scores for each department within DOE, TEAM, ASI and DCI to the overall mean for their respective organizations on the Safety Scale.

\subsubsection{Differences Between Organizations on the Safety Scale}

No statistically significant differences between organizations at PETC were obtained on the Safety Scale. Appendix A contains the mean values for each organization on this scale.

\subsubsection{Differences Between DOE Departments on the Safety Scale}

No statistically significant differences between DOE Departments on the Safety Scale were obtained at PETC. Appendix B contains the mean value for each DOE Department on this scale.

\subsubsection{Differences Between TEAM Departments on the Safety Scale}

No statistically significant differences between TEAM Departments on the Safety Scale were obtained at PETC. The mean values for each TEAM Department on this scale are contained in Appendix C. 


\subsection{6}

Differences Between ASI Departments on the Safety Scale

No statistically significant differences between ASI Departments on the Safety Scale were obtained at PETC. Appendix D contains the mean values for each ASI Department on this scale.

\subsubsection{Differences Between DCI Departments on the Safety Scale}

No statistically significant differences between DCI Departments on the Safety Scale were obtained at PETC. The mean values for each DCI Department on the scale are contained in Appendix E.

\subsubsection{Differences Between Staff Classifications on the Safety Scale}

Regardless of the way in which staff classifications were analyzed, no statistically significant differences were obtained on the Safety Scale. See Appendices $F$ through I for the mean values obtained on this scale for each group for which an analysis was conducted.

\subsubsection{Differences Between Supervisory Levels on the Safety Scale}

No statistically significant differences between supervisory levels on the Safety Scale were obtained regardless of the way in which supervisory level was analyzed. Additionally, no statistically significant differences were found between supervisory levels, regardless of the way in which supervisory level was analyzed, within any of the PETC organizations. Appendices $J$ through $Q$ contain the mean values on this scale obtained for each group included in any analysis.

\subsection{Environment, Safety, and Health Questions}

\subsubsection{Question Descriptions}

The administration of the Organizational Survey (OS) at PETC included four questions pertaining to environment, safety and health issues. Each question ranged frcm a low score of 1 (not at all or little) to a high score of 7 (very likely or a lot).

The first environmental, safety and health question deals with the likelihood of serious offsite environmental damages/consequences due to improper or substandard performance by a work group. The second question deals with the likelihood of serious onsite environmental damages/consequences due to improper or substandard performance by a work group. The third environment, safety, and health question asks employees to assess the amount of emphasis they believe management places on environmental issues. Finally, the fourth question asks employees for their perception of how well informed they are of possible risks in their work environment.

\subsubsection{Overall PETC Results}

For the first environmental, safety, and health question, a mean value of 2.69 (Figure 4.19) was obtained for the PETC sample. Thus, PETC employees believe that if improper or substandard work was performed by their working group, the potential for serious offsite environmental consequences is low. 


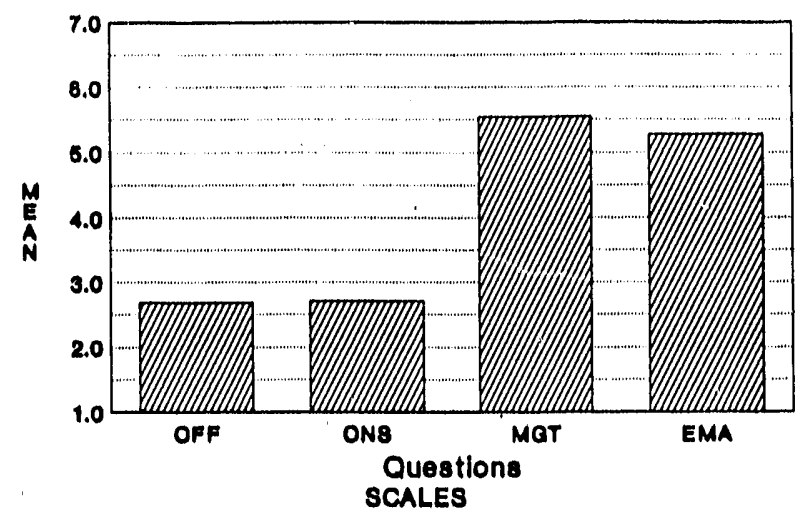

Figure 4.19. Overall means on environment, safety, and health questions

The mean value for the PETC sample on the second question was 2.71 (Figure 4.19). This indicates that respondents believe the potential for onsite environmental consequences to be equivalent to the potential for offsite environmental consequences.

The mean value obtained for the third environment, safety, and health question was 5.54 (Figure 4.19). PETC employees believe management places a fairly high amount of emphasis on environmental issues.

The mean value obtained for the fourth environment, safety, and health question was 5.26, slightly lower than the previous question (Figure 4.19). PETC employees believe themselves to be fairly well informed concerning the risks in their work environment.

Appendix $U$ contains figures which compare each organization to the overall mean value of the PETC sample on the environment, safety and health questions. Appendices HH, II, JJ, and KK contain figures which compare the mean scores for each department within DOE, TEAM, ASI and DCI to the overall mean for their respective organizations on the environment, safety, and health questions.

\subsubsection{Differences Between Organizations on the Environment, Safety, and Health Questions}

Statistically significant differences between organizations occurred on only the Onsite Consequences Question (Figure 4.20). The ASI Organization had the lowest mean value on this question and was statistically significantly different from the DCI and TEAM Organizations. The DCI Organization had the highest mean score on this question. No other statistically significant differences between the organizations at PETC existed on this question. The mean values for each organization on this and the other environment, safety, and health questions, are contained in Appendix A.

\subsubsection{Differences Between DOE Departments on the Environment, Safety, and Health Questions}

Statistically significant differences between DOE Departments were obtained on two of the four environment, safety, and health questions. Figure 4.21 pre $p$ nts the statistically significant differences between the DOE Departments on the Management Emphasis Question. The Administrative Support 
Department had the lowest mean score on this question, and was statistically lower than the Director's Office and Research and Development Departments. The Director's Office had the highest mean value on this question.

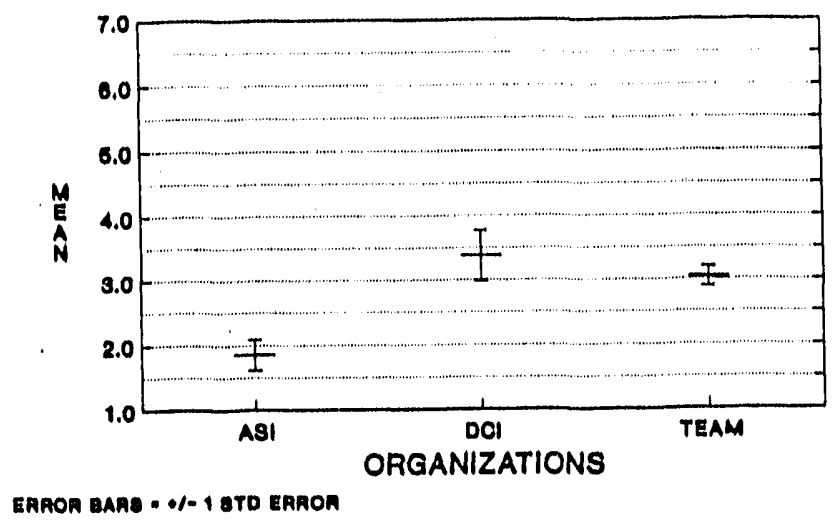

Figure 4.20. Significant differences between organizations on the onsite environment, safety, and health question

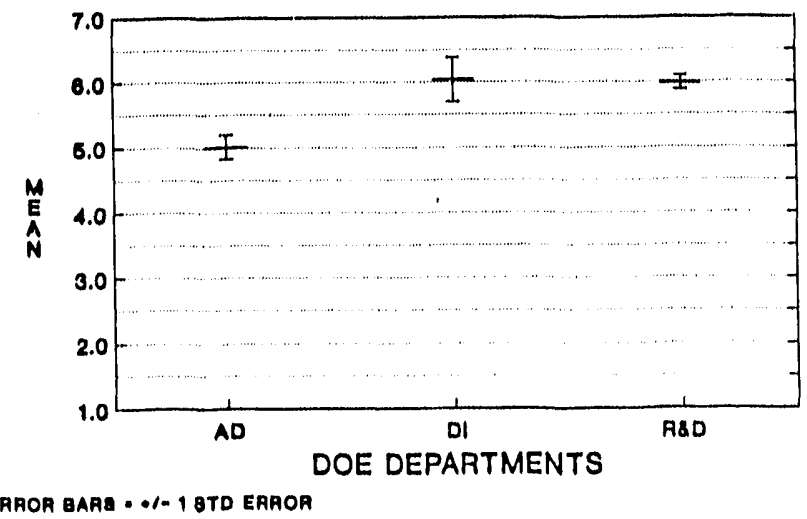

Figure 4.21. Significant differences between DOE departments on the management emphasis question

Figure 4.22 presents the statistically significant differences between the DOE Departments on the Employee Awareness Question. The Administrative Support Department had the lowest mean score on this question, and was statistically lower than the Clean Coal Technology, Director's Office, and Research and Development Departments. The Director's Office had the highest mean value on this question.

Appendix B contains the mean values obtained by each DOE Department on each of the four environment, safety, and health questions. 


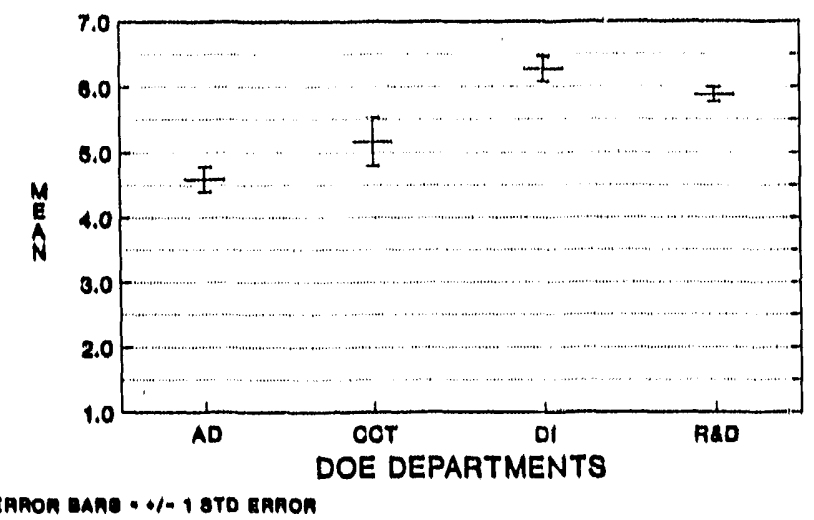

Figure 4.22. Significant differences between $\mathrm{DCZ}$ departments on the employee awareness question

4.9.5 Differences Between TEAM Departments on the Environment, Safety, and Health Questions

Statistically significant differences between TEAM Departments were obtained on three of the four environment, safety, and health questions. Figure 4.23 depicts the statistically significant differences between TEAM Departments on the Offsite Consequences Question. The Environment, Safety, and Health Services Department had the highest mean score on this question, and was statistically significantly different from the Project Support, Technical Management Services, Administration Services and the Management and Information Services Departments. The Management and Information Services Department had the lowest mean value on this question. The Research and Development and Real Property Management Services Departments had the second and third highest mean scores on this question and were statistically significantly greater than the Administration Services and the Management and Information Services Departments.

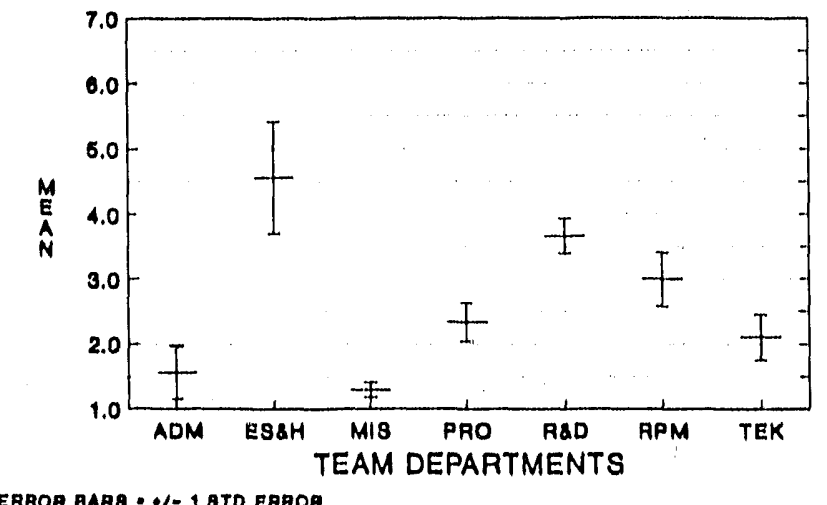

Figure 4.23. Significant differences between TEAM departments on the offsite consequences question 
Figure 4.24 depicts the statistically significant difforences between TEAM Departments on the Onsite Consequences Question. The Environment, Safety, and Health Services Department had the highest mean score on this question, and was statistically significantly greater than the Project Support, Technical Management Services, Administration Services, and the Management and Information Services Departments. The Research and Development Department had the second highest mean score on this question and was significantly greater than the Technical Management Services, Administration Services and the Management and Information Services Departments. The Real Property Management Department had the third highest mean score on this question and was significantly greater than the Administration Services and the Management and Information Services Departments. The Management and Information Services Department had the lowest mean value on this question.

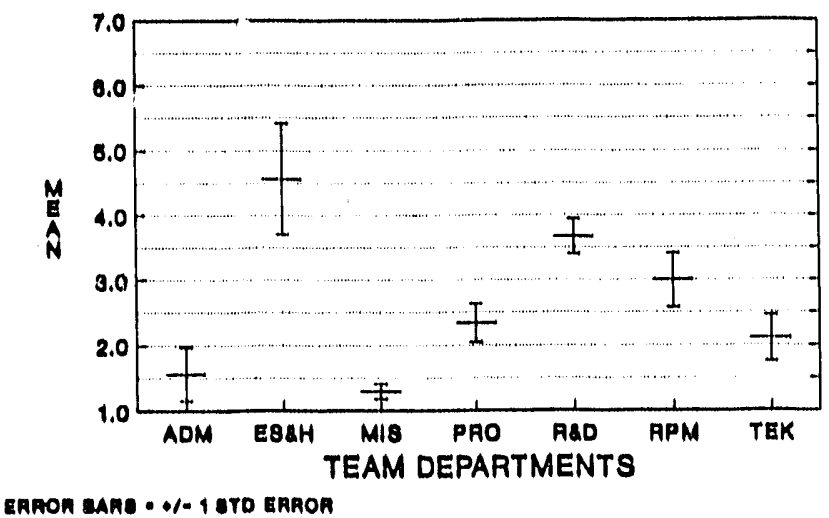

Figure 4.24. Significant differences between TEAM departments on onsite consequences question

Statistically significant differences between TEAM Departments were also obtained on the Employee Awareness Question (Figure 4.25). The Research and Development Department had the highest mean score on this question, and was statistically significantly different from the Real Property Management Department, which had the lowest mean score on this question.

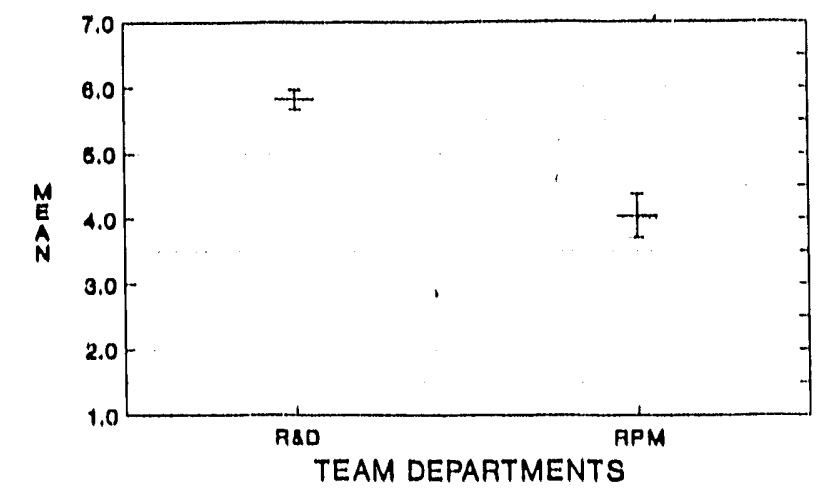

ERAOR BARB * +/- 1 8TD ERAOR

Figure 4.25. Significant differences between TEAM departments on the employee awareness question 
No other statistically significant differences between TEAM departments were obtained on the environment, safety, and health questions. Appendix $\mathrm{C}$ contains the mean values for each TEAM Department on each of the questions.

\subsubsection{Differences Between ASI Departments on the Environment, Safety and Health Questions}

No statistically significant differences between ASI Departments on the environment, safety and health questions were obtained at PETC. Appendix D contains the mean values for each of the ASI Departments on each of the questions.

\subsubsection{Differences Between DCI Departments on the Environment, Safety and Health Questions}

No statistically significant differences between DCI Departments on the environment, safety and health questions were obtained at PETC. The mean values obtained for each of the DCI Departments on each of the questions are contained in Appendix $E$.

\subsubsection{Differences Between Staff Classifications on the Environment, Safety, and Health Questions}

Statistically significant differences between staff classifications at PETC were obtained on three of the four environment, safety, and health questions. Figure 4.26 depicts the statistically significant differences between staff classifications on the Offsite Consequences Question. The Environment, Safety, and Health Classification believes their work involves the most potential for offsite environmental consequences. The mean score of the Environment, Safety, and Health Staff Classification is statistically significantly greater than the Other, Administration, Public Affairs, Office/Clerical, and Systems Staff Staff Classifications. The Systems Staff Staff Classification believes their work involves the least potential for offsite environmental consequences. The mean score of the System Staff group is statistically significantly lower than the Environment, Safety, and Health, Laboratory Research, Research and Development, Program Management, Maintenance/Janitorial, and Engineering/Scientific Staff Staff Classifications.

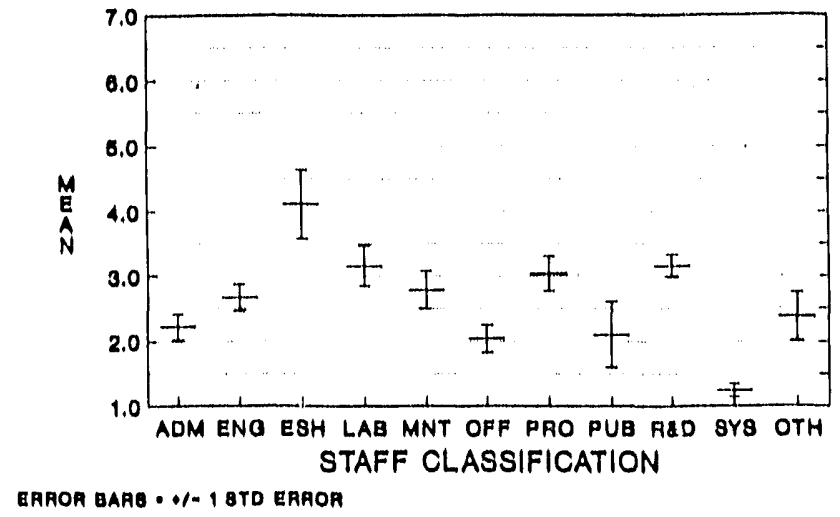

Figure 4.26. Significant differences between staff classifications on the offsite consequences question

Figure 4.27 depicts the statistically significant differences between staff classifications on the Onsite Consequences Question. Again, the Environment, Safety, and Health Staff Classification had 
the highest mean score on this question. The mean score for the Environment, Safety, and Health group was statistically significantly greater than the Engineering/Scientific Staff, Other, Program Management, Administration, Office/Clerical, Public Affairs, and Systems Staff Staff Classifications. The Systems Staff, which had the lowest mean value on this question, and Public Affairs Staff Classifications were statistically significantly lower than the Environment, Safety, and Health, Laboratory Research, Research and Development, and Maintenance/Janitorial Staff Classifications. No other statistically significant differences between staff classifications were found on this question. Appendix $F$ contains the mean values for each classification on this question.

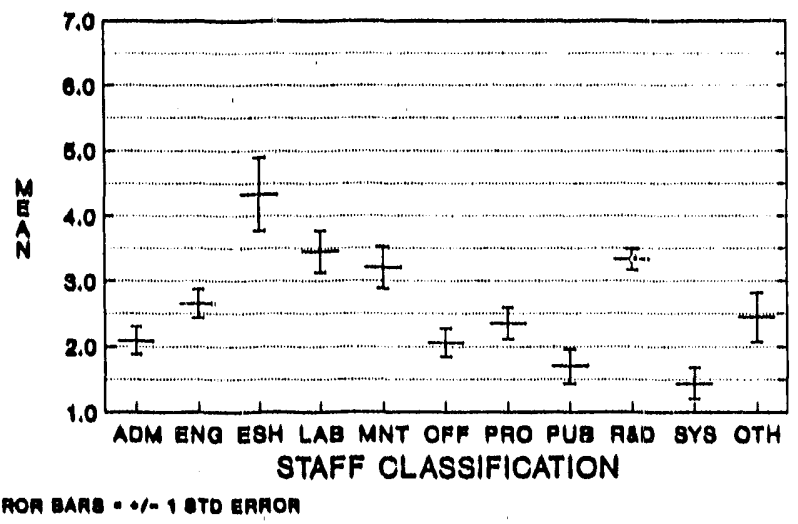

Figure 4.27. Significant differences between staff classifications on the onsite consequences question

Statistically significant differences between staff classifications for the overall PETC population were also found on the Employee Awareness Question (Figure 4.28). The Administrative Staff had the lowest mean on this question an was statistically significantly different from the Laboratory Research and Research and Development Staff Classifications. The Laboratory Research Staff Classification had the highest mean value on this question.

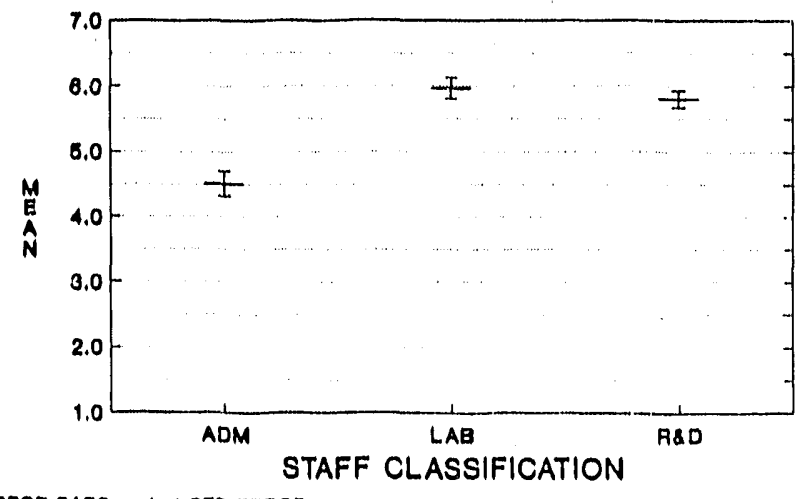

ERROA BAAB - $/-1$ STO EAROR

Figure 4.28. Significant differences between staff classifications on the employee awareness question 
When differences between staff classifications in the DOE Organization on the environment, safety, and health questions were assessed, no statistically significant differences were found. Appendix $G$ contains the mean values for each DOE Staff Classification on each of the environment, safety, and health questions.

When differences between staff classifications on the environment, safety, and health questions within the TEAM organization were assessed, statistically significant differences between staff classifications were obtained on three of the four questions. Figure 4.29 depicts the statistically significant differences between TEAM Staff Classifications on the Offsite Consequences Question. As in the overall case, the Environment, Safety, and Health Staff Classification believes their work involves the greatest potential for offsite environmental consequences. The inean score of the Environment, Safety, and Health Staff Classification was statistically significantly different from the mean score for the Other, Administration, Public Affairs, Office/Clerical, and Systems Staff Staff Classifications. The Systems Staff Staff Classification had the lowest mean score on this question.

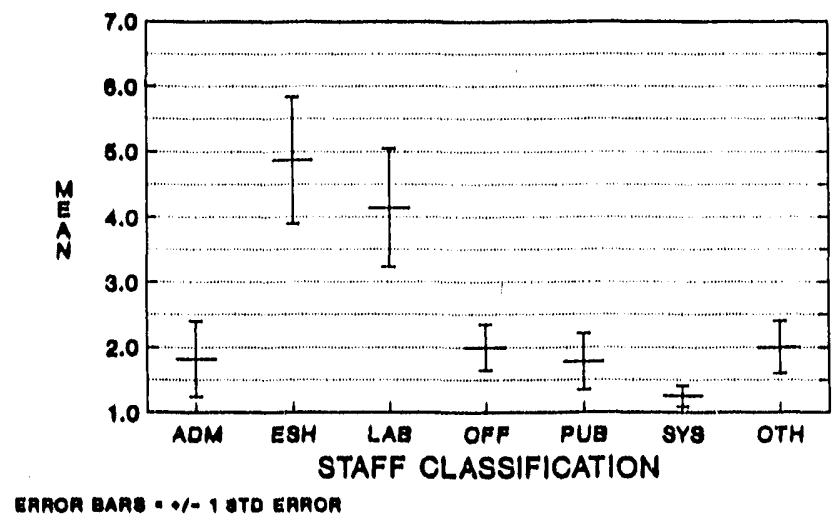

Figure 4.29. Significant differences between TEAM staff classifications on the offsite consequences question

Figure 4.30 depicts the differences between TEAM Staff Classifications on the Onsite Consequences Question. Again, the Environment, Safety, and Health Staff Classification had the highest mean value on this question. The mean score for the Environment, Safety, and Health group was statistically significantly greater than the mean score for the Program Management, Office/Clerical, Other, Systems Staff, Administration, and Public Affairs Staff Classifications. The Public Affairs Staff Classification had the lowest mean value on this question. The Laboratory Research Staff had the second highest mean on this question, and was statistically significantly different from the Other, Systems Staff, Administration, and Public Affairs Staff Classifications. The Research and Development Staff had the third highest mean on this scale, and was only statistically significantly greater than the Public Affairs group.

Statistically significant differences between staff classifications for the TEAM organization were also found on the Employee Awareness Question (Figure 4.31). In this case, the Systems Staff Staff Classification had the highest mean value, and was statistically significantly greater than the Other group, which had the lowest mean value on this question. 


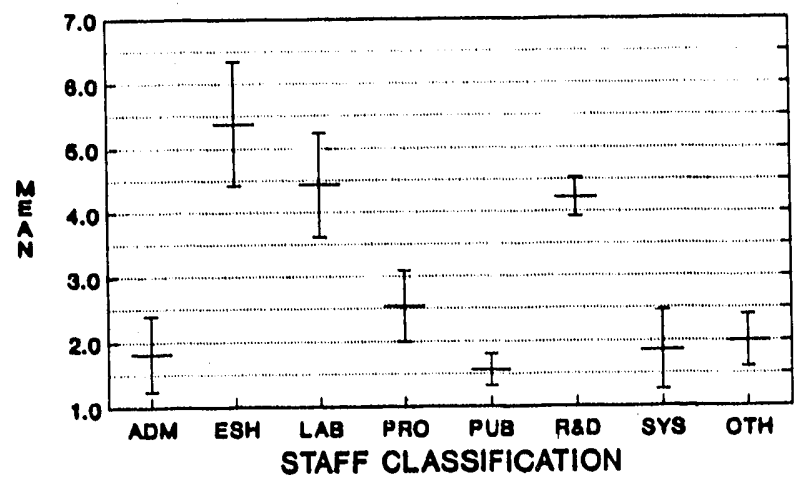

EARON DARE - -1- 1 8TO EARON

Figure 4.30. Significant differesrces between TEAM staff classifications on the onsite consequences question

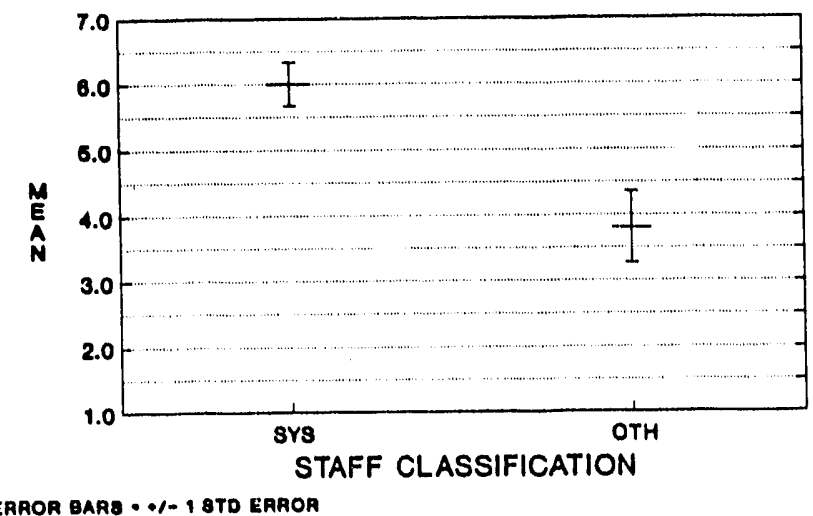

Figure 4.31. Significant differences between TEAM staff classifications on the employee awareness question

4.9.9 Differences Between Supervisory Levels on the Environment, Safety, and Health Questions

No statistically significant differences between supervisory levels, regardless of the way in which they were analyzed, were obtained for the overall PETC sample, or within the organizations on any of the environment, safety, and health questions. Appendices J through $Q$ contain the mean value obtained on each question for each of the groups which were included in an analysis. No other statistically significant differences occurred between the TEAM Staff Classifications on the environment, safety, and health questions. Appendix $\mathrm{H}$ contains the mean values obtained for each TEAM Staff Classification on each of the questions. 
No statistically significant differences between the ASI Staff Classifications occurred on the environment, safety, and health questions. Appendix I contains the mean values for each of the ASI Staff Classifications on each question. 


\section{CONCLUSIONS}

The Organizational Survey (OS) administered at the Pittsburgh Energy Technology Center (PETC) on August 6, 1991, was the eighth to occur at a U.S. Department of Energy (DOE) facility. The facility differs from most other previous sites, utilizing DOE as well as Authorized Systems, Inc. (ASI), Dynamic Concepts, Inc. (DCI), and TEAM (Burns and Roe Services Corporation, Gilbert/Commonwealth Inc., and Science Applications International Corporation) contractor employees to operate the facility. One half of the employees are from DOE.

All 627 employees received notice of the OS administration. A total of 565 employees actually completed the survey, yielding a very high response rate of 90.1 percent. Within the four organizations, DOE, ASI, DCI, and TEAM, the response rates were $89.8,89.4,65.0$, and 82.1 percent, respectively.

The overall organizational profile which emerges from the results of the PETC OS is indicative of a culture which is largely constructive, as indicated by the mean scores on the HumanisticEncouraging (C1), Affiliative (C2), Achievement (C11), and Self-Actualizing (C12) Scales. However, the results also indicate a culture which has a tendency to deal with some issues in a passive, yet defensive manner, as seen mainly in the mean scores for the Dependent (C5), Conventional (C4), and Approval (C3) Scales.

On the communication scales, the PETC Organization had moderate to moderately high mean values. The organization scored lowest on the Trust in Communications and Satisfaction with Communications Scales. The highest communication scale score occurred on the Desire for Interaction Scale.

While members of the organization describe their working groups as being fairly cohesive, they indicate a lower commitment to the PETC organization, as well as fairly low coordination between organizational units. PETC employees do not generally perceive their jobs to be highly hazardous; however, they do believe the attributes related to operating in a safe manner are important. Employees at PETC also believe there to be some, although not a very high, potential for both on- and offsite environmental consequences due to substandard performance. Management emphasis on environment, safety, and health issues is also perceived to be high. Employee awareness of environment, safety, and health issues is also perceived to be high, although it is somewhat lower than perceived management emphasis on these same issues.

Few statistically significant differences were found between the four organizations at PETC. No statistically significant differences occurred on the $\mathrm{OCI}$ scales. On the communication scales, one statistically significant difference was obtained on the Accuracy Scale. DOE Employees perceive the information they receive to be more accurate than DCI employees indicate. On the additional scales, statistically significant differences were obtained only on the Hazard Scale, with respondents from both the TEAM and DCI Organizations indicating their jobs involve statistically significantly more hazard than ASI employees indicated for their work. The final statistically significant difference found between PETC organizations was on the Onsite Environmental Consequences Question. The ASI respondents had a statistically significantly lower mean value on this question than both the DCI and the TEAM organizations. 
Within organizations, relatively few statistically significant differences were found. No statistically significant differences were found between the ASI departments. Of the differences which occurred between the departments of the other three organizations, none involved any of the scales on the OCI.

The differences found between departments in the DOE Organization all involved the environment, safety, and health aspects of the work. On the Hazard Scale, the Research and Development Department had a statistically significantly higher mean value on this scale than every other department at DOE. Two statistically significant differences were found between the DOE Departments on the Environment, Safety, and Health Questions. Both the Research and Development and the Director's Office Departments had statistically significantly higher mean values on the question concerning management emphasis on environmental issues than the Administration Department. The Director's Office was also statistically significantly higher than the Administration Department on the Employee Awareness Question.

Within the DCI Organization, three statistically significant differences were found between departments. On the Cohesion Scale, the Security Department had a statistically significantly lower mean value than both the Environment, Safety, and Health, and the Maintenance/Janitorial Departments. The Environment, Safety, and Health Department had a statistically significantly higher mean value on both the Communication-Trust and the Communication-Interaction Scales than the Maintenance/Janitorial and Security Departments.

Statistically significant differences between the TEAM Departments occurred on four of the scales from the OS, all of which involved environment, safety, and health issues. On the Hazard Scale, the Administrative Services, Management and Information Services, and Technical Management Services Departments all had statistically significantly lower mean values than the Environment, Safety, and Health Services, the Research and Development, and the Real Property Management Services Departments. On both the Offsite and Onsite Environmental Consequences Questions, the Environment, Safety, and Health Services and the Research and Development Departments had statistically significantly higher mean values than the Administrative Services and the Management and Information Services Departments. Finally, on the Employee Awareness Question, the Real Property Management Services had a statistically significantly lower mean value than the Research and Development Department. This result for the Real Property Management Services Department is in contrast to the results obtained for this department on the Hazard Scale.

Four of the five differences found between staff classifications were related to environment, safety, and health issues. The fifth result is one of two statistically significant differences found on the OCI scales. Both the Administration and the Environment, Safety, and Health Staff Classifications had statistically significantly higher mean values on the Perfectionistic (C10) Scale than the Systems Staff Staff Classification.

Only one statistically significant difference was found between supervisory levels and one between supervisors and non-supervisors at PETC. Both differences involved satisfaction with the communication process at PETC. The differences obtained between supervisory levels within organizations were not numerous and were not unexpected, based on the results from other OS administrations. 
The few differences obtained between groups at PETC indicate an organizatior: with a very homogeneous culture. This statement is further supported by the very few differences found on the OCI. This finding is unique from other DOE facilities at which multiple organizations are represented. Many of the differences obtained occurred on scales related to environment, safety, and health issues (i.e., Hazard Scale, Off- and Onsite Environmental Consequences, Management Emphasis, and Employee Awareness Questions). The differences obtained on these scales appear consistent with work function. 
APPENDIX A

SIGNIFICANT DIFFERENCES BETWEEN ORGANIZATIONS ON THE OS 


\begin{tabular}{|c|c|c|c|c|c|c|c|}
\hline$\stackrel{0}{\circ}$ & $\overrightarrow{\tilde{n}}$ & & 8 & & $\stackrel{+}{+}$ & 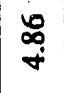 & \\
\hline Оิ & $\underset{+}{\text { ఫి }}$ & & $\underset{q}{q}$ & & $\stackrel{\mathscr{7}}{\not}$ & $\hat{m}$ & \\
\hline 承 & $\overrightarrow{\overrightarrow{0}}$ & & 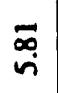 & & nn & f & \\
\hline$\underline{x}$ & $\stackrel{0}{\stackrel{2}{*}}$ & $\mathcal{F}$ & $\underset{m}{b}$ & - & $\underset{\mathrm{m}}{\mathrm{s}}$ & जे & - \\
\hline 퐁 & 요 & & $\approx$ & & $\frac{m}{i}$ & $\frac{n}{n}$ & \\
\hline 8 & $\stackrel{\mathscr{q}}{\stackrel{+}{*}}$ & & $\underset{\text { Tั }}{+}$ & & $\underset{+}{\mathscr{+}}$ & $\bar{j}$ & \\
\hline 를 & ஸ̊ & & ले & & $\frac{n}{m}$ & 8 & \\
\hline$\overline{\overline{0}}$ & $\tilde{n}$ & & $\underset{m}{\stackrel{q}{p}}$ & & qu & $\tilde{m}$ & \\
\hline 은 & กั & & $\underset{\mathrm{m}}{\stackrel{\mathrm{m}}{\mathrm{n}}}$ & & $\stackrel{g}{i}$ & $\stackrel{\infty}{\stackrel{\infty}{i}}$ & \\
\hline 8 & సี & & $\underset{\sim}{\mathbb{N}}$ & & సे & 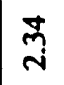 & \\
\hline$\ddot{0}$ & $\stackrel{n}{n}$ & & $\stackrel{\infty}{\stackrel{\infty}{\sim}}$ & & $\underset{\vec{\sim}}{\vec{i}}$ & $\tilde{n}$ & • \\
\hline 5 & i̊n. & & $\bar{n}$ & & i্ & in & \\
\hline$\ddot{0}$ & $\frac{ \pm}{i}$ & & $\overline{\mathcal{N}}$ & & ్ㅠ & $\overline{\text { nु }}$ & \\
\hline$\tilde{u}$ & $\frac{\square}{\dot{m}}$ & & $\frac{\Xi}{\dot{m}}$ & & $\underset{m}{\tilde{m}}$ & ָூ & \\
\hline$\vec{U}$ & ๙ू & & $\stackrel{\tilde{m}}{m}$ & & $\underset{\text { m }}{\stackrel{8}{ }}$ & $\frac{O}{m}$ & \\
\hline 3 & $\begin{array}{l}0 \\
\infty \\
i\end{array}$ & & $\begin{array}{l}\stackrel{8}{0} \\
\text { i }\end{array}$ & & $\underset{\infty}{\stackrel{\infty}{\text { i }}}$ & ก̊. & \\
\hline$\tilde{U}$ & $\frac{P}{m}$ & & $\underset{m}{\stackrel{R}{m}}$ & & $\underset{m}{\tilde{m}}$ & îj & \\
\hline$\vec{u}$ & $\bar{n}$ & & $\underset{\dot{m}}{\bar{j}}$ & & $\stackrel{n}{m}$ & $\frac{m}{m}$ & \\
\hline 离 & $\bar{s}$ & & $\bar{\Xi}$ & & 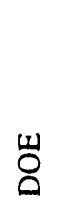 & $\underset{\mathscr{H}}{E}$ & \\
\hline تั & - & & 4 & & $m$ & $\tau$ & \\
\hline
\end{tabular}

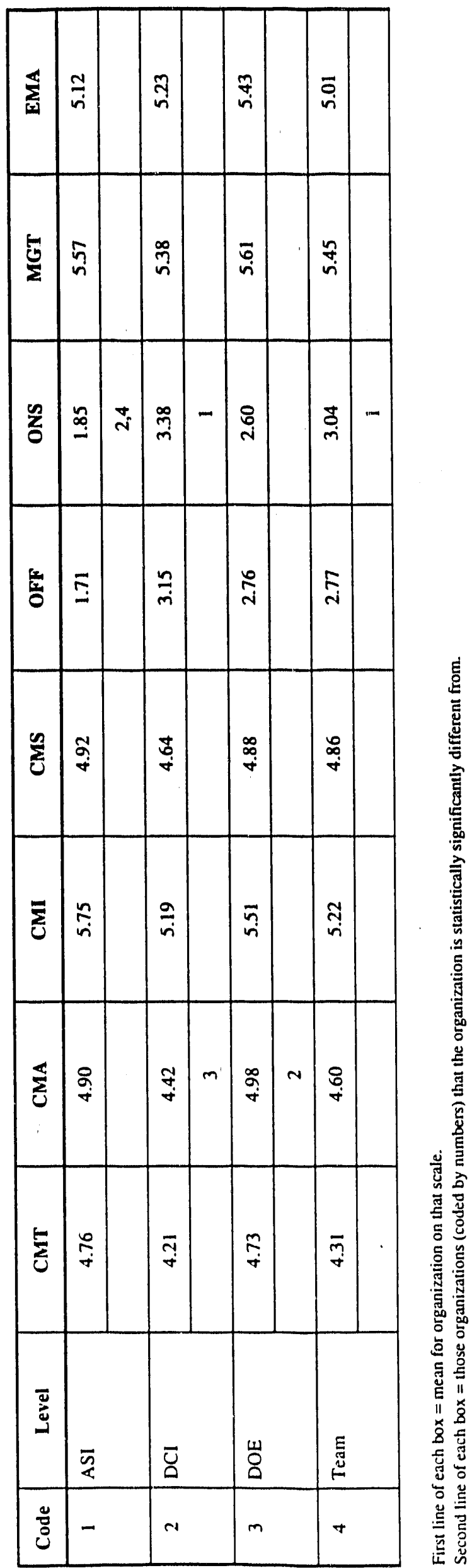




\section{APPENDIX B}

SIGNIFICANT DIFFERENCES BETWEEN DOE DEPARTMENTS ON THE OS 


\begin{tabular}{|c|c|c|c|c|c|c|c|c|c|c|}
\hline 옹 & ซิ & & $\underset{+}{\stackrel{9}{*}}$ & & ถุ & & $\begin{array}{l}8 \\
\dot{8}\end{array}$ & & $\begin{array}{c}n \\
n\end{array}$ & \\
\hline ठิ & $\bar{\sigma}$ & & $\frac{5}{7}$ & & $\begin{array}{l}\overrightarrow{0} \\
+\end{array}$ & & $\begin{array}{l}8 \\
\text { mे }\end{array}$ & & ริ & \\
\hline 跑 & $\underset{n}{\tilde{n}}$ & & $\underset{\delta}{\tilde{D}}$ & & $\begin{array}{l}\infty \\
\stackrel{\infty}{n} \\
\sim\end{array}$ & & 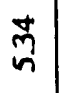 & & Fै & \\
\hline$\underset{\mathbf{y}}{\mathbf{y}}$ & 요 & $n$ & নุ & $n$ & ì & $n$ & $\underset{N}{F}$ & $n$ & $\begin{array}{l}\infty \\
\dot{m} \\
\dot{m}\end{array}$ & ने \\
\hline 명 & $\begin{array}{l}\infty \\
\dot{c} \\
\dot{n}\end{array}$ & & $\frac{\pi}{n}$ & & $\begin{array}{l}\text { 莒 } \\
\text { vi }\end{array}$ & & สิ & & $\begin{array}{l}\text { Z } \\
\text { vi }\end{array}$ & \\
\hline 8 & $\ddot{q}$ & & $\underset{7}{F}$ & & $\stackrel{n}{n}$ & & $\stackrel{:}{:}$ & & 5 & \\
\hline$\tilde{u}$ & $\begin{array}{l}\dot{0} \\
\dot{m}\end{array}$ & & స్లి & & $\underset{m}{\tilde{F}}$ & & $\underset{m}{\stackrel{\rho}{m}}$ & & $\stackrel{5}{m}$ & \\
\hline$\overline{0}$ & $\stackrel{n}{m}$ & & $\stackrel{\vec{m}}{\mathrm{~m}}$ & & $\frac{m}{m}$ & & $\bar{n}$ & & $\underset{m}{\mathscr{q}}$ & \\
\hline 일 & बे & & กั & & $\begin{array}{l}+ \\
\text { i } \\
\text { i }\end{array}$ & & $\stackrel{2}{3}$ & & $\widehat{b}$ & \\
\hline 8 & 学 & & సี & & $\frac{n}{i}$ & & $\frac{8}{4}$ & & $\ddot{\jmath}$ & \\
\hline$\infty$ & 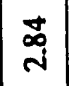 & & $\underset{N}{+}$ & & 尔 & & $\overrightarrow{0}$ & & $\bar{n}$ & \\
\hline 5 & 兴 & & $\ddot{n}$ & & $\stackrel{\infty}{\pi}$ & & స̃ & & ป & \\
\hline$\ddot{~}$ & $\tilde{n}$ & & $\overline{\mathrm{A}}$ & & $\overline{9}$ & & $\pi$ & & స̊ & \\
\hline$n$ & สี & & ले & & ñ & & $\frac{a}{\dot{m}}$ & & ने & \\
\hline$\Xi$ & $\begin{array}{l}\text { gे } \\
m\end{array}$ & & $\begin{array}{l}\tilde{\alpha} \\
i\end{array}$ & & $\overrightarrow{\tilde{\sigma}}$ & & $\frac{m}{m}$ & & 8 & \\
\hline 3 & $\begin{array}{l}\infty \\
\infty \\
i\end{array} \mid$ & & $\frac{n}{i}$ & & $\stackrel{n}{n}$ & & $\begin{array}{c}n \\
i \\
i\end{array}$ & & $\vec{\infty}$ & \\
\hline$\tilde{U}$ & $\bar{m}$ & & 䎡 & & $\left|\begin{array}{l}n \\
\infty \\
m \\
m\end{array}\right|$ & & $\underset{m}{\vec{n}}$ & & m. & \\
\hline $\bar{u}$ & 苻 & & $\underset{\sim}{\stackrel{\sim}{i}}$ & & $\begin{array}{l}n \\
\dot{m}\end{array}$ & & $\tilde{\pi}$ & & $\stackrel{\infty}{m}$ & \\
\hline অ্ّ & $\stackrel{Q}{4}$ & & 它 & & $\overrightarrow{0}$ & & $\Sigma$ & & $\begin{array}{l}\partial \\
\approx \\
\propto\end{array}$ & \\
\hline تี & - & & 4 & & $m$ & & + & & $n$ & \\
\hline
\end{tabular}

祉

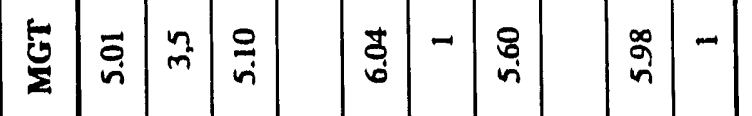

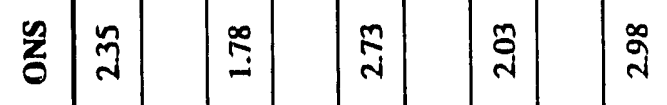

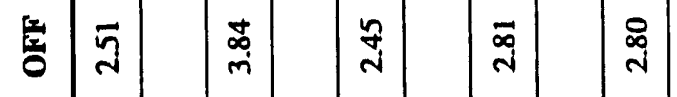

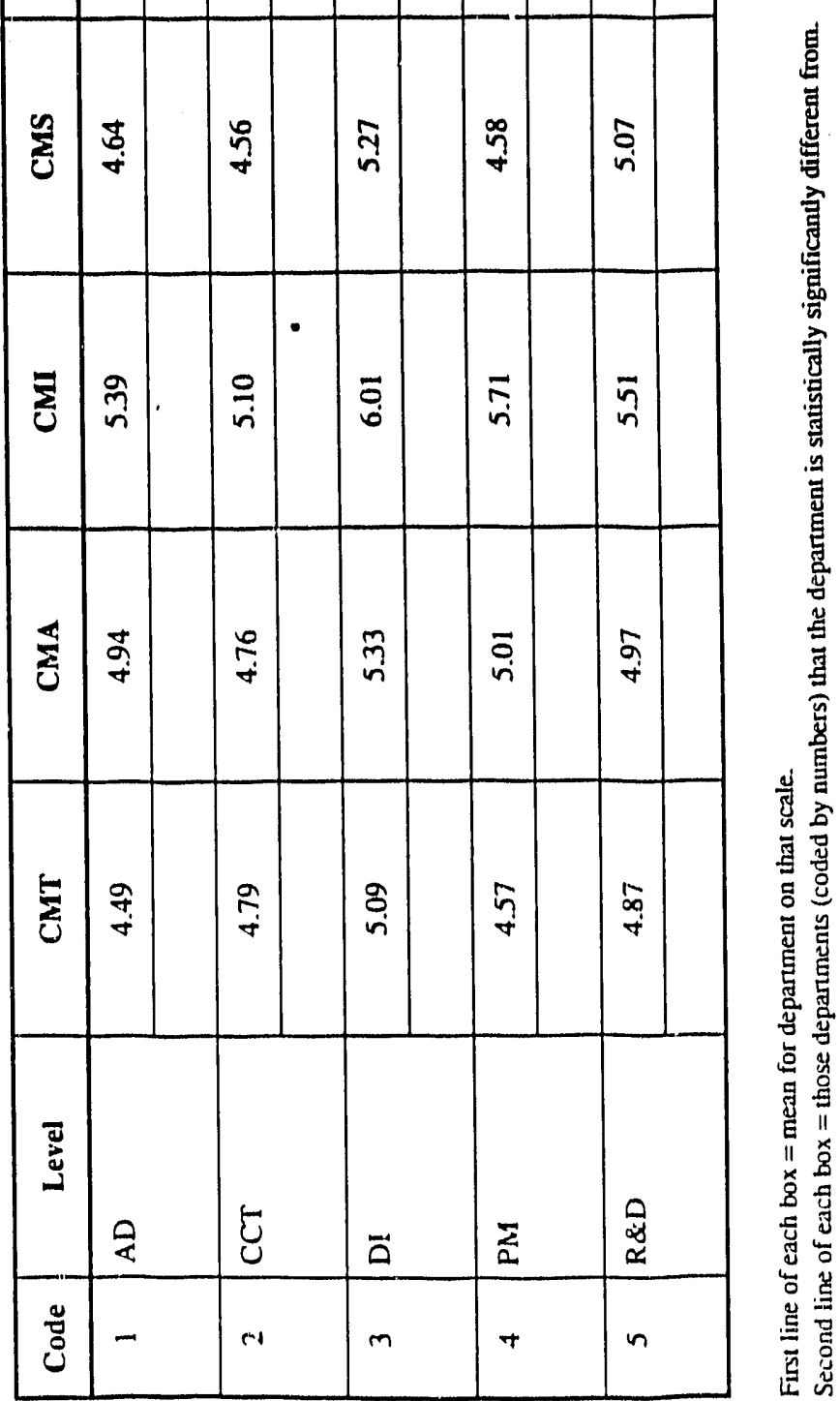




\section{APPENDIX C}

SIGNIFICANT DIFFERENCES BETWEEN TEAM DEPARTMENTS ON THE OS 


\begin{tabular}{|c|c|c|c|c|c|c|c|c|c|c|c|c|c|c|}
\hline 号 & $\begin{array}{l}8 \\
\text { ज. }\end{array}$ & & $\stackrel{5}{7}$ & & $\overline{\vec{n}}$ & & $\begin{array}{l}8 \\
8\end{array}$ & & $\overrightarrow{\text { ते }}$ & & $\dddot{7}$ & & $\begin{array}{l}\text { से } \\
\text { m }\end{array}$ & \\
\hline 8ิ & 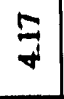 & & $\bar{m}$ & & ś & & $\begin{array}{c} \pm \\
\text { m }\end{array}$ & & $\stackrel{9}{7}$ & & $\begin{array}{c}\tilde{m} \\
m\end{array}$ & & $\bar{\sigma}$ & \\
\hline 4 & $\begin{array}{l}\mathscr{n} \\
\text { nิ }\end{array}$ & & $\begin{array}{l}\text { 导 } \\
\text { n' }\end{array}$ & & $\begin{array}{l}\vec{b} \\
\text { vi }\end{array}$ & & สี & & $\begin{array}{l}\ddot{B} \\
n\end{array}$ & 1 & 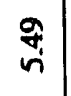 & & $\underset{n}{n}$ & \\
\hline $\mathbf{D}$ & $\overline{\mathbf{A}}$ & $\begin{array}{l}0 \\
\tilde{y}\end{array}$ & \% & $\mathrm{m}$ & $\tilde{n}$ & $\begin{array}{l}0 \\
2 \\
\sqrt{2}\end{array}$ & $\dddot{m}$ & 0 & 苟 & $\tilde{z}$ & ชู & z: & $\stackrel{\infty}{d}$ & $\begin{array}{l}0 \\
\text { y. }\end{array}$ \\
\hline 명 & 영 & & 3 & & ते & & $\underset{F}{F}$ & & 品 & & $\frac{\pi}{n}$ & & .5 & \\
\hline 8 & $\underset{m}{F}$ & & जे & & $F$ & & 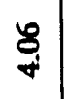 & & ฟे & & 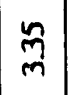 & & 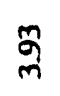 & \\
\hline ฮี & สิ & & ฉે & & สี & & 品 & & $\begin{array}{l}\infty \\
\dot{m} \\
m\end{array}$ & & $\stackrel{n}{i}$ & & a & \\
\hline $\bar{\Xi}$ & $\stackrel{B}{m}$ & & न & & $\begin{array}{l}8 \\
\dot{m} \\
\dot{m}\end{array}$ & & సి & & ले & & ㄱ. & & స్లె & \\
\hline 룹 & 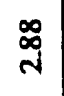 & & नู & & $\frac{4}{4}$ & & $\vec{a}$ & & $\frac{n}{\lambda}$ & & ก) & & స్ & \\
\hline 8 & $\stackrel{\circ}{N}$ & & $\ddot{\nu}$ & & $\tilde{n}$ & & $\stackrel{\vartheta}{N}$ & & $\tilde{\lambda}$ & & 习ิ & & $\ddot{\nu}$ & \\
\hline 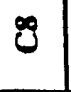 & ฟ & & $\begin{array}{c}8 \\
m \\
m\end{array}$ & & 5 & & $\overrightarrow{\mathrm{j}}$ & & ज्ञ & & స̊․ & & $\frac{\infty}{\sqrt{n}}$ & \\
\hline 5 & $\stackrel{\infty}{\beth}$ & & $\overrightarrow{\vec{b}}$ & & $\overrightarrow{2}$ & & $\ddot{n}$ & & 导 & & $\sqrt[5]{2}$ & & 苛 & \\
\hline ن & 9 & & $\begin{array}{l}\infty \\
\dot{m} \\
\dot{m}\end{array}$ & & $\frac{\pi}{4}$ & & J & & สิ & & $\tilde{n}$ & & $\hat{n}$ & \\
\hline 3 & $\bar{r}$ & & $\hat{n}$ & & चे & & m & & $\begin{array}{l}\ddot{\theta} \\
\dot{m}\end{array}$ & & $\overline{\bar{m}}$ & & $\bar{m}$ & \\
\hline J & $\vec{\infty}$ & & $\begin{array}{c}\tilde{\infty} \\
\dot{m}\end{array}$ & & 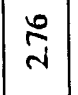 & & กั & & ने & & $\frac{n}{m}$ & & 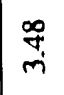 & \\
\hline 0 & $\begin{array}{l}\infty \\
i \\
i\end{array}$ & & $\begin{array}{l}\infty \\
\text { ì } \\
m\end{array}$ & & $\frac{n}{4}$ & & $\bar{m}$ & & $\frac{\infty}{4}$ & & a & & ते & \\
\hline$\tilde{U}$ & $\begin{array}{l}\infty \\
0 \\
\dot{m} \\
\dot{m}\end{array}$ & & $\underset{m}{F_{i}}$ & & $\begin{array}{l}\vec{n} \\
m\end{array}$ & & $\begin{array}{l}y \\
m\end{array}$ & & $\begin{array}{l}\vec{m} \\
m\end{array}$ & & $\begin{array}{l}8 \\
\dot{m} \\
m\end{array}$ & & ने & \\
\hline$\vec{u}$ & $\stackrel{n}{m}$ & & $\stackrel{\circ}{\stackrel{m}{m}}$ & & $\stackrel{n}{m}$ & & $\begin{array}{l}\tilde{O} \\
\dot{m}\end{array}$ & & $\frac{\infty}{m}$ & & $\begin{array}{l}\infty \\
7 \\
7\end{array} \mid$ & & $\overline{\bar{m}}$ & \\
\hline $\bar{d}$ & 紊 & & 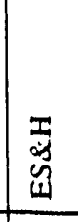 & & $\stackrel{\varrho}{\Sigma}$ & & 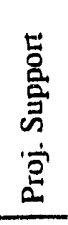 & & 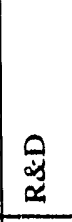 & & 充 & & 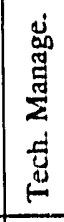 & \\
\hline نัّ & - & & $\mathrm{OA}$ & & $m$ & & + & & $n$ & & 0 & & $r$ & \\
\hline
\end{tabular}
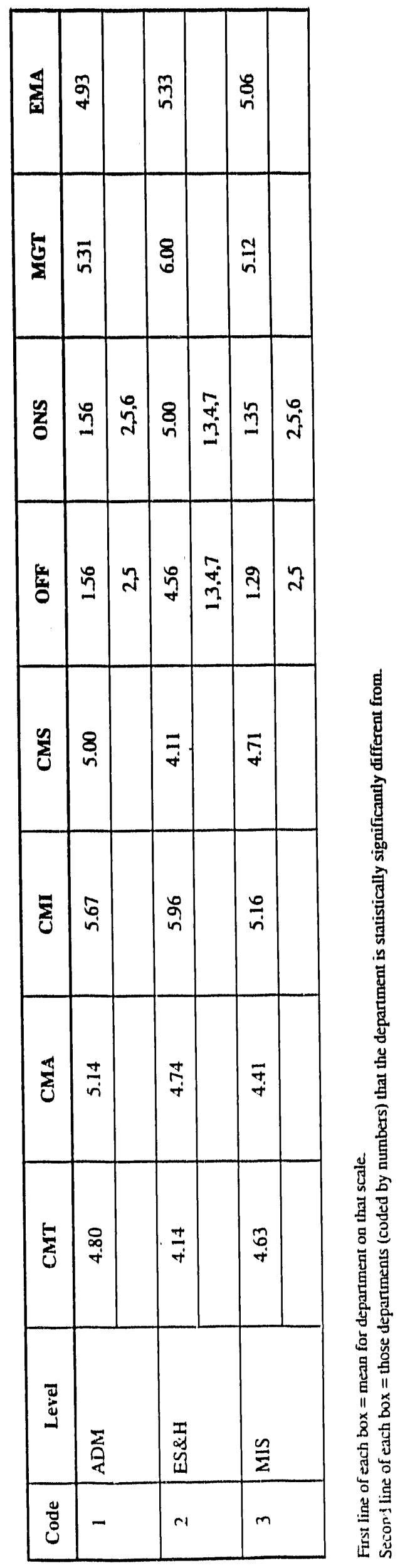


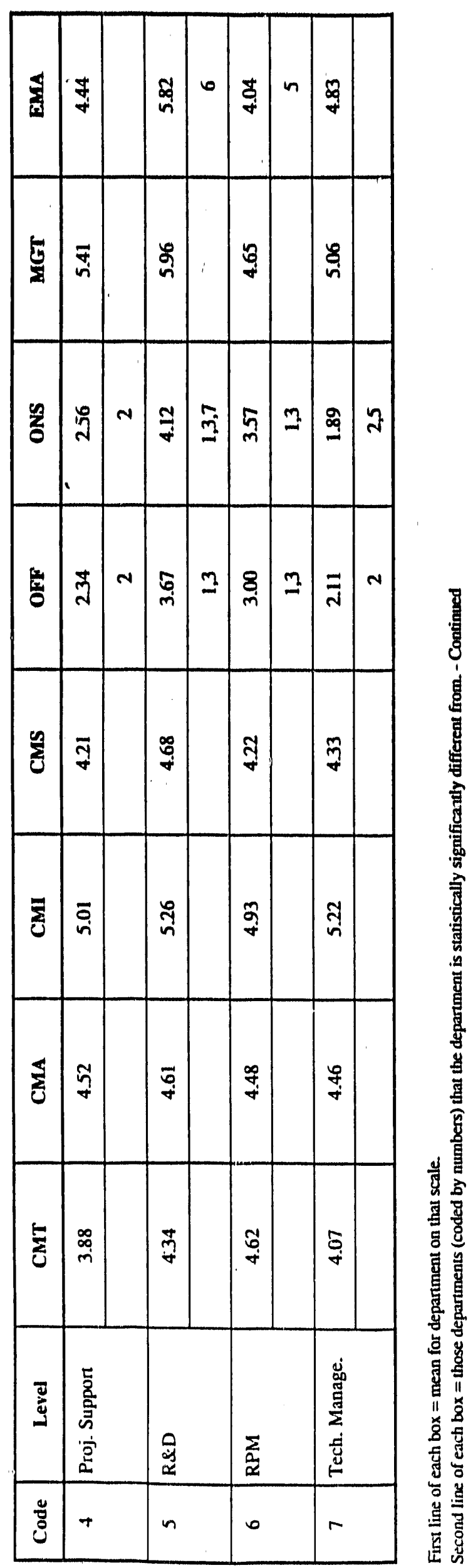




\section{APPENDIX D}

SIGNIFICANT DIFFERENCES BETWEEN ASI DEPARTMENTS ON THE OS 


\begin{tabular}{|c|c|c|c|c|}
\hline 兒 & 9 & 8 & 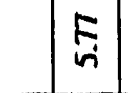 & \\
\hline ठิ & $\stackrel{9}{q}$ & $\underset{+}{\dot{+}}$ & สุ & \\
\hline ڤ્s & $\begin{array}{l}\vec{b} \\
\dot{n}\end{array}$ & ถึ & $\begin{array}{l}8 \\
\dot{p} \\
\dot{1}\end{array}$ & \\
\hline 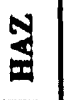 & 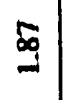 & $\vec{m}$ & $\stackrel{n}{n}$ & \\
\hline 명 & $\frac{0}{n}$ & $\begin{array}{c}\infty \\
\tilde{n} \\
\tilde{n}\end{array}$ & 望 & \\
\hline 8 & $\hbar$ & \pm & $\begin{array}{l}\dot{b} \\
\dot{\omega}\end{array}$ & \\
\hline บै & సે & sू & n & 1 \\
\hline $\bar{\jmath}$ & जे & \begin{tabular}{l}
\multirow{j}{*}{} \\
$\mathrm{m}$
\end{tabular} & $\underset{m}{\stackrel{n}{m}}$ & \\
\hline 은 & $\hat{\hat{~}}$ & $\bar{A}$ & $\hat{\tilde{j}}$ & \\
\hline 8 & $\overline{\text { సี }}$ & ปे & $\frac{ \pm}{N}$ & \\
\hline 8 & 㲾 & $\overline{\mathrm{N}}$ & 节 & \\
\hline 5 & $\overline{2}$ & जे & స̆ & \\
\hline 8 & $\overline{7}$ & $\overline{\mathcal{\lambda}}$ & $\hat{a}$ & \\
\hline n & $\overrightarrow{\tilde{n}}$ & ลे & ণั & \\
\hline$\Xi$ & ì & $\stackrel{\text { ఎे }}{\text { d }}$ & ঐે & \\
\hline 0 & $\stackrel{n}{i}$ & $\stackrel{4}{a}$ & ঐి & \\
\hline$\tilde{U}$ & $\begin{array}{c}\hat{\sigma} \\
\dot{m} \\
\end{array}$ & ปี & $\stackrel{8}{8}$ & \\
\hline$\vec{u}$ & iे & $\stackrel{\vec{m}}{m}$ & 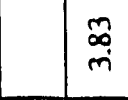 & \\
\hline $\bar{\Xi}$ & 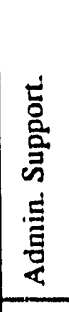 & 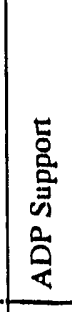 & 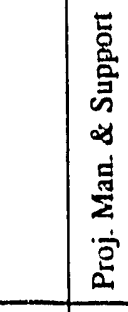 & \\
\hline$\ddot{g}$ & - & $\mathrm{N}$ & $m$ & \\
\hline
\end{tabular}

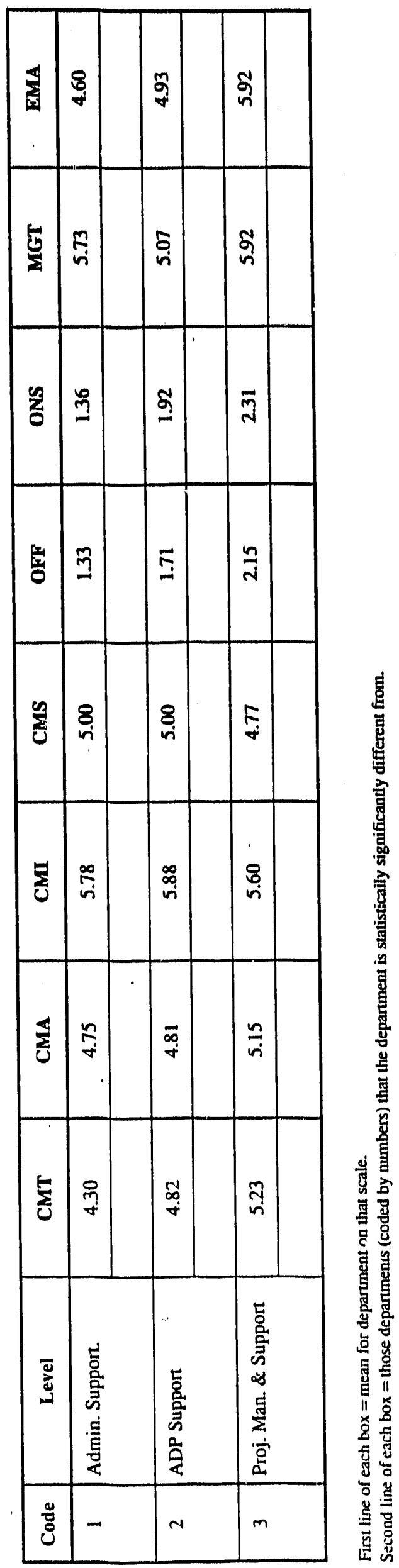

D-1 
APPENDIX E

SIGNIFICANT DIFFERENCES BETWEEN DCI DEPARTMENTS ON THE OS 


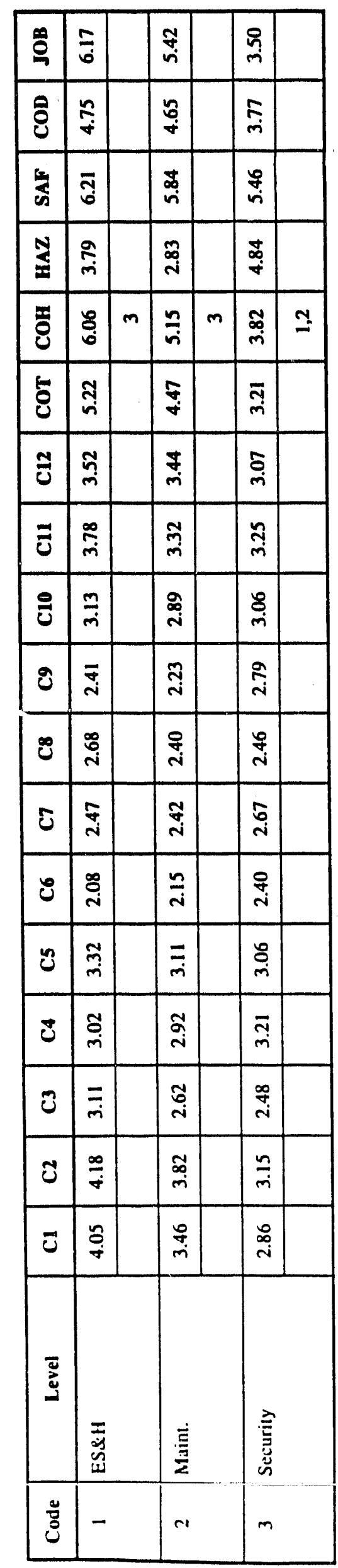

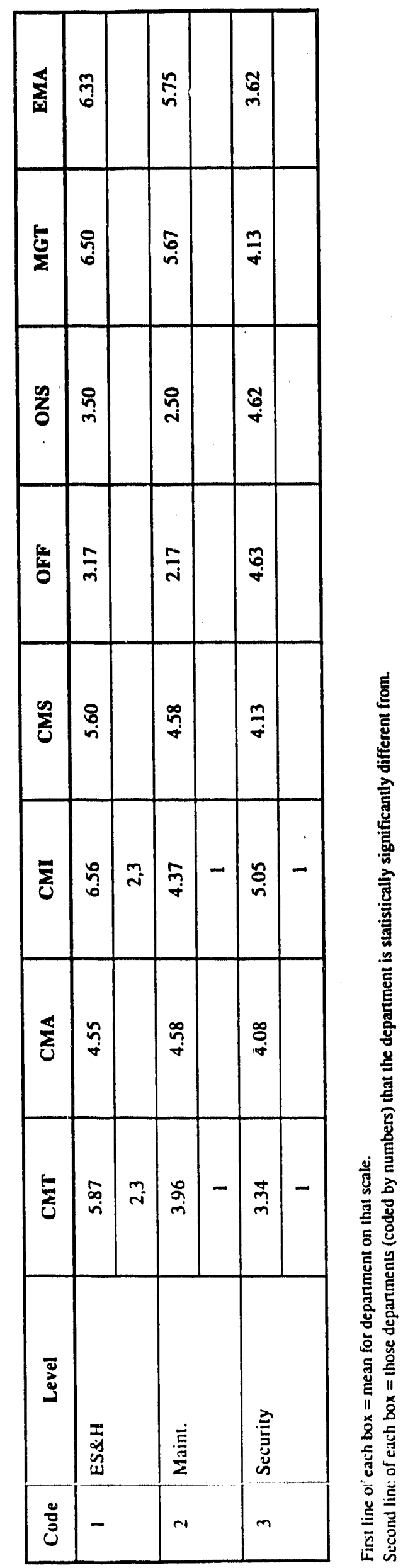

E-1 


\begin{abstract}
APPENDIX F
SIGNIFICANT DIFFERENCES BETWEEN STAFF CLASSIFICATIONS ON THE OS
\end{abstract}




\begin{tabular}{|c|c|c|c|c|c|c|c|c|c|c|c|c|c|c|c|c|c|c|c|c|}
\hline$\stackrel{\varphi}{\varrho}$ & $\frac{7}{7}$ & & $\overline{9}$ & & $\stackrel{m}{f}$ & & กี & & $\begin{array}{l}5 \\
\\
\end{array}$ & & $\begin{array}{c}0 \\
0 \\
\dot{D} \\
\end{array}$ & & 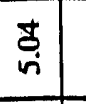 & $\stackrel{\infty}{\underset{+}{*}}$ & & $\begin{array}{l}\overline{0} \\
\end{array}$ & ஓ̊ & & $\begin{array}{l}8 \\
n\end{array}$ & \\
\hline 용 & $\underset{\dot{+}}{\dot{+}}$ & & $\begin{array}{l} \\
\\
\end{array}$ & & $\begin{array}{l} \\
\\
\end{array}$ & & $\underset{+}{ \pm}$ & & $\begin{array}{l}t \\
+ \\
+\end{array}$ & & $\frac{5}{7}$ & & $\bar{\sigma}$ & ฆุ & & ‡̛ & gे & & $\begin{array}{l}0 \\
\infty \\
\dot{m}\end{array}$ & \\
\hline 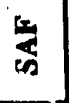 & 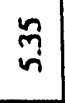 & & $\begin{array}{l}\tilde{a} \\
\text { ज }\end{array}$ & & 号 & & qu & & $\begin{array}{l}0 \\
\dot{+} \\
\dot{n}\end{array}$ & & जे & & ฟู & 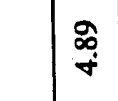 & & 乞n & $\begin{array}{l}8 \\
\text { ஸे }\end{array}$ & & \begin{tabular}{c}
$\infty$ \\
\multirow{+}{*}{} \\
v.
\end{tabular} & \\
\hline$\underset{\mathbf{X}}{\mathbf{X}}$ & స్ & $\begin{array}{l}\dot{v} \\
\tilde{n} \\
\tilde{m}^{\prime}\end{array}$ & $\underset{m}{m}$ & $m$ & $\underset{\mathcal{F}}{\mathcal{Z}}$ & $\begin{array}{l}\overline{0} \\
0 \\
0 \\
\tilde{n} \\
\tilde{N} \\
0 \\
= \\
=\end{array}$ & $\begin{array}{l}8 \\
\dot{m} \\
m\end{array}$ & $\begin{array}{c}\overrightarrow{0} \\
0 \\
0 \\
-0\end{array}$ & जे & $\begin{array}{l}\overrightarrow{0} \\
0 \\
0 \\
\sim_{0}^{\circ}\end{array}$ & 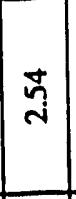 & $\begin{array}{l}\dot{v} \\
\tilde{n} \\
\tilde{m}^{2}\end{array}$ & 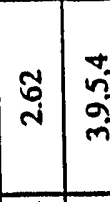 & 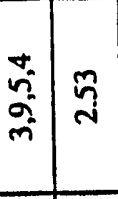 & $\begin{array}{c}\dot{y} \\
\tilde{n} \\
\tilde{m} \\
\text { n. }\end{array}$ & 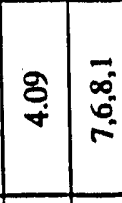 & 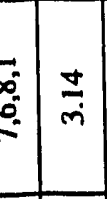 & $m$ & $\frac{\equiv}{m}$ & $m$ \\
\hline 四 & ñ & & $\overline{\bar{n}}$ & & $\begin{array}{l}\text { to } \\
\dot{v}\end{array}$ & & $\underset{+}{+}$ & & $\frac{n}{n}$ & & 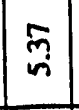 & & 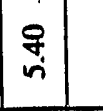 & $\frac{ \pm}{n}$ & & 官 & ฟุ & & \% & \\
\hline 5 & $\underset{7}{+}$ & & $\frac{n}{7}$ & & 5 & & $\stackrel{+}{+}$ & & nี & & $\begin{array}{l}0 \\
+ \\
+\end{array}$ & & $\stackrel{m}{+}$ & 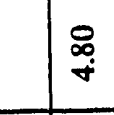 & & $\begin{array}{l}n \\
\dot{q}\end{array}$ & 5 & & $\underset{⿱}{*}$ & \\
\hline 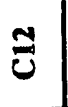 & $\underset{r}{\Delta}$ & & $\frac{m}{m}$ & & $\stackrel{\infty}{m}$ & & $\begin{array}{l}8 \\
\dot{m}\end{array}$ & & 官 & & $\frac{\bar{m}}{m}$ & & $\underset{m}{\Delta}$ & 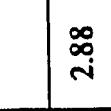 & & $\frac{ \pm}{m}$ & $\stackrel{g}{\dot{m}}$ & & $\stackrel{\Xi}{m}$ & \\
\hline$\overline{3}$ & $\begin{array}{l}f \\
\dot{f}\end{array}$ & & 華 & & $\begin{array}{l}n \\
m \\
\end{array}$ & & $\begin{array}{l}\tilde{y} \\
\dot{m} \\
\end{array}$ & & $\frac{ \pm}{m}$ & & $\begin{array}{c} \\
\dot{n} \\
m\end{array}$ & & $\begin{array}{c}\infty \\
m \\
m \\
\end{array}$ & ஸุ & & $\bar{m}$ & $\underset{\sim}{\tilde{m}}$ & & $\left|\begin{array}{l}n \\
n \\
m\end{array}\right|$ & \\
\hline 율 & $\begin{array}{c}\overrightarrow{0} \\
\dot{m}\end{array}$ & $\varrho$ & $\bar{i}$ & & $\overline{\dot{m}}$ & 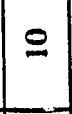 & $\begin{array}{l}0 \\
0 \\
\\
\end{array}$ & & $\underset{i}{\stackrel{t}{i}}$ & & Sิ & & $\underset{i}{\stackrel{d}{i}}$ & 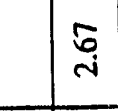 & & $\underset{\sim}{\sigma}$ & $\underset{\sim}{\mathcal{H}}$ & $\eta$ & a & \\
\hline 8 & F & & ले & & ت & & సึ & & ) & & సิ & & ì & $\underset{\sim}{\mathbb{d}}$ & & $\tilde{m}$ & $\frac{\sim}{N}$ & & 总 & \\
\hline 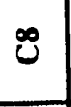 & $\frac{0}{i}$ & & 呇 & & 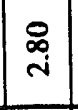 & & $\overline{\mathbf{i}}$ & & $\underset{7}{\stackrel{7}{i}}$ & & ì & & $\begin{array}{l}\infty \\
\stackrel{\infty}{0} \\
\end{array}$ & $\stackrel{i}{i}$ & & 곡 & $\stackrel{\infty}{7}$ & & ฟิ & \\
\hline 5 & $\tilde{n}$ & & ત્તે & & $\stackrel{n}{i}$ & & 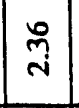 & & $\stackrel{?}{\text { i }}$ & & $\underset{\text { i }}{\stackrel{9}{i}}$ & & तु & $\tilde{n}$ & & $\stackrel{\overrightarrow{7}}{\mathrm{i}}$ & స્సે & & $\stackrel{\infty}{\stackrel{\sim}{\sim}}$ & \\
\hline 8 & $\stackrel{\text { त }}{\text { i }}$ & & $\overline{\hat{i}}$ & & $\stackrel{\mathcal{F}}{\mathrm{N}}$ & & iे & & $\underset{\sim}{\mathbb{i}}$ & & $\stackrel{\infty}{\stackrel{\infty}{i}}$ & & 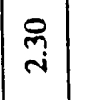 & $\underset{\mathrm{N}}{\mathrm{H}}$ & & $\stackrel{\vec{J}}{\mathrm{~N}}$ & $\frac{\infty}{\vec{N}}$ & & $\underset{\sim}{\stackrel{\sim}{\sim}}$ & \\
\hline$\tilde{3}$ & స్ & & $\stackrel{0}{m}$ & . & $\bar{m}$ & & $\begin{array}{l}\stackrel{a}{ } \\
\dot{i} \\
\end{array}$ & & $=$ & & शे & & $\dot{m}$ & ஸి & & 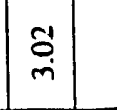 & 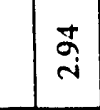 & & $\stackrel{\bar{y}}{m}$ & \\
\hline$\vec{U}$ & $\frac{\rho}{m}$ & & $\begin{array}{c}\bar{\sigma} \\
\dot{m}\end{array}$ & & $\frac{ \pm}{m}$ & & 곡 & & $\underset{\dot{m}}{\stackrel{m}{n}}$ & & $\overline{\bar{m}}$ & & $\stackrel{\infty}{\stackrel{\sim}{N}}$ & $\frac{r}{m}$ & & $\underset{\dot{m}}{\stackrel{8}{ }}$ & $\stackrel{\infty}{\stackrel{\sim}{i}}$ & & $\frac{ \pm}{m}$ & \\
\hline$\hat{0}$ & $\begin{array}{l}n \\
\infty \\
i\end{array}$ & & $\begin{array}{l}n \\
\infty \\
i\end{array}$ & & $\begin{array}{l}\infty \\
\stackrel{\infty}{\sim} \\
i\end{array}$ & & $\stackrel{\bar{\infty}}{i}$ & & $\underset{i}{\Delta}$ & & $\underset{\dot{m}}{\infty}$ & & $\underset{i}{\stackrel{t}{i}}$ & a & & $\stackrel{a}{i}$ & $\sqrt[n]{7}$ & & $\sqrt{i}$ & \\
\hline$\tilde{U}$ & $\underset{m}{m}$ & & $\stackrel{n}{f}$ & & $\vec{m}$ & & $\frac{0}{\dot{m}}$ & & $\stackrel{m}{m}$ & & $\underset{\dot{m}}{\overleftarrow{b}}$ & & mi & 월 & & $\stackrel{P}{\stackrel{P}{+}}$ & $\stackrel{\sim}{m}$ & & $\stackrel{\bar{n}}{m}$ & \\
\hline $\bar{u}$ & $\bar{r}$ & & $\stackrel{5}{9}$ & & $\stackrel{n}{m}$ & & $\frac{n}{m}$ & & $\frac{\sim}{m}$ & & $\underset{\dot{q}}{\stackrel{q}{\vec{p}}}$ & & $\stackrel{n}{n}$ & $\stackrel{\circ}{\stackrel{\rho}{m}}$ & & $\underset{m}{\stackrel{p}{n}}$ & 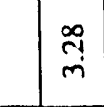 & & $\underset{m}{\vec{m}}$ & \\
\hline 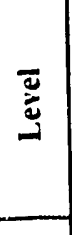 & 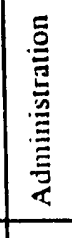 & & 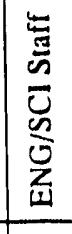 & & 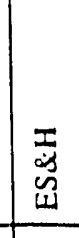 & & 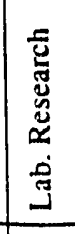 & & 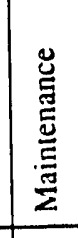 & & 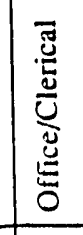 & & 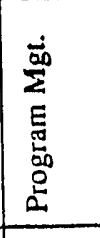 & 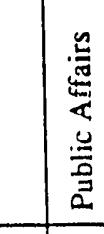 & & $\begin{array}{l}\stackrel{\otimes}{8} \\
\propto \\
\end{array}$ & 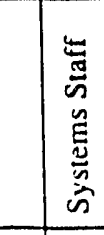 & & 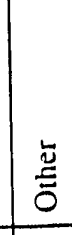 & \\
\hline 苛 & - & & $a$ & & $m$ & & $\rightarrow$ & & $n$ & & 0 & & I & $\infty$ & & $a$ & 은 & & $=$ & \\
\hline
\end{tabular}




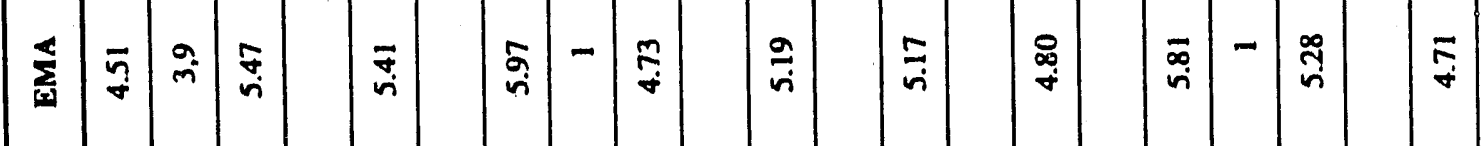

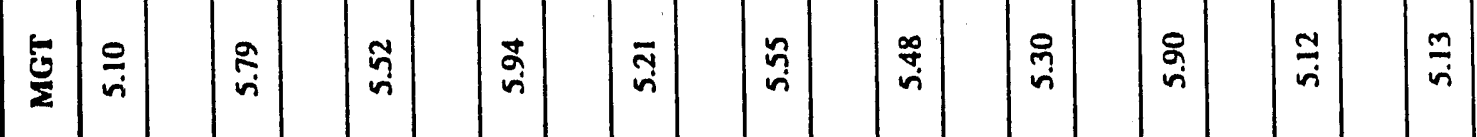

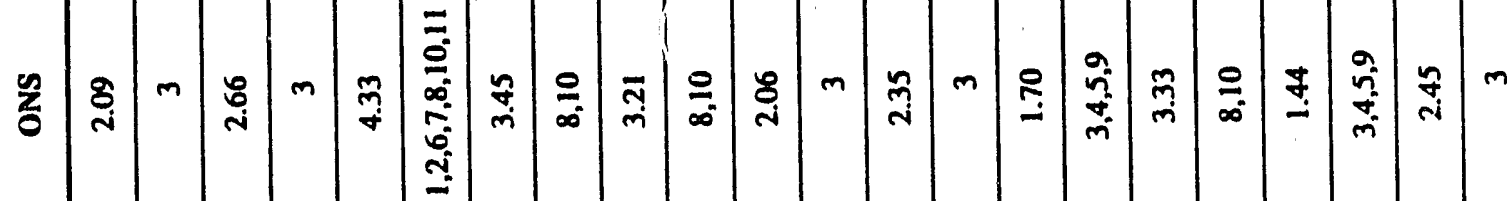

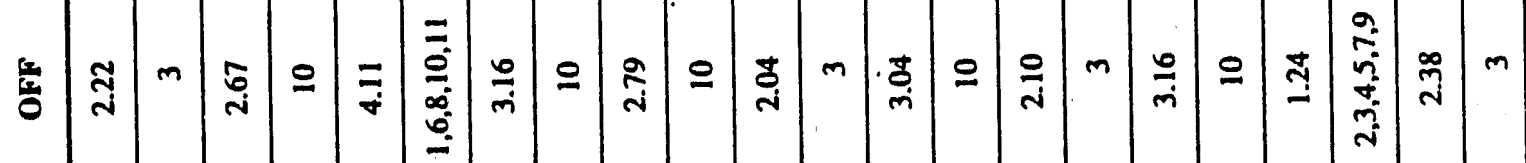

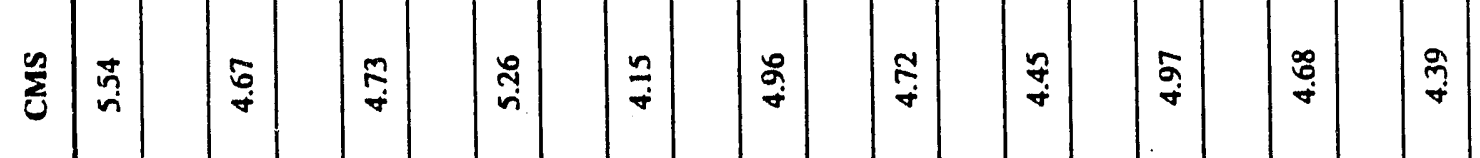

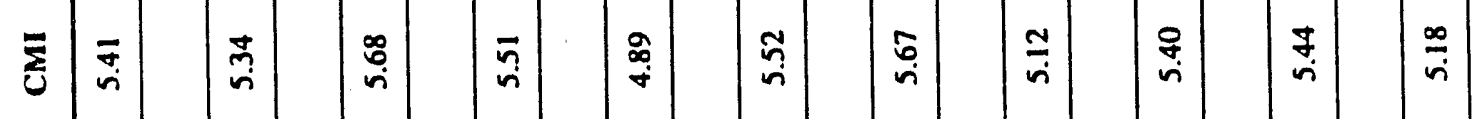

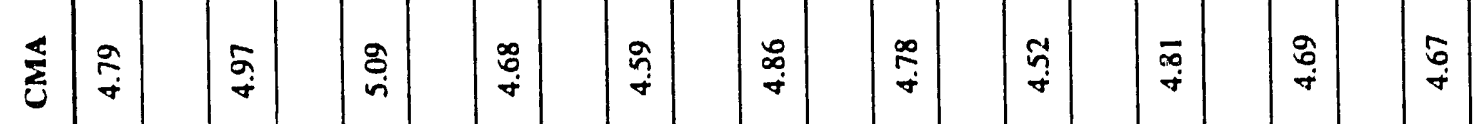

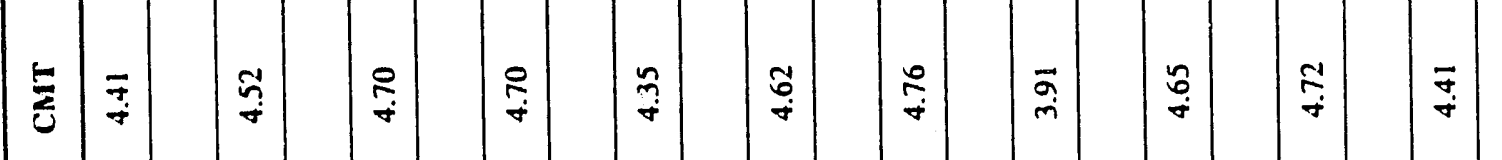

\begin{tabular}{|c|c|c|c|c|c|c|c|c|c|c|c|}
\hline 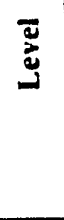 & 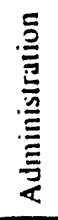 & 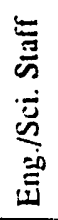 & $\begin{array}{l}\mathbf{T} \\
\tilde{w} \\
\tilde{w}\end{array}$ & 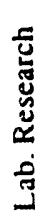 & 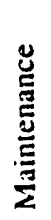 & 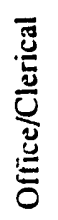 & 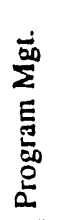 & 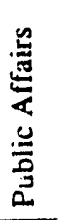 & $\begin{array}{l}\stackrel{\partial}{\partial} \\
\alpha\end{array}$ & 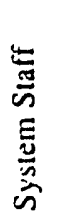 & 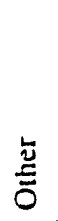 \\
\hline 苛 & - & - & $m$ & $T$ & $n$ & 0 & $r$ & $\infty$ & $a$ & 인 & $=$ \\
\hline
\end{tabular}

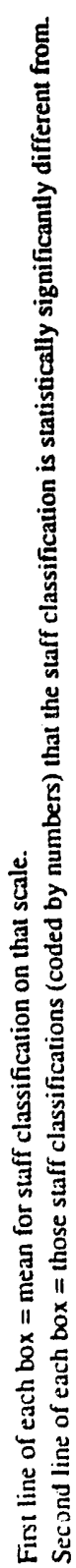


APPENDIX G

SIGNIFICANT DIFFERENCES BETWEEN DOE STAFF CLASSIFICATIONS ON THE OS 


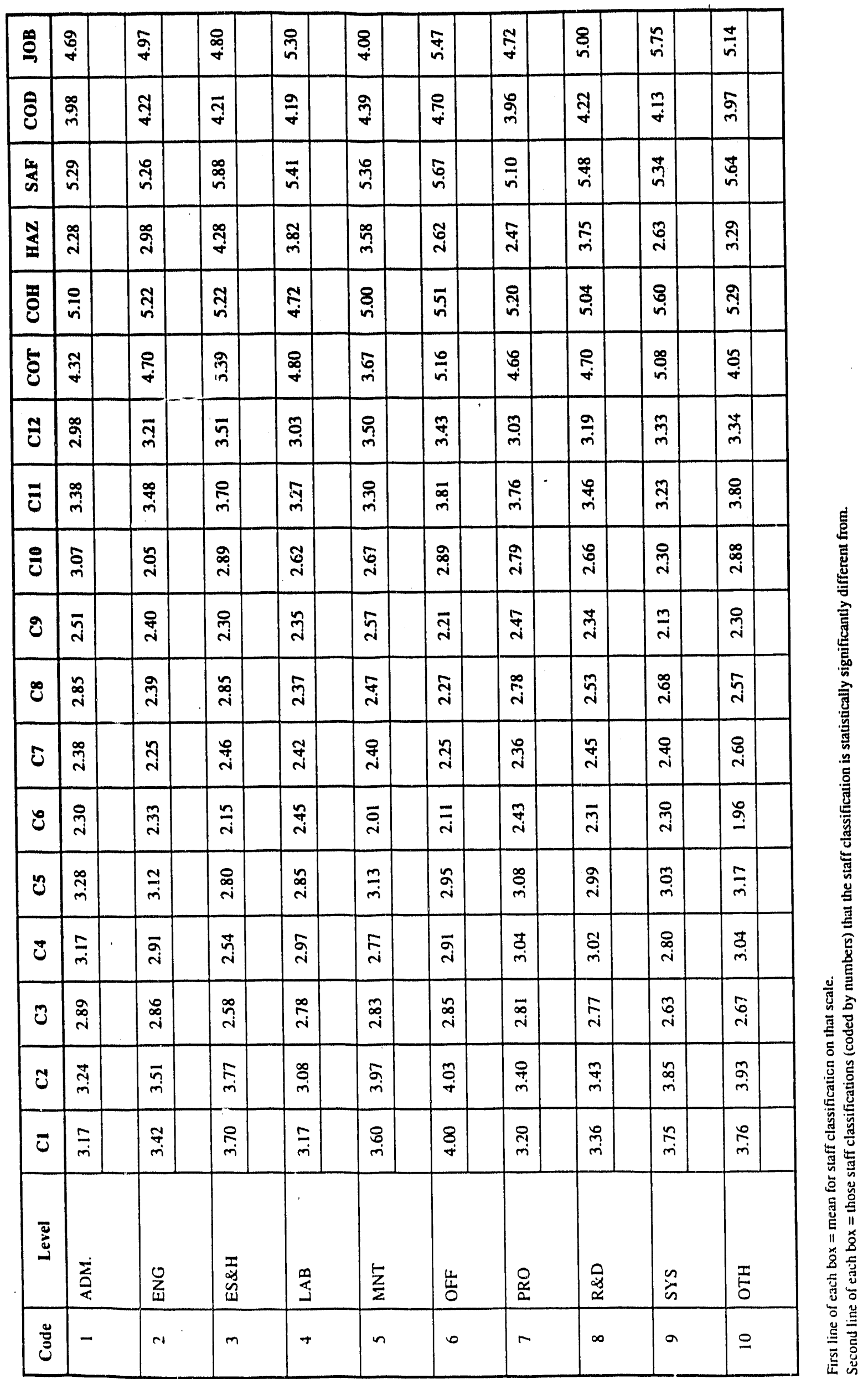




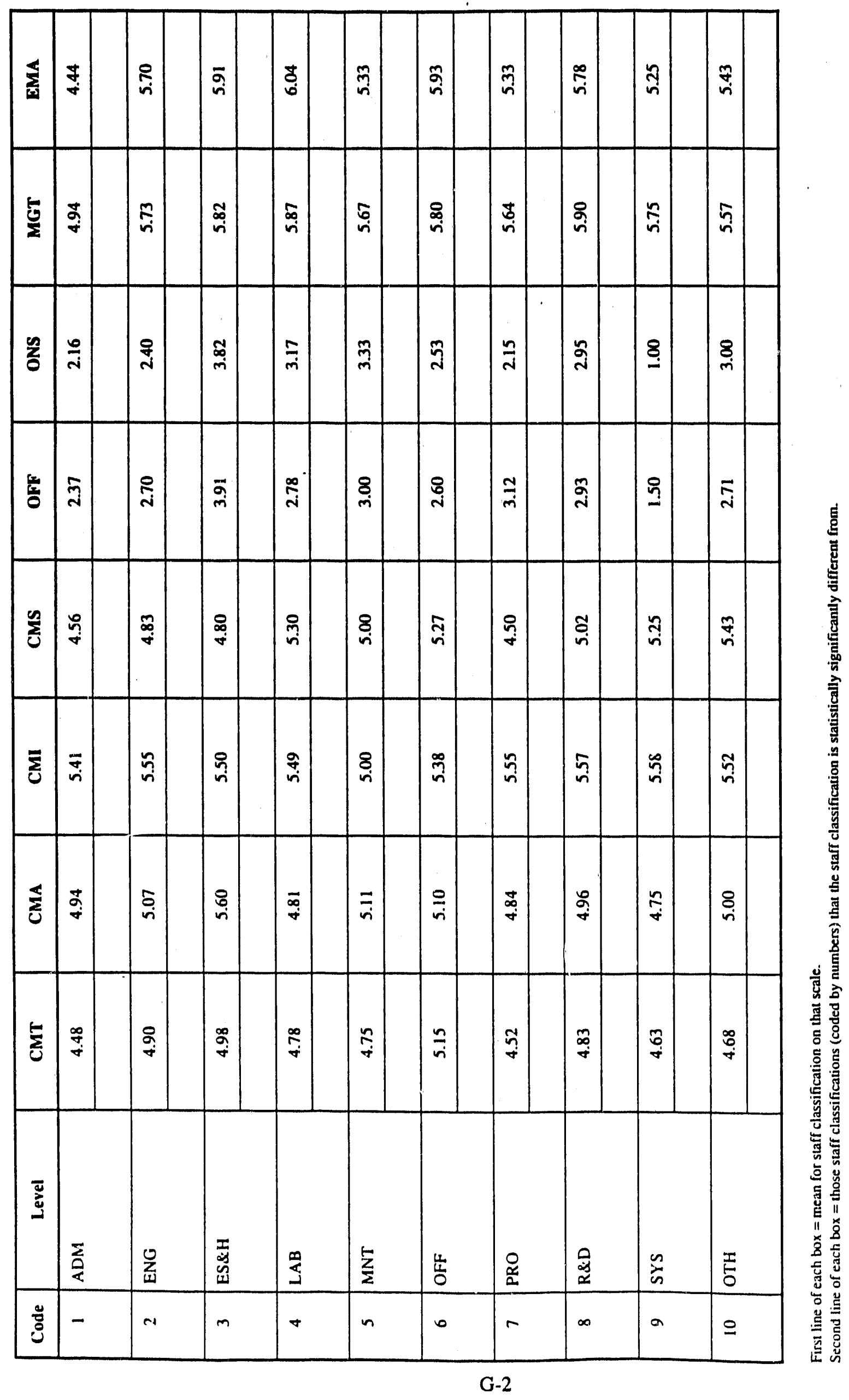


APPENDIX H

SIGNIFICANT DIFFERENCES BETWEEN TEAM STAFF CLASSIFICATIONS ON THE OS 


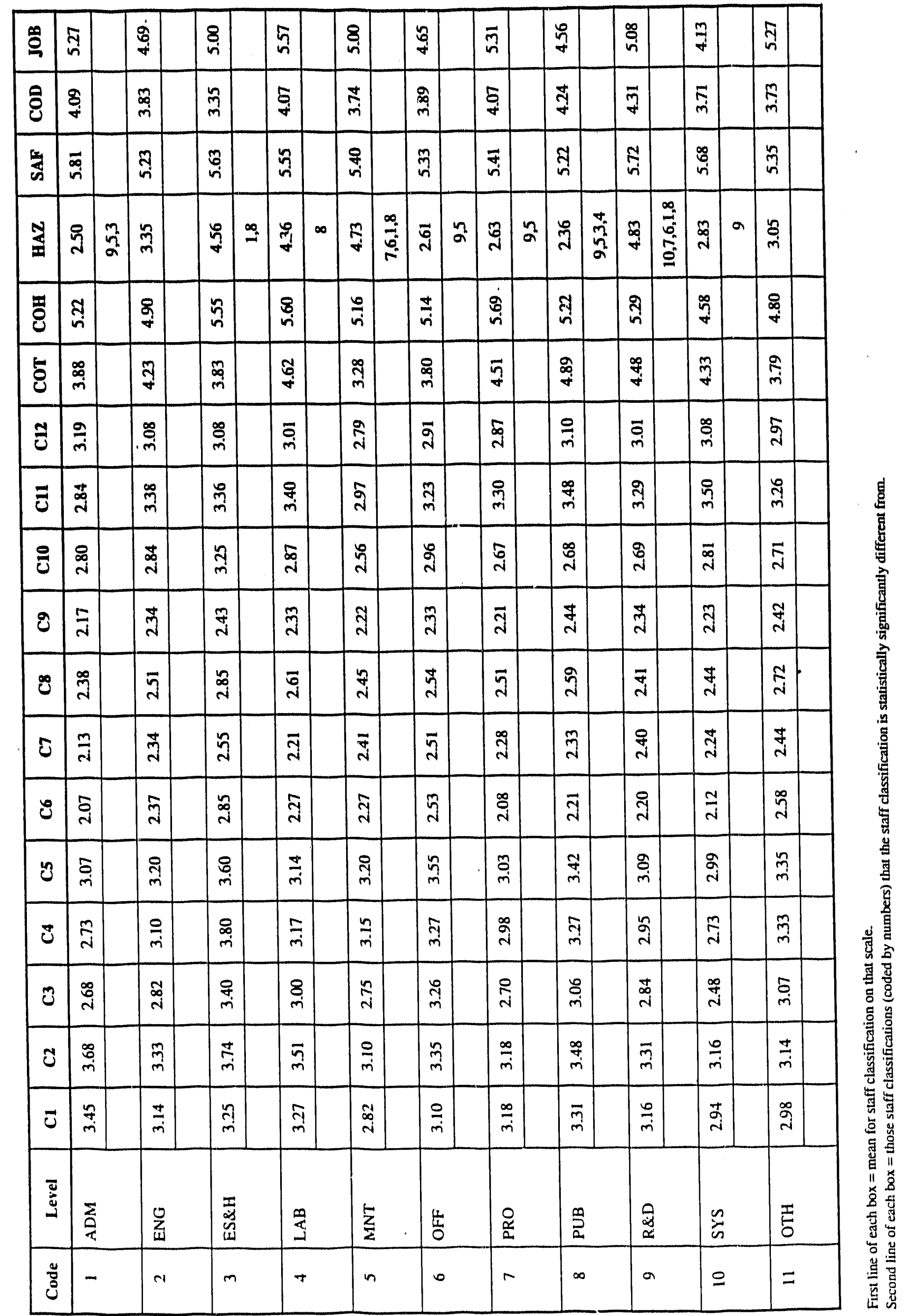




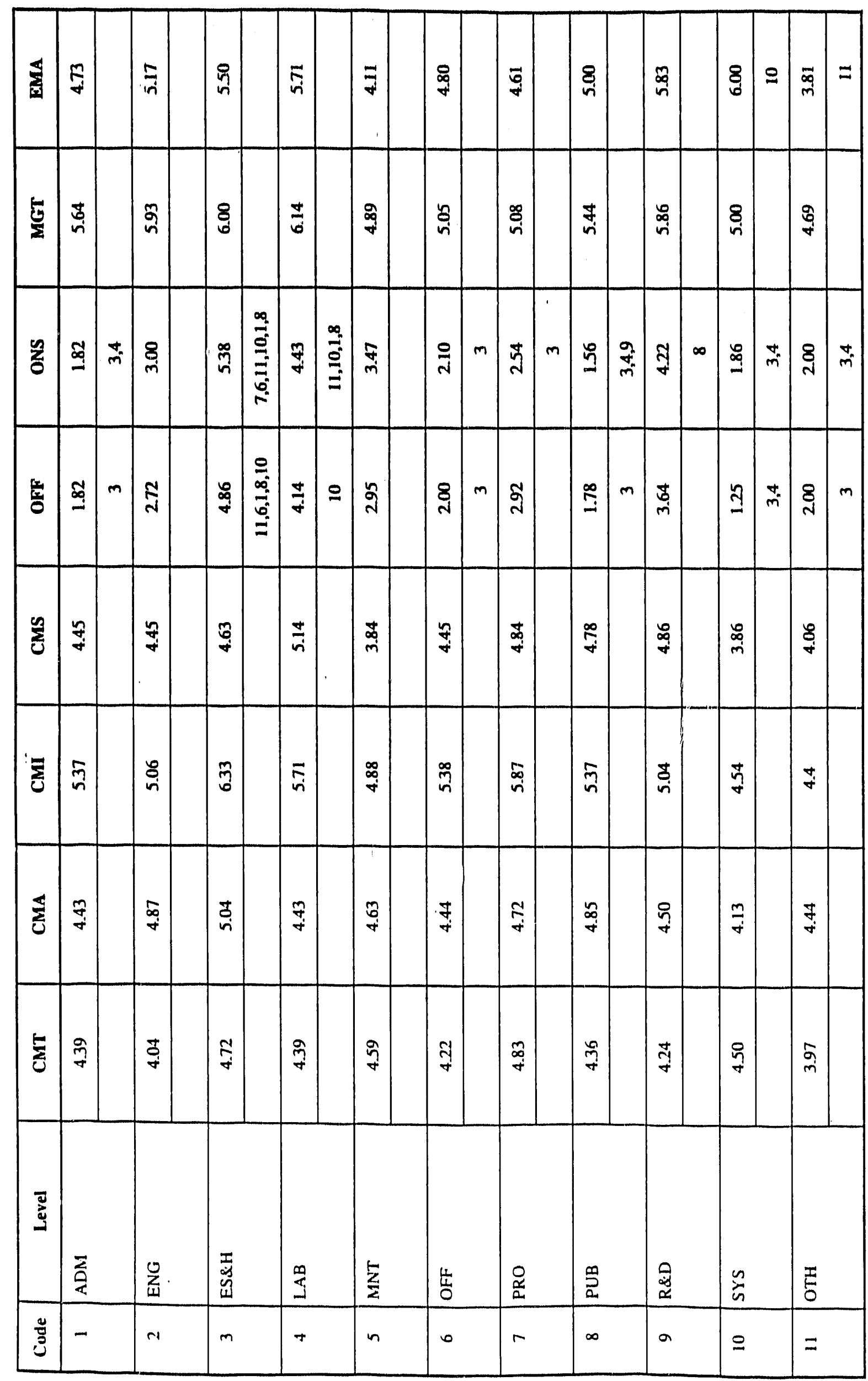

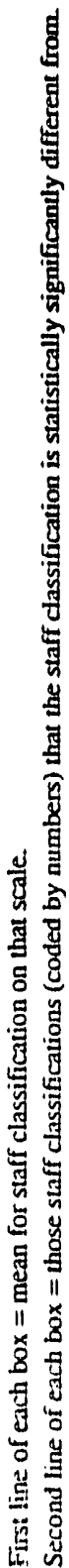




\section{APPENDIX I}

SIGNIFICANT DIFFERENCES BETWEEN ASI STAFF CLASSIFICATIONS ON THE OS 


\begin{tabular}{|c|c|c|c|c|c|c|}
\hline$\stackrel{9}{g}$ & \pm & $\begin{array}{l}\text { के } \\
\text { मे }\end{array}$ & $\begin{array}{l}8 \\
0\end{array}$ & ถู & 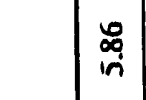 & \\
\hline 8 & $\overrightarrow{\bar{g}}$ & 品 & $\ddot{7}$ & $\stackrel{5}{7}$ & शి & \\
\hline 离 & $\begin{array}{c}\infty \\
\dot{c} \\
\dot{v}\end{array}$ & ڤิ & ติ & $\begin{array}{c}\text { ช్ } \\
\text { जิ }\end{array}$ & $\begin{array}{l}\text { 苛 } \\
\text { wi }\end{array}$ & \\
\hline \pm & $\underline{q}$ & ฟ & $\hat{7}$ & 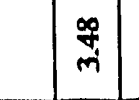 & 吕 & \\
\hline 뽕 & 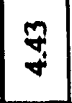 & $\tilde{n}$ & $\begin{array}{l}\vec{b} \\
\dot{n}\end{array}$ & $n$ & 5 & \\
\hline 8 & $\frac{9}{4}$ & $\stackrel{8}{7}$ & $\frac{\infty}{n}$ & สิ & $\stackrel{\circ}{i n}$ & \\
\hline บี & $\bar{m}$ & 芦 & $\begin{array}{l}5 \\
m\end{array}$ & Sิ & $\tilde{n}$ & \\
\hline$\overline{0}$ & 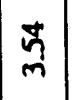 & $\bar{m}$ & $\begin{array}{l}\not \\
\dot{m} \\
\dot{m}\end{array}$ & m & $\underset{+}{8}$ & \\
\hline 융 & 5 & $\stackrel{n}{N}$ & $\frac{0}{3}$ & สี & 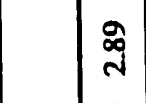 & \\
\hline 8 & 竎 & $\tilde{n}$ & 9 & $\begin{array}{l}8 \\
\text { ज }\end{array}$ & $\bar{N}$ & \\
\hline$\ddot{3}$ & F & ने & สิ & สี่ & गे & \\
\hline 5 & 出 & กิ & 9 & సิ & 감 & \\
\hline 8 & $\frac{n}{n}$ & & 9 & $\frac{\infty}{d}$ & $\stackrel{\infty}{\infty}$ & \\
\hline 3 & స̃ & בิ & הิ & $\begin{array}{l}\infty \\
\infty \\
\end{array}$ & $\frac{\infty}{m}$ & \\
\hline $\bar{U}$ & 5 & $\underset{m}{\delta}$ & $\begin{array}{l}8 \\
\dot{m}\end{array}$ & $\vec{\infty}$ & $\underset{\mathbf{D}}{\mathbf{H}}$ & \\
\hline 3 & $\begin{array}{l}0 \\
\text { त } \\
\end{array}$ & ה & $\sqrt[7]{ }$ & $\vec{b}$ & $\underset{m}{8}$ & \\
\hline$\tilde{U}$ & $\begin{array}{l} \pm \\
m\end{array}$ & $\underset{m}{\stackrel{R}{m}}$ & $\stackrel{\ominus}{\underset{7}{*}}$ & $\stackrel{j}{m}$ & $\hat{m}$ & \\
\hline$\vec{u}$ & $\underset{m}{\stackrel{0}{m}}$ & $\underset{m}{\stackrel{F}{m}}$ & $\begin{array}{l}\stackrel{\infty}{\infty} \\
\dot{m}\end{array}$ & $\begin{array}{c}m \\
m \\
m\end{array}$ & $\vec{\sigma}$ & \\
\hline $\bar{\Xi}$ & 竞 & 点 & 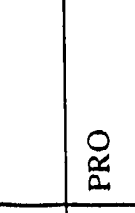 & $\sum_{2}^{\infty}$ & 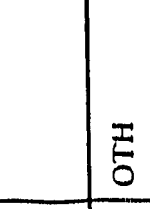 & \\
\hline 苛 & - & n & $m$ & + & $n$ & \\
\hline
\end{tabular}

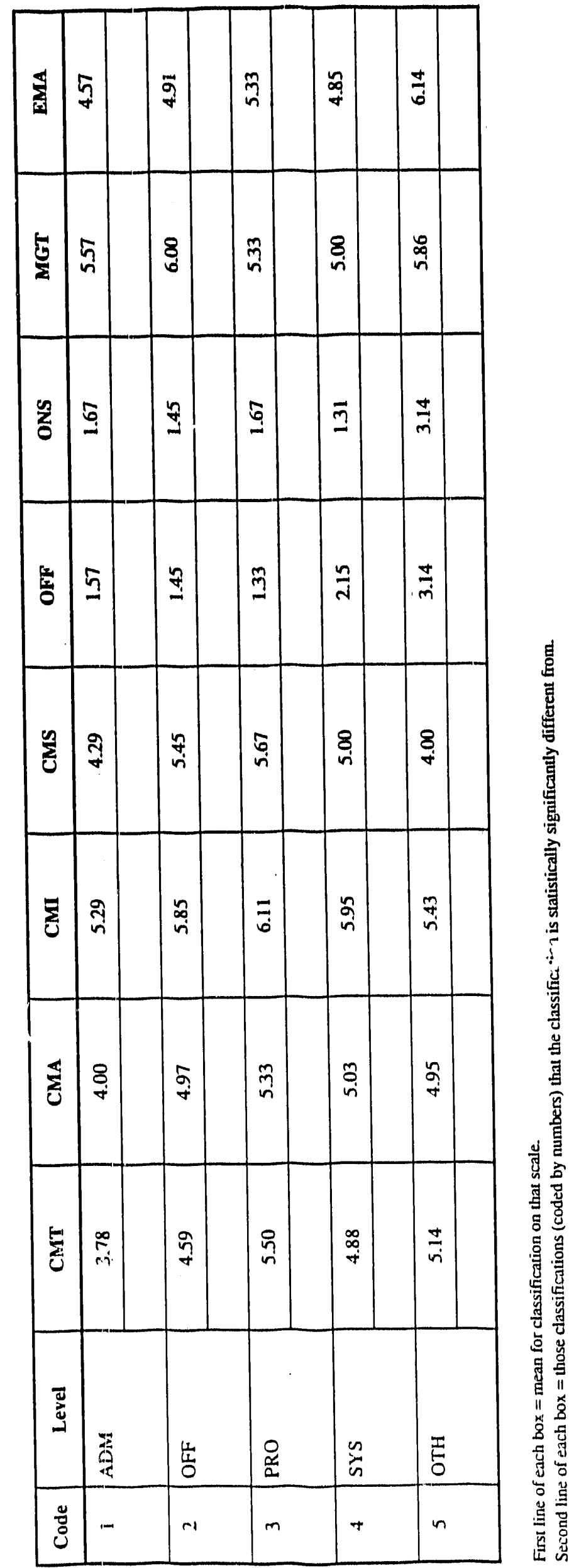




\section{APPENDIX J}

SIGNIFICANT DIFFERENCES BETWEEN SUPERVISORY LEVELS ON THE OS 


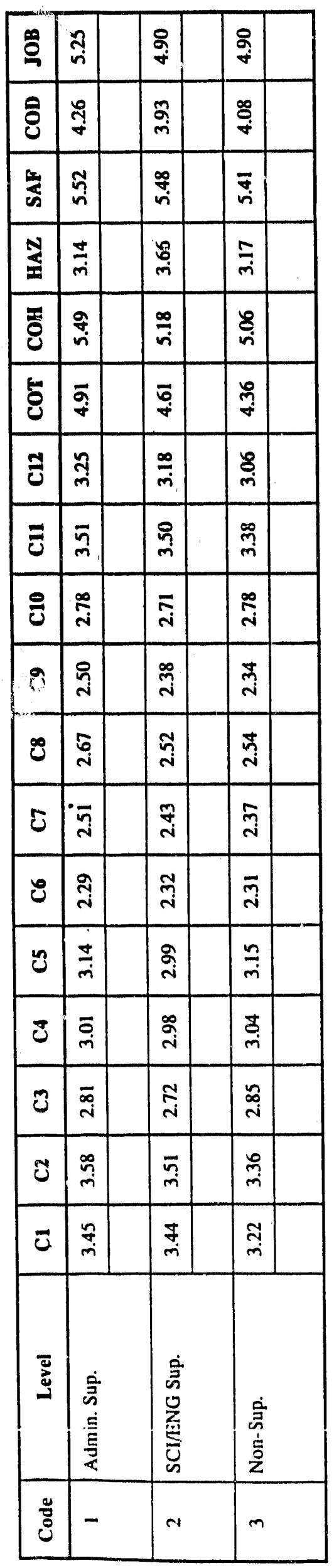

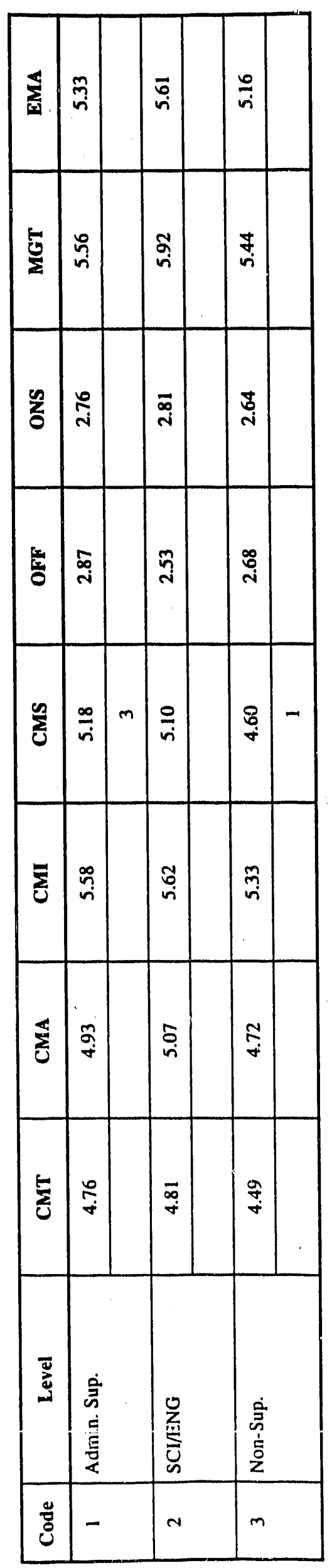

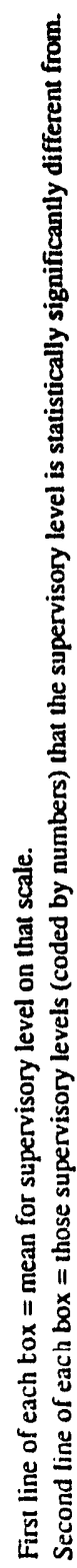


APPENDIX K

SIGNIFICANT DIFFERENCES BETWEEN DOE SUPERVISORY LEVELS ON THE OS 


\begin{tabular}{|c|c|c|c|c|}
\hline 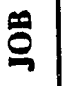 & $\frac{o}{n}$ & ஜ̊ & ชี & \\
\hline 인 & $\stackrel{q}{+}$ & $\underset{+}{\stackrel{8}{+}}$ & $\stackrel{m}{\vec{j}}$ & \\
\hline sis & స్ & 点 & $\hat{\tilde{n}}$ & \\
\hline 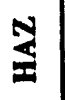 & 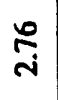 & $\underset{n}{n}$ & 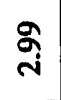 & \\
\hline 풍 & $\stackrel{\infty}{\sim}$ & $\frac{m}{\dot{v}}$ & $\begin{array}{l}8 \\
\dot{n}\end{array}$ & \\
\hline 5 & สู่ & 8 & 苛 & \\
\hline ฮี & $\underset{m}{m}$ & స్ & $\underset{\mathrm{m}}{\mathrm{j}}$ & \\
\hline 5 & $\stackrel{\wp}{n}$ & $\bar{n}$ & 导 & \\
\hline 원 & $\begin{array}{l}\infty \\
\stackrel{\sim}{i}\end{array}$ & i⿱ & $\underset{\&}{\stackrel{8}{i}}$ & \\
\hline 8 & $\underset{i}{\stackrel{9}{i}}$ & $\underset{\mathbf{I}}{\bar{J}}$ & חั & \\
\hline$\ddot{~}$ & $\stackrel{\mathfrak{s}}{\mathfrak{N}}$ & సี & $\sqrt{3}$ & \\
\hline 5 & $\underset{i}{\stackrel{8}{0}}$ & $\stackrel{g}{i}$ & $\stackrel{\vec{n}}{\mathrm{~N}}$ & \\
\hline 8 & $\underset{\mathcal{H}}{\mathrm{N}}$ & $\sqrt[5]{i}$ & ㄱ. & \\
\hline 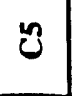 & $\frac{\varrho}{m}$ & $\approx$ & $\underset{m}{\stackrel{\rho}{2}}$ & \\
\hline$\Xi$ & $\stackrel{n}{\hat{n}}$ & $\hat{i}$ & $\stackrel{\tilde{o}}{\dot{m}}$ & \\
\hline$\tilde{u}$ & $\bar{a}$ & $\vec{i}$ & $\begin{array}{l}\bar{\infty} \\
\stackrel{i}{i}\end{array}$ & \\
\hline$\tilde{U}$ & $\underset{m}{\stackrel{ \pm}{m}}$ & ज़ & $\stackrel{n}{n}$ & \\
\hline $\bar{U}$ & $\stackrel{n}{\tilde{n}}$ & $\bar{n}$ & సి & \\
\hline 可 & $\frac{2}{2}$ & 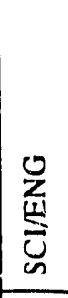 & $\begin{array}{l}\dot{2} \\
\text { n. } \\
\dot{L} \\
\dot{0} \\
\end{array}$ & \\
\hline نั & - & $\mathrm{C}$ & $m$ & \\
\hline
\end{tabular}

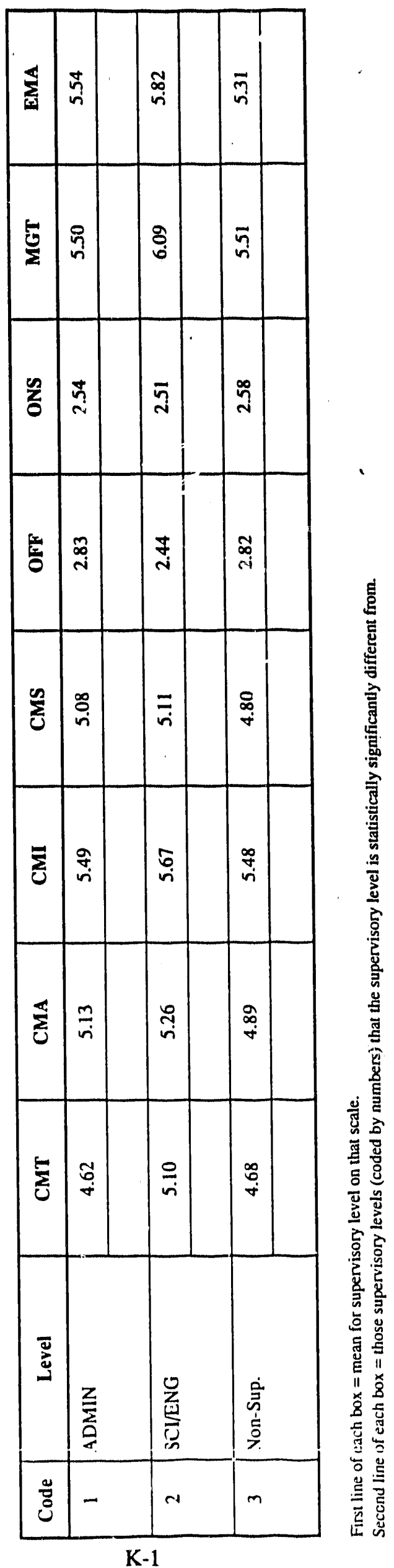


APPENDIX L

SIGNIFICANT DIFFERENCES BETWEEN TEAM SUPERVISORY LEVELS ON THE OS 


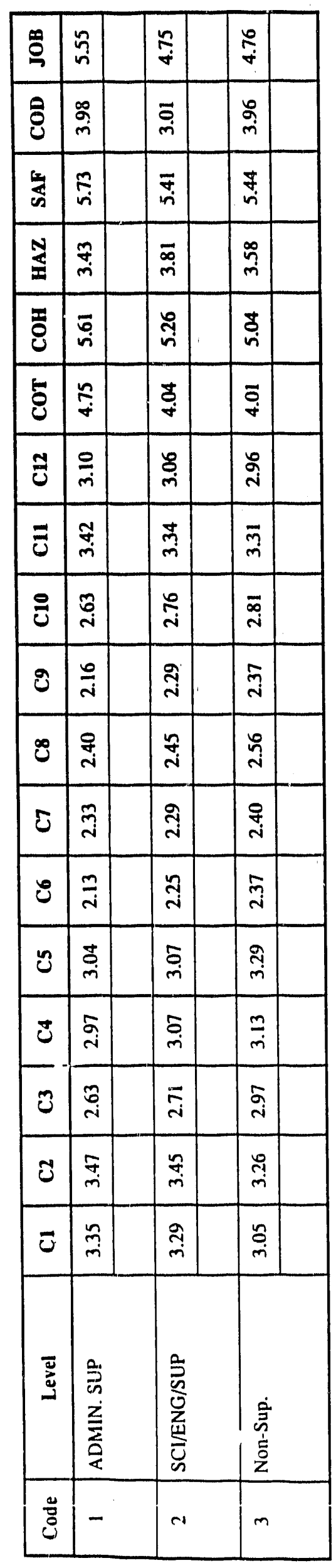

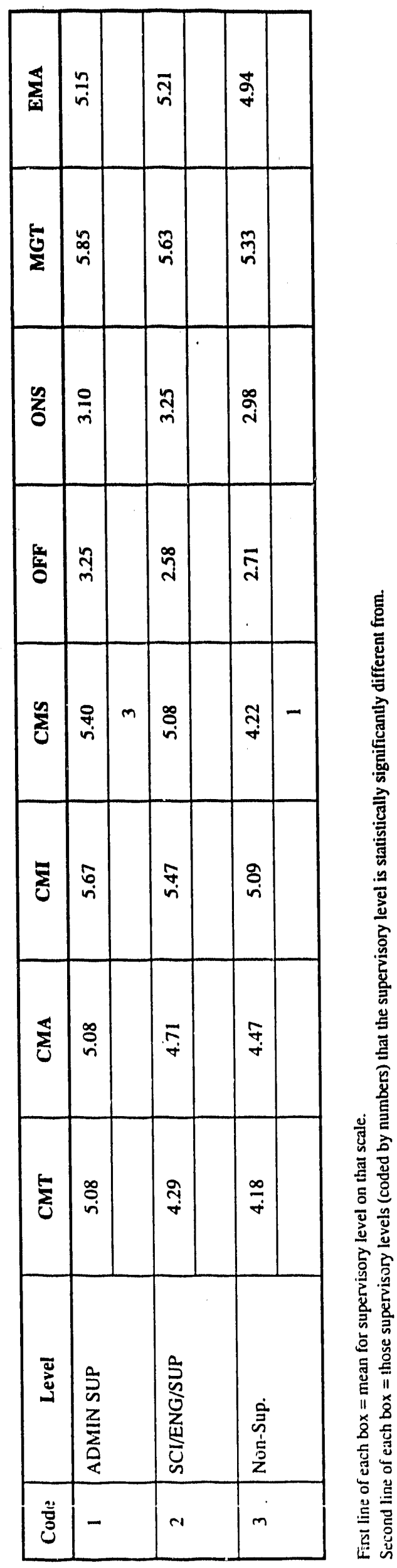




\section{APPENDIX M \\ SIGNIFICANT DIFFERENCES BETWEEN SUPERVISORS AND NONSUPERVISORS ON THE OS}




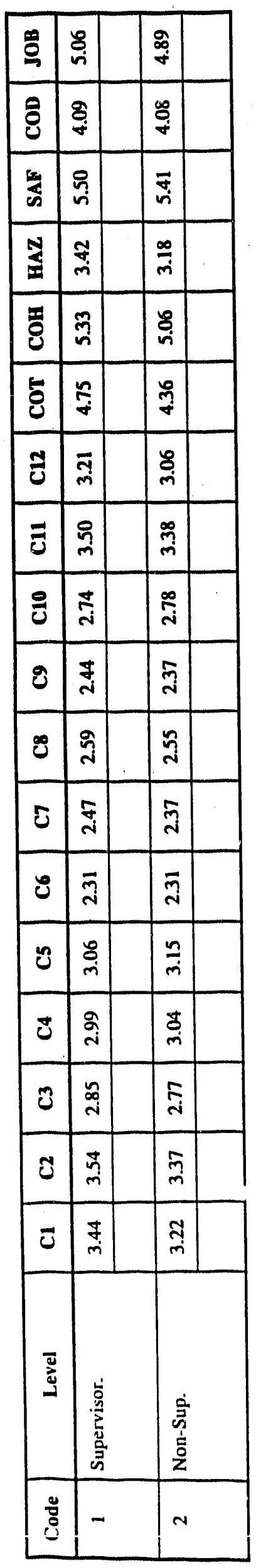

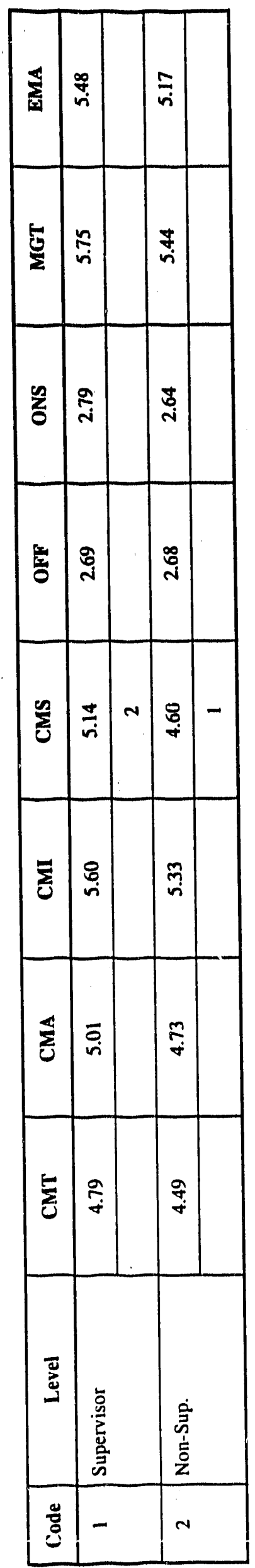

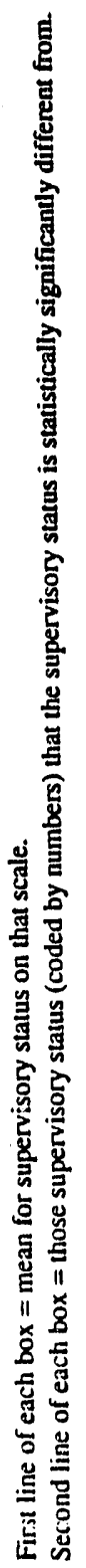




\section{APPENDIX N}

SIGNIFICANT DIFFERENCES BETWEEN DOE SUPERVISORS AND NONSUPERVISORS ON THE OS 


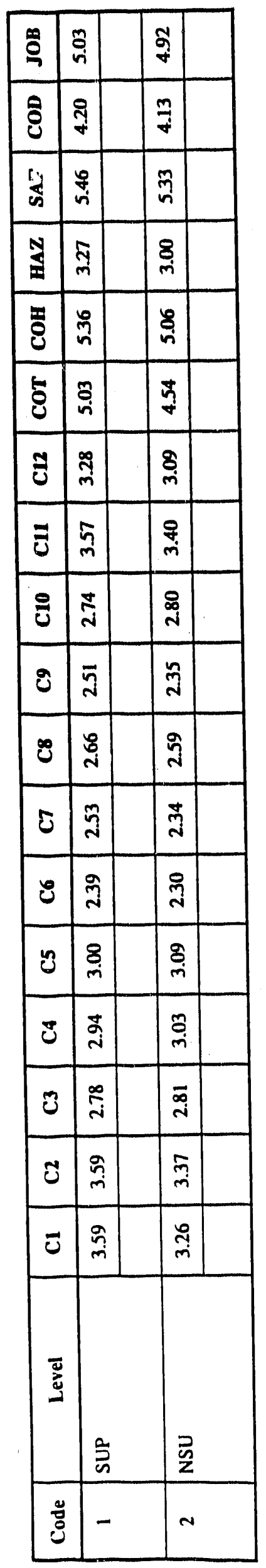
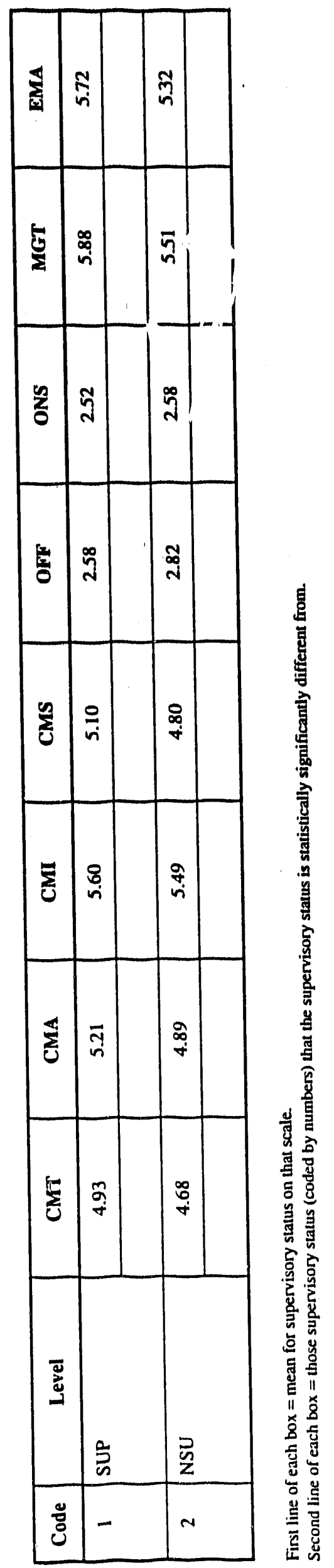
APPENDIX 0

SIGNIFICANT DIFFERENCES BETWEEN TEAM SUPERVISORS AND NONSUPERVISORS ON THE OS 


\begin{tabular}{|c|c|c|}
\hline 思 & $\overline{\bar{n}}$ & $\stackrel{2}{\mathfrak{f}}$ \\
\hline 8ิ & $\underset{\sim}{\stackrel{\infty}{m}}$ & $\frac{\infty}{m}$ \\
\hline है & $\begin{array}{l}\text { ڤ̆ } \\
\text { ñ }\end{array}$ & 吕 \\
\hline $\mathbf{x}$ & 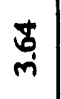 & mे \\
\hline 평 & F & 韋 \\
\hline 5 & $\stackrel{י}{7}$ & $\overline{7}$ \\
\hline כै & $\begin{array}{l}\stackrel{n}{m} \\
m\end{array}$ & స̊ \\
\hline$\overline{3}$ & $\sqrt[5]{m}$ & $\bar{m}$ \\
\hline క & కె & $\overrightarrow{\mathbf{N}}$ \\
\hline 8 & สิ & $\sqrt[5]{2}$ \\
\hline$\approx$ & ป & సొ \\
\hline$\Xi$ & 에 & i \\
\hline ن̊ & สิ & ก) \\
\hline 3 & $\stackrel{n}{a}$ & ஸి \\
\hline J & $\stackrel{g}{g}$ & $\underset{m}{\stackrel{m}{m}}$ \\
\hline 3 & $\underset{6}{0}$ & ล \\
\hline$\tilde{U}$ & 昌 & 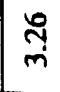 \\
\hline $\bar{u}$ & $\bar{m}$ & $\stackrel{n}{m}$ \\
\hline অ্ّ & 空 & $\begin{array}{l}2 \\
2 \\
z \\
\end{array}$ \\
\hline घั & - & $\mathrm{r}$ \\
\hline
\end{tabular}
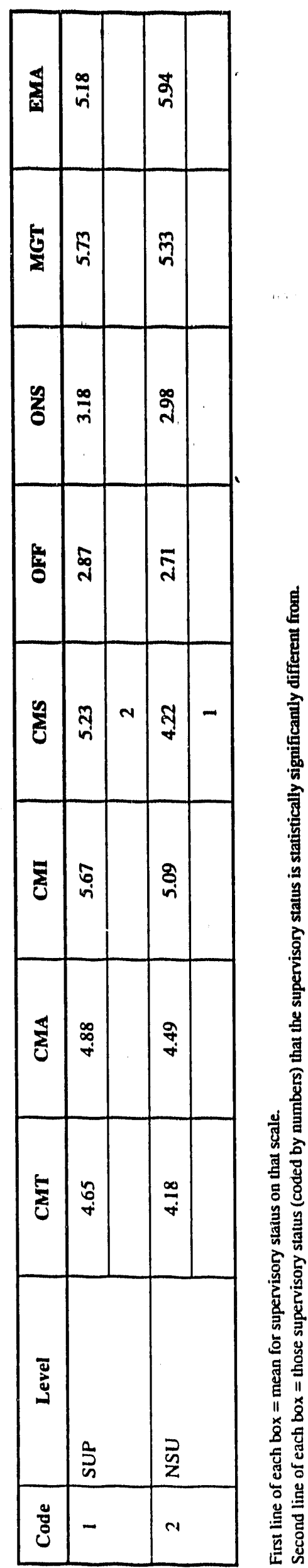

O-1 
APPENDIX P

SIGNIFICANT DIFFERENCES BETWEEN ALI SUPERVISORS AND NONSUPERVISORS ON THE OS 


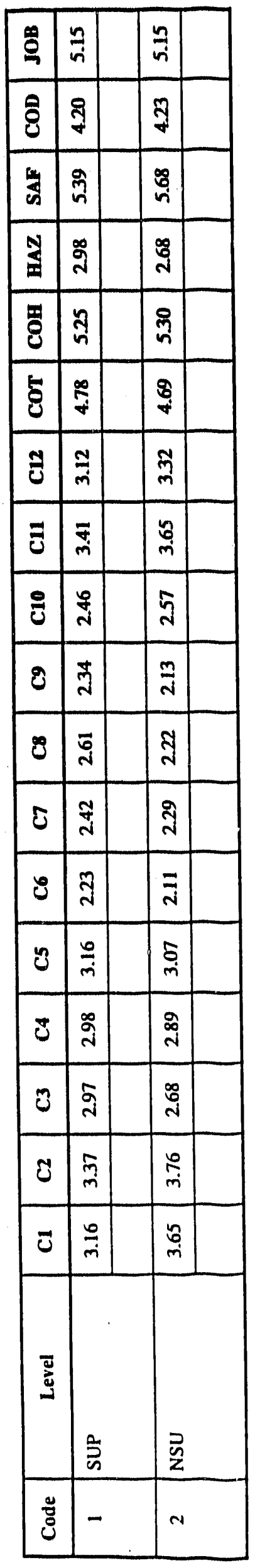
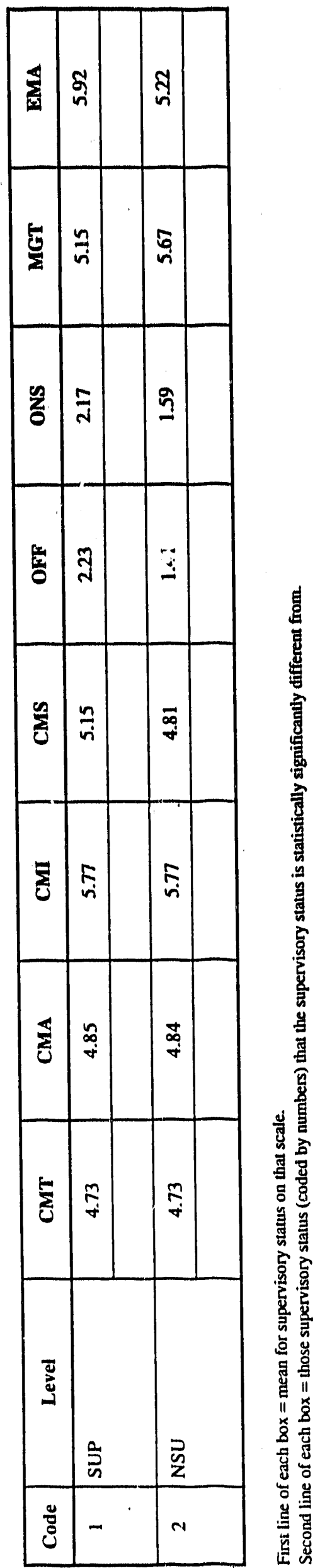
APPENDIX Q

SIGNIFICANT DIFFERENCES BETWEEN DCI SUPERVISORS AND NONSUPERVISORS ON THE OS 


\begin{tabular}{|c|c|c|c|c|}
\hline$\stackrel{\oplus}{\circ}$ & $\frac{ \pm}{v^{\prime}}$ & & $\underset{+}{\stackrel{*}{*}}$ & \\
\hline రิ & $\underset{7}{7}$ & & 亏ัँ & \\
\hline sis & nู & & $\underset{n}{\text { S }}$ & \\
\hline$\underset{\mathbf{x}}{\mathbf{x}}$ & \pm & & 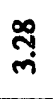 & \\
\hline 풍 & $\underset{\&}{\stackrel{\&}{+}}$ & & \% & \\
\hline 8 & $\underset{6}{\circ}$ & & $\stackrel{m}{\dot{m}}$ & \\
\hline$\tilde{u}$ & $\underset{m}{\stackrel{m}{m}}$ & & స్ & \\
\hline $\bar{\Xi}$ & $\stackrel{\circ}{m}$ & & $\underset{m}{m}$ & \\
\hline 영 & $\vec{\sigma}$ & $N$ & $\underset{i}{\stackrel{N}{*}}$ & - \\
\hline 8 & 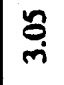 & & స్ & \\
\hline$\ddot{0}$ & \& & & กี & \\
\hline 3 & $\frac{n}{i}$ & & 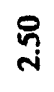 & \\
\hline ن & $\frac{a}{i}$ & & สี & \\
\hline$\tilde{3}$ & 華 & & $\stackrel{n}{\text { nे }}$ & \\
\hline उ & 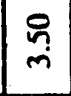 & & $\stackrel{\infty}{i}$ & \\
\hline$\tilde{v}$ & $\underset{\mathbf{D}}{\mathbf{N}}$ & & $\stackrel{F}{i}$ & \\
\hline$\tilde{U}$ & $\hat{m}$ & & $\overline{\dot{m}}$ & \\
\hline $\bar{u}$ & $\begin{array}{l}\mathscr{n} \\
\text { m }\end{array}$ & & $\stackrel{0}{\circ}$ & \\
\hline 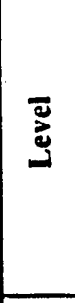 & $\stackrel{5}{n}$ & & $\begin{array}{l}\vec{n} \\
z \\
\end{array}$ & \\
\hline تัँ & - & & $\mathrm{H}$ & \\
\hline
\end{tabular}

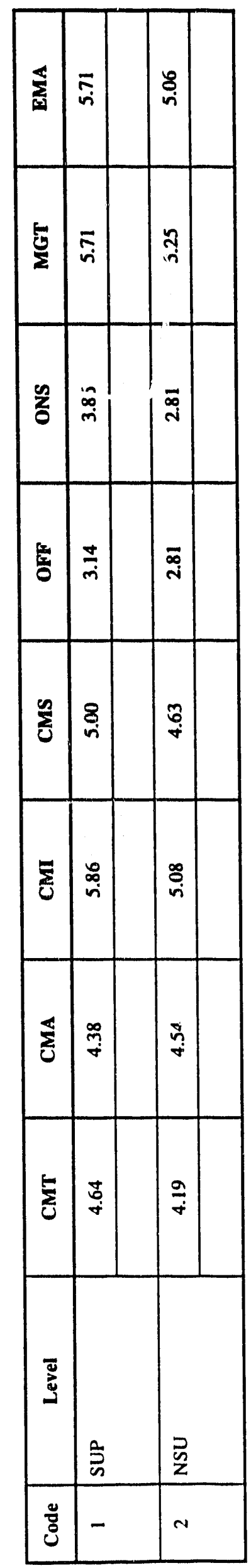

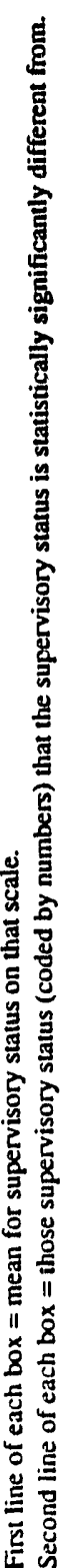


!

$\therefore \quad$ APPENDIX R

COMPARISON OF PEC ORGANIZATIONS TO OVERALL PETE MEAN VALUES ON THE OS 


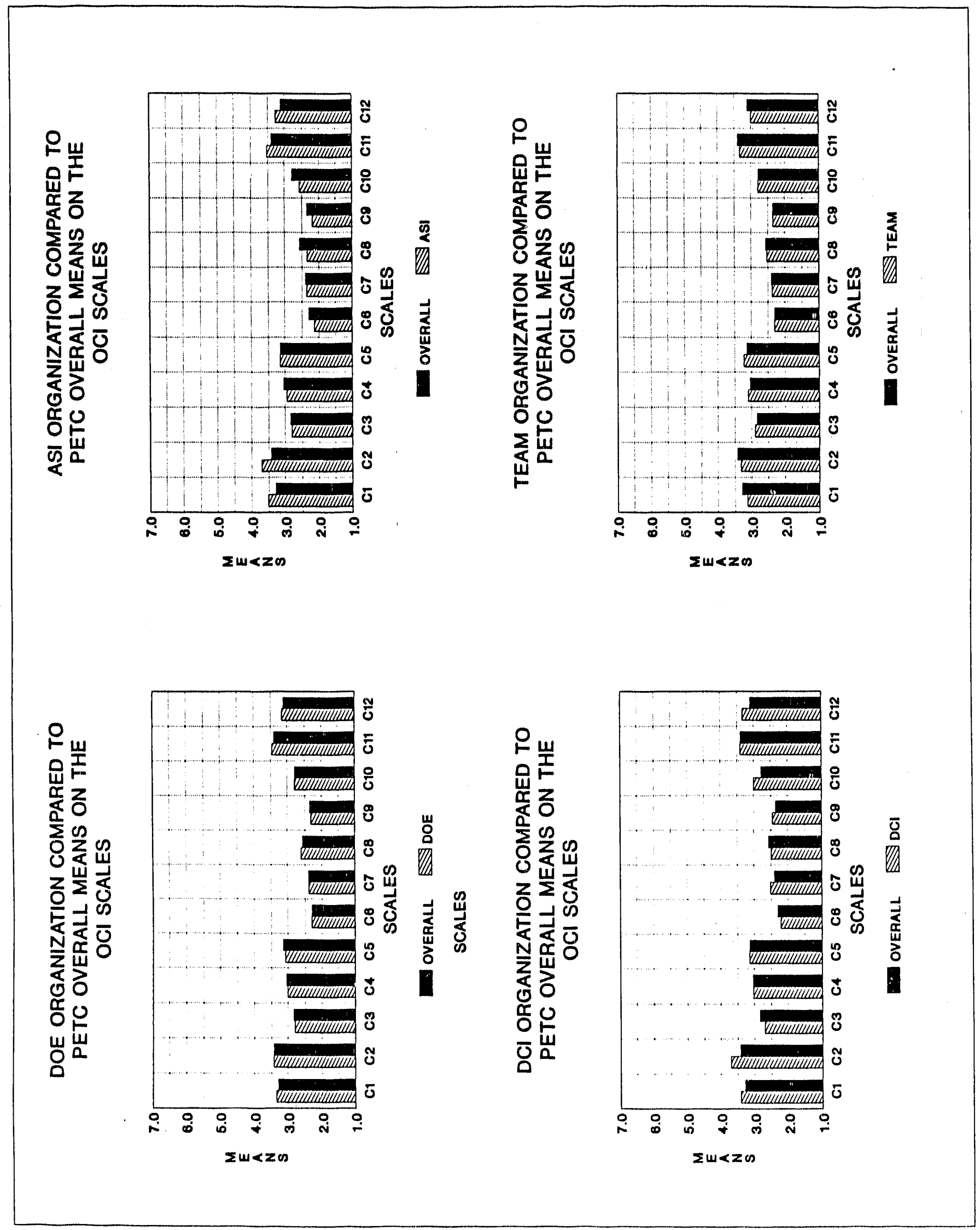




\section{APPENDIX S}

COMPARISON OF PETC ORGANIZATIONS TO OVERALL PETC MEAN VALUES

ON THE COMMUNICATIONS SCALES 


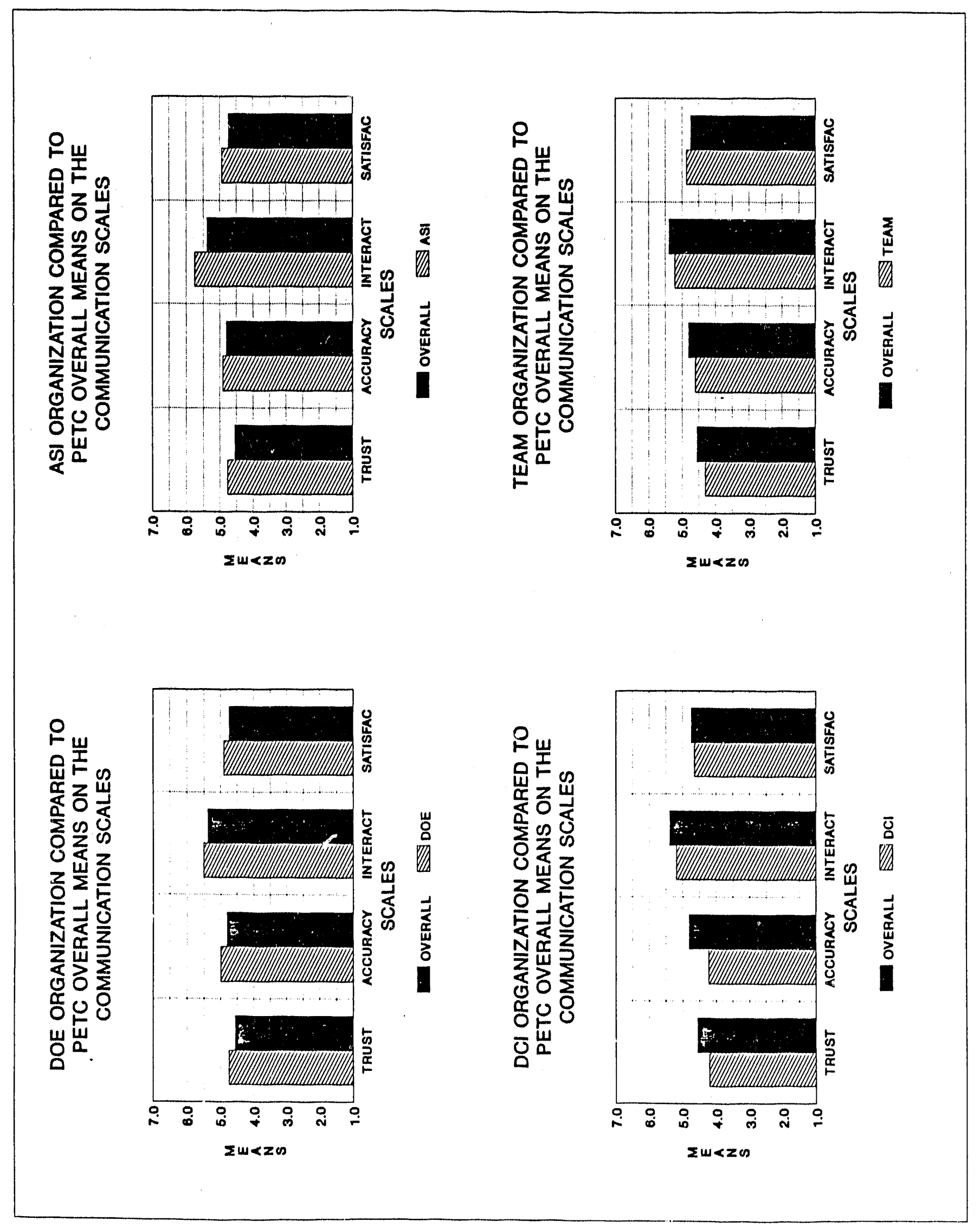




\section{APPENDIX T}

COMPARISON OF PETC ORGANIZATIONS TO OVERALL PETC MEAN VALUES ON THE ADDITIONAL SCALES 

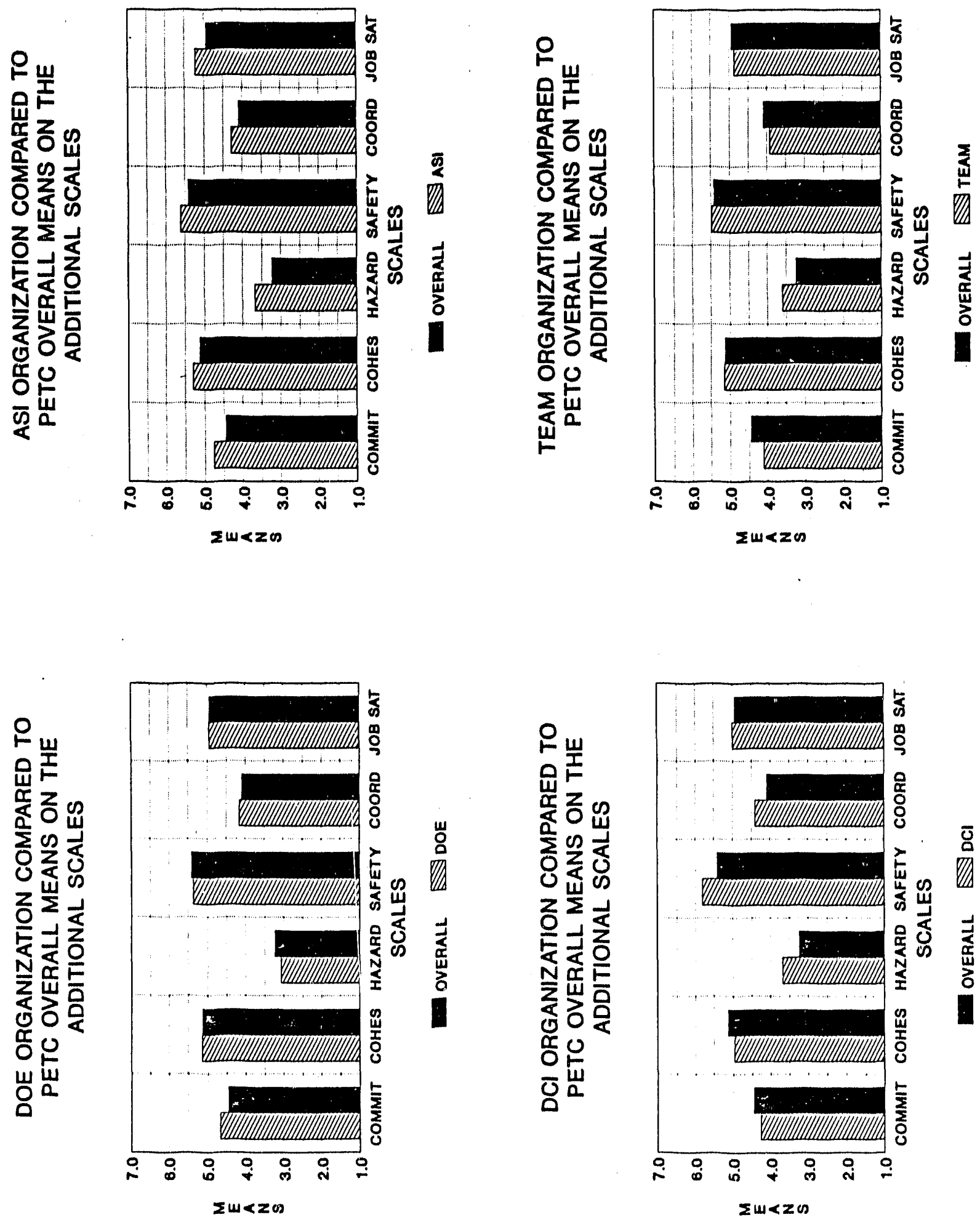


\section{APPENDIX U}

COMPARISON OF PETC ORGANIZATIONS TO OVERALL PETC MEAN VALUES ON THE ENVIRONMENT, SAFETY; AND HEALTH QUESTIONS 

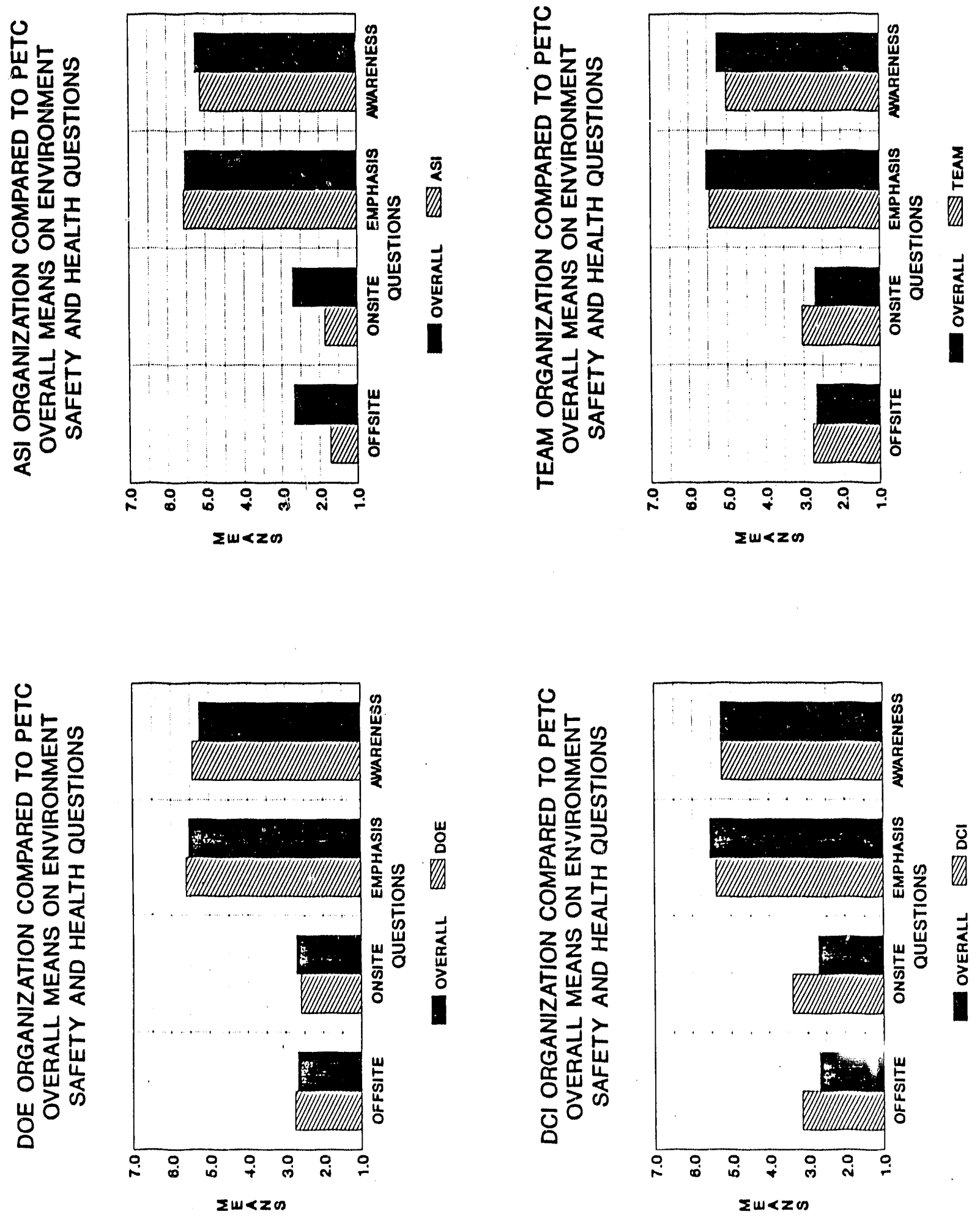
APPENDIX V

COMPARISON OF DOE DEPARTMENTS TO THE OVERALL DOE MEAN VALUES ON THE OS 

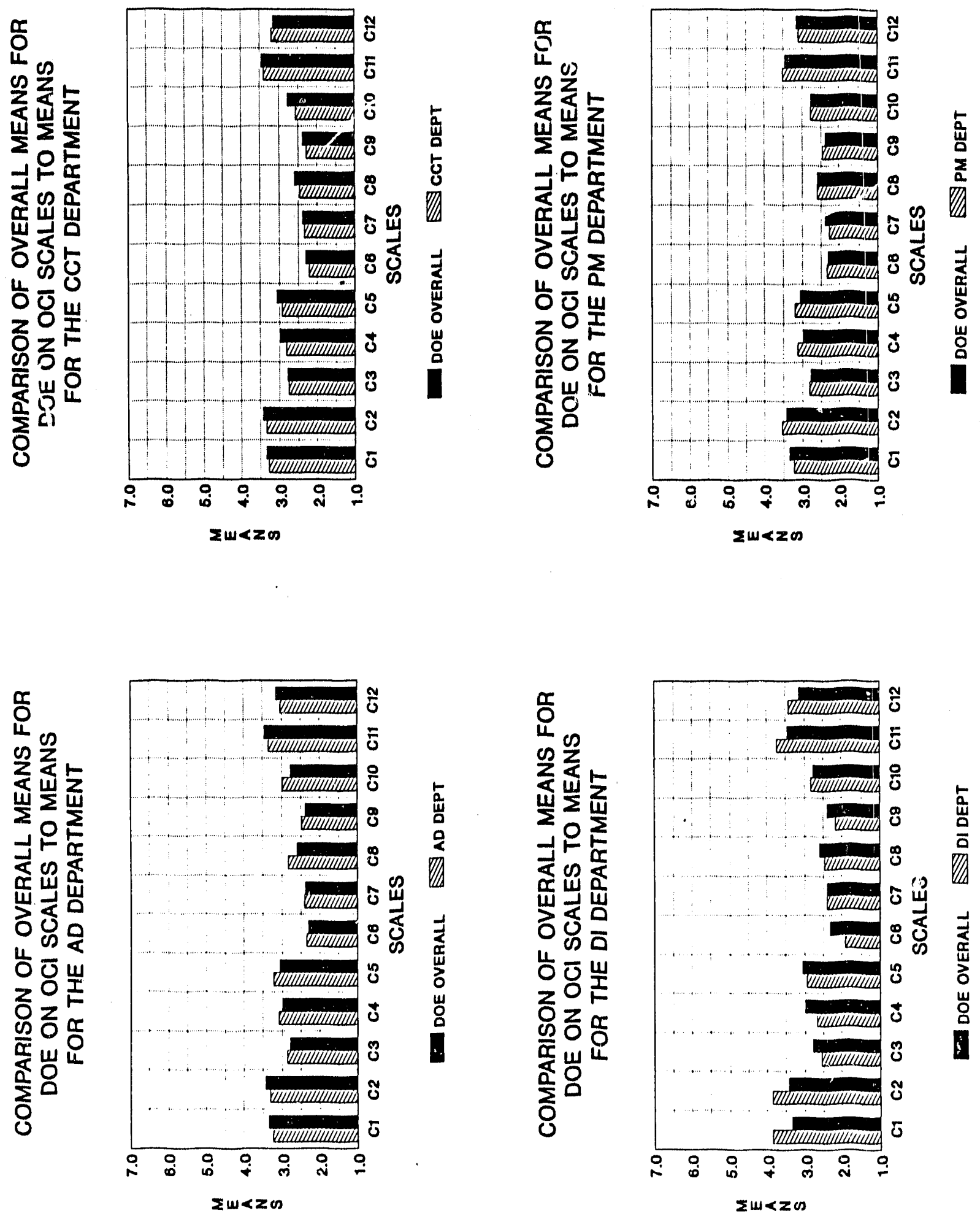


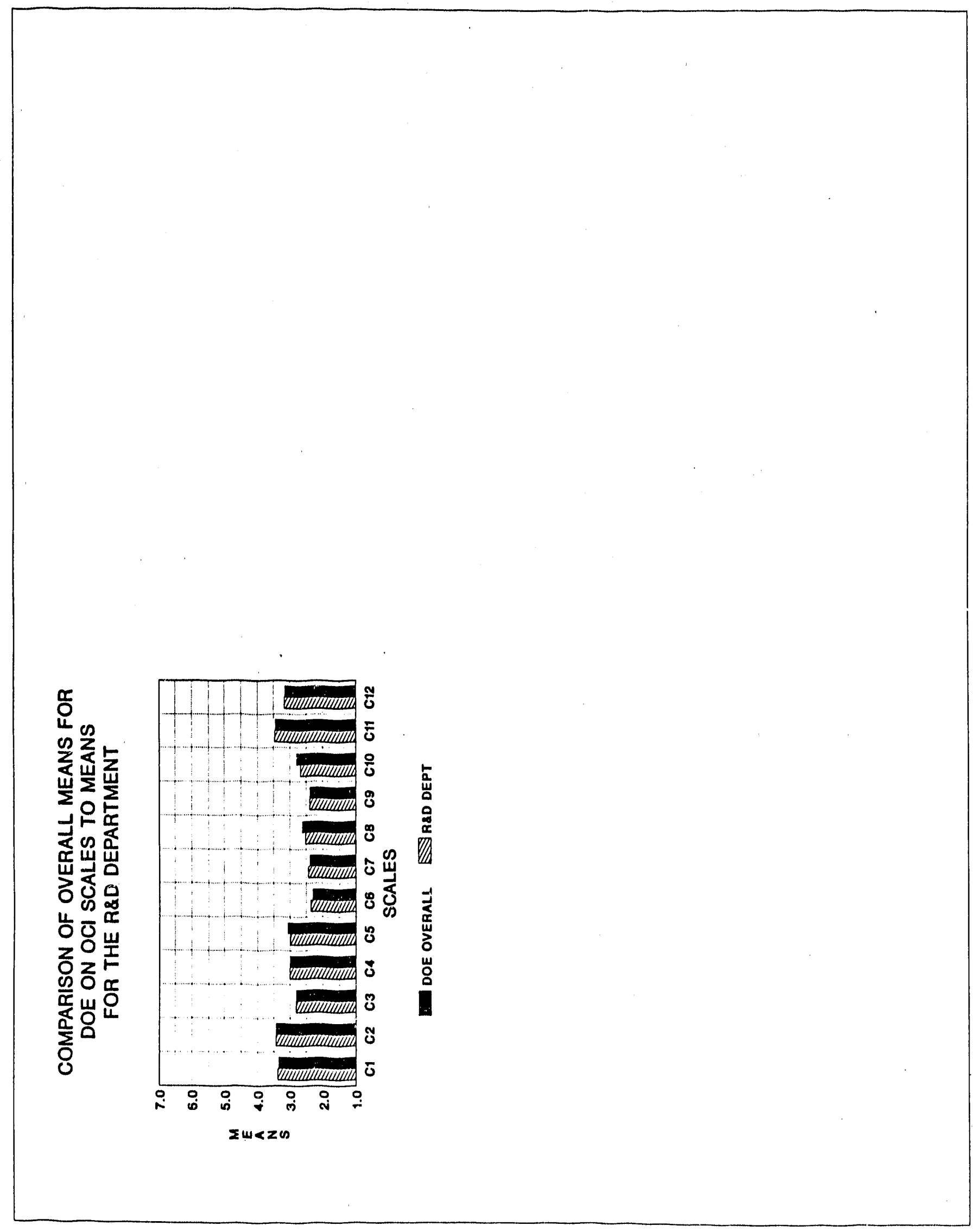




\begin{abstract}
APPENDIX W
COMPARISON OF TEAM DEPARTMENTS TO THE OVERALL TEAM MEAN VALUES ON THE OS
\end{abstract}




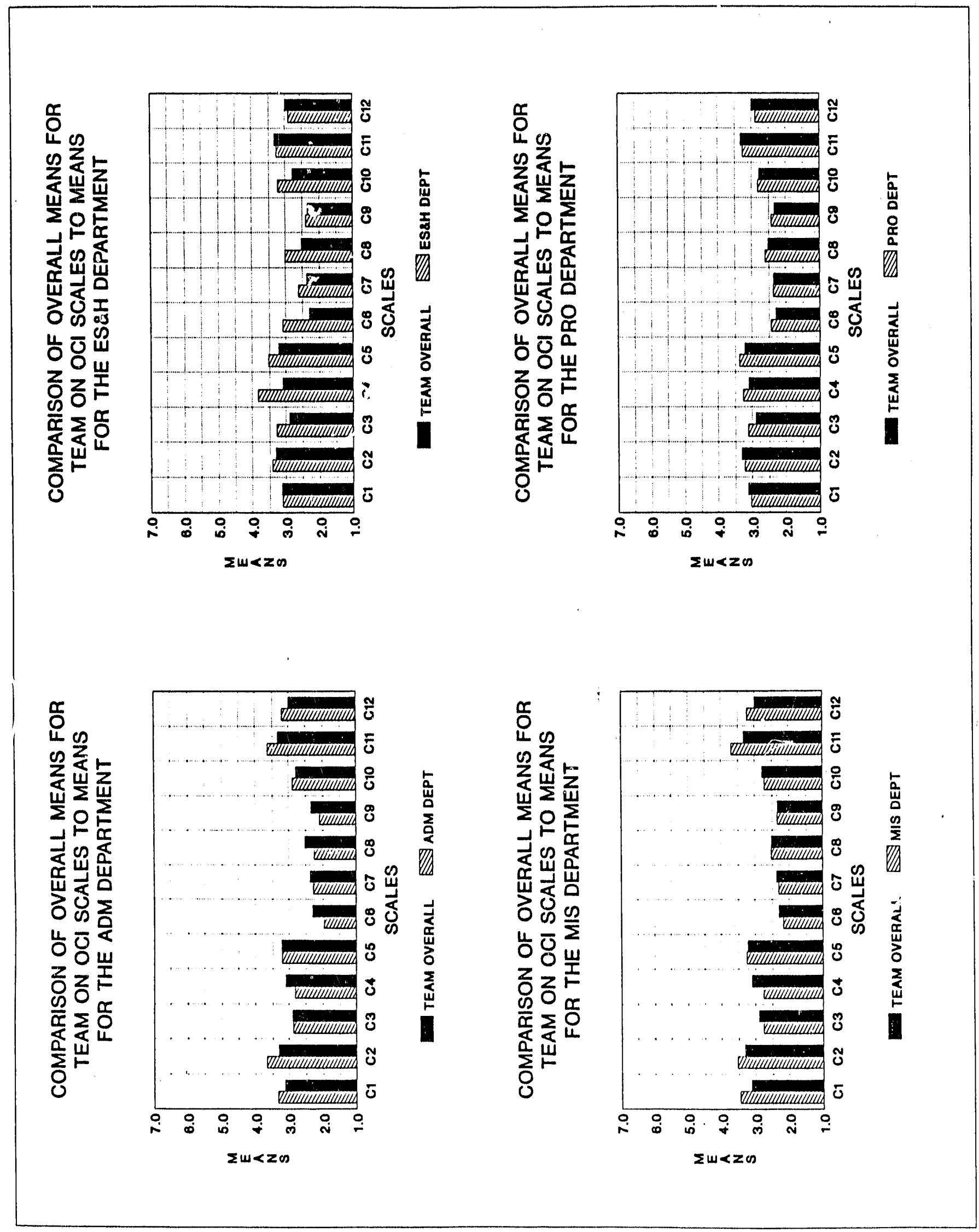

W-1 


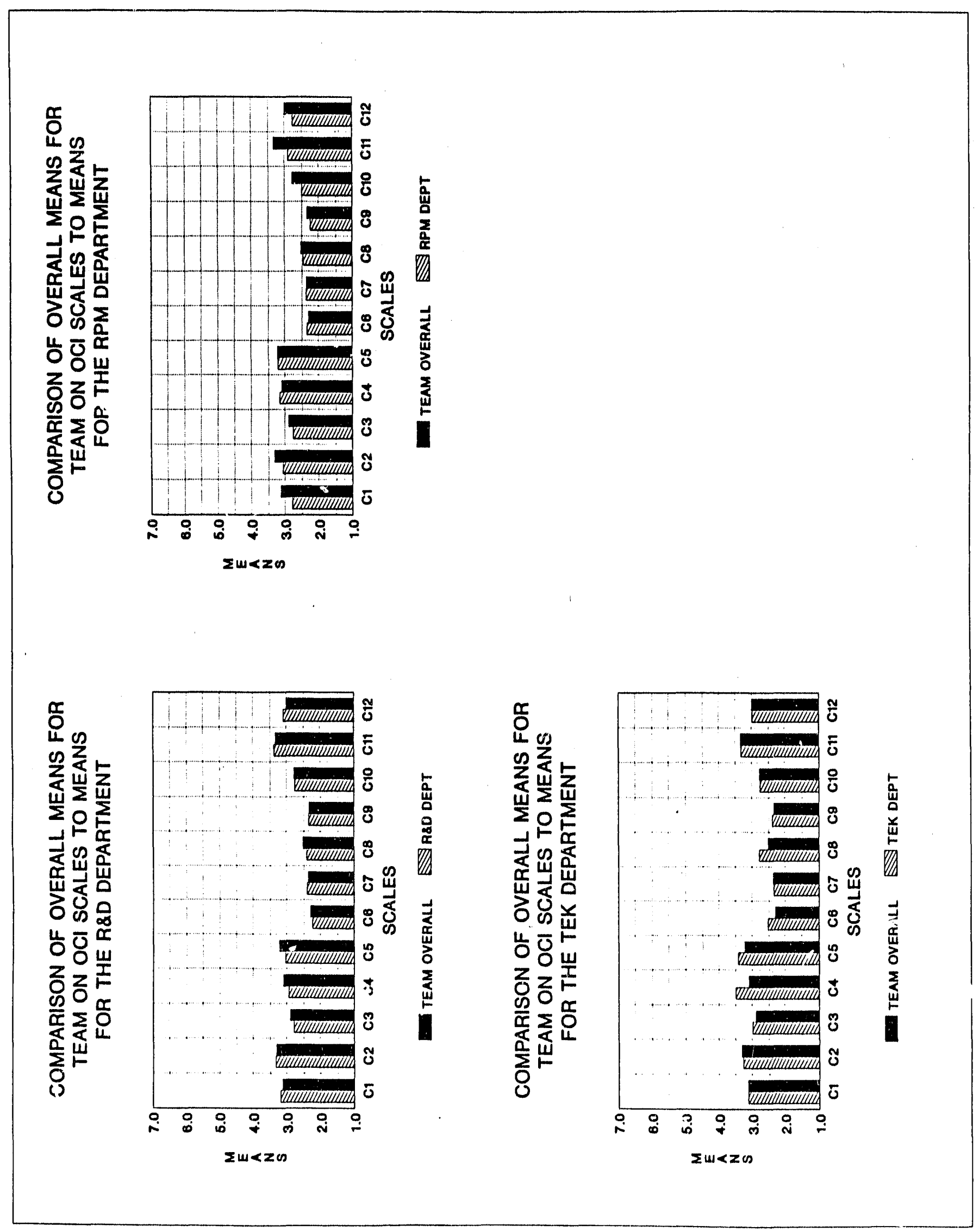




\section{APPENDIX $\mathrm{X}$ \\ COMPARISON OF ASI DEPARTMENTS TO THE OVERALL ASI MEAN VALUES ON THE OS}




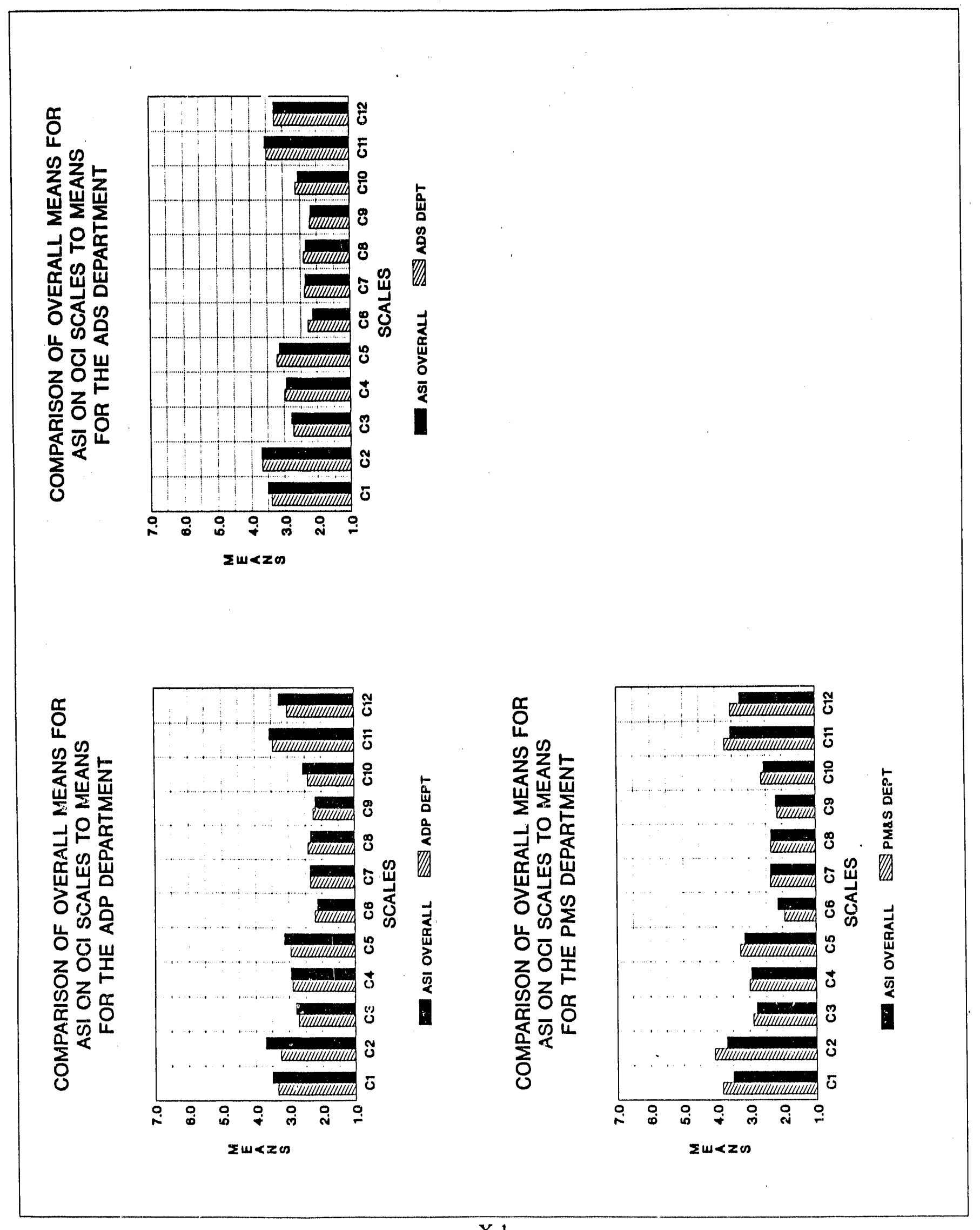


APPENDIX Y

COMPARISON OF DC DEPARTMENTS TO THE OVERALL DCI MEAN VALUES ON THE OS 


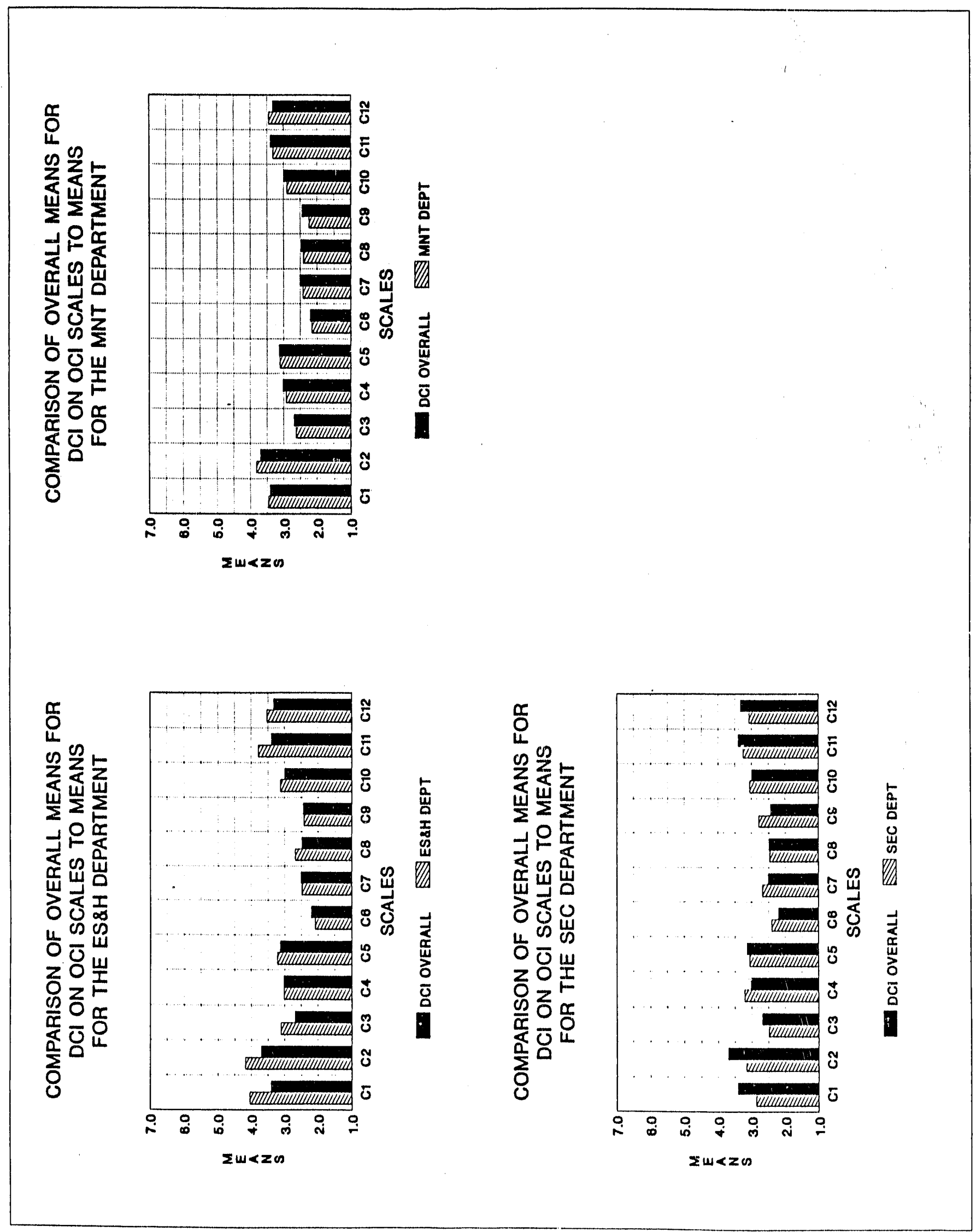


APPENDIX Z

COMPARISON OF DOE DEPARTMENTS TO THE OVERALL DOE MEAN VALUES ON THE COMMUNICATIONS SCALES 


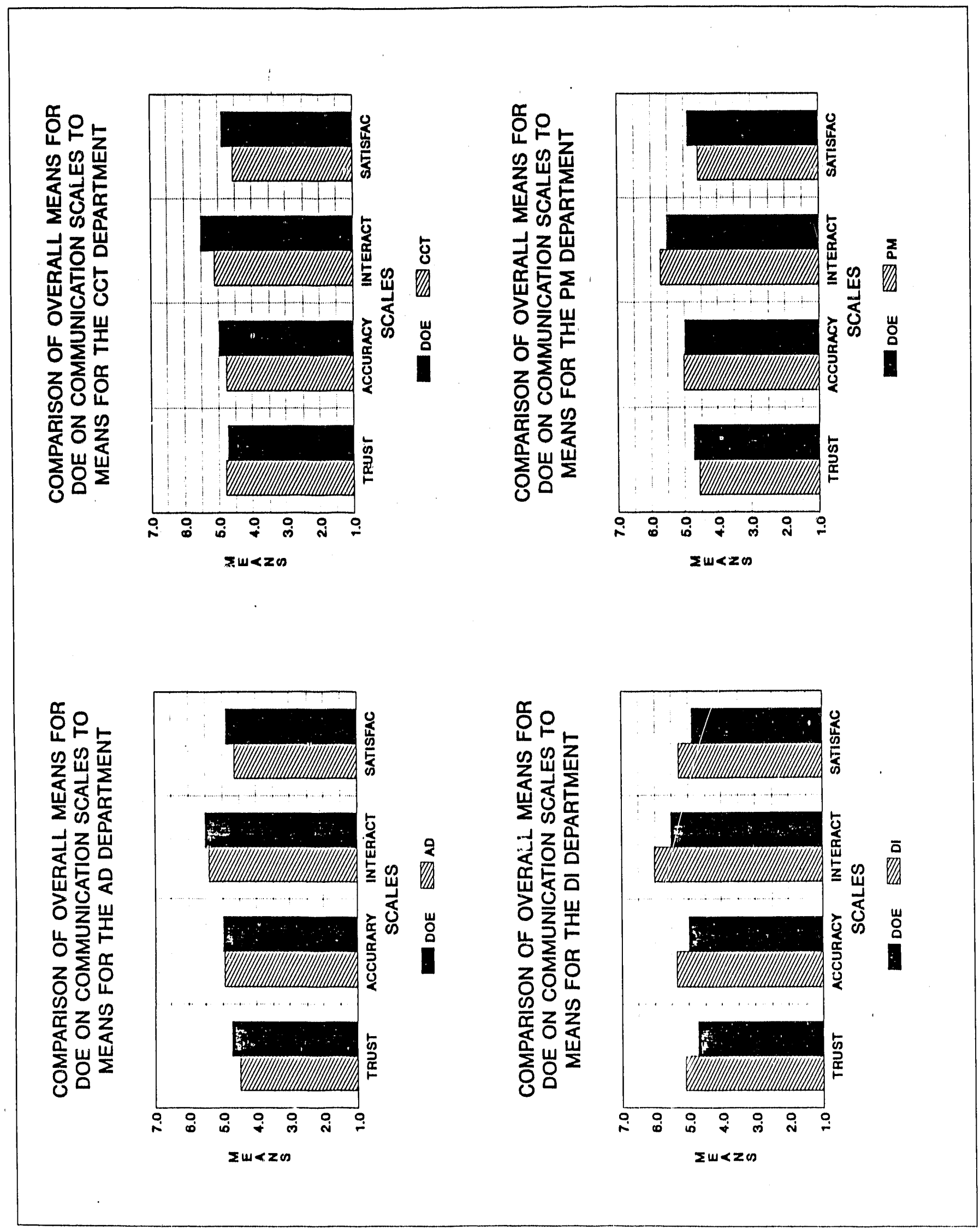




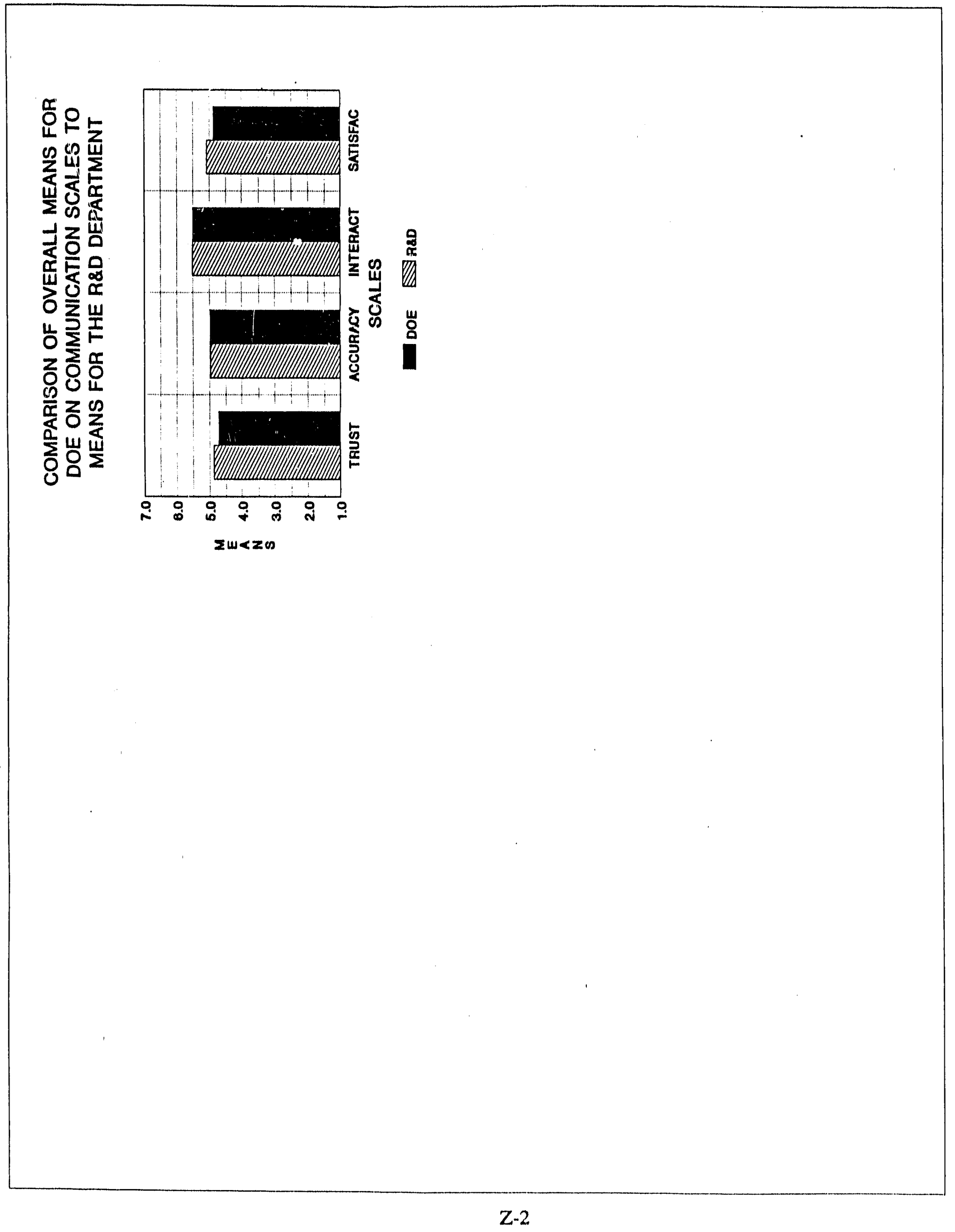


APPENDIX AA

COMPARISON OF TEAM DEPARTMENTS TO THE OVERALL TEAM MEAN VALUES

ON THE COMMUNICATIONS SCALES 

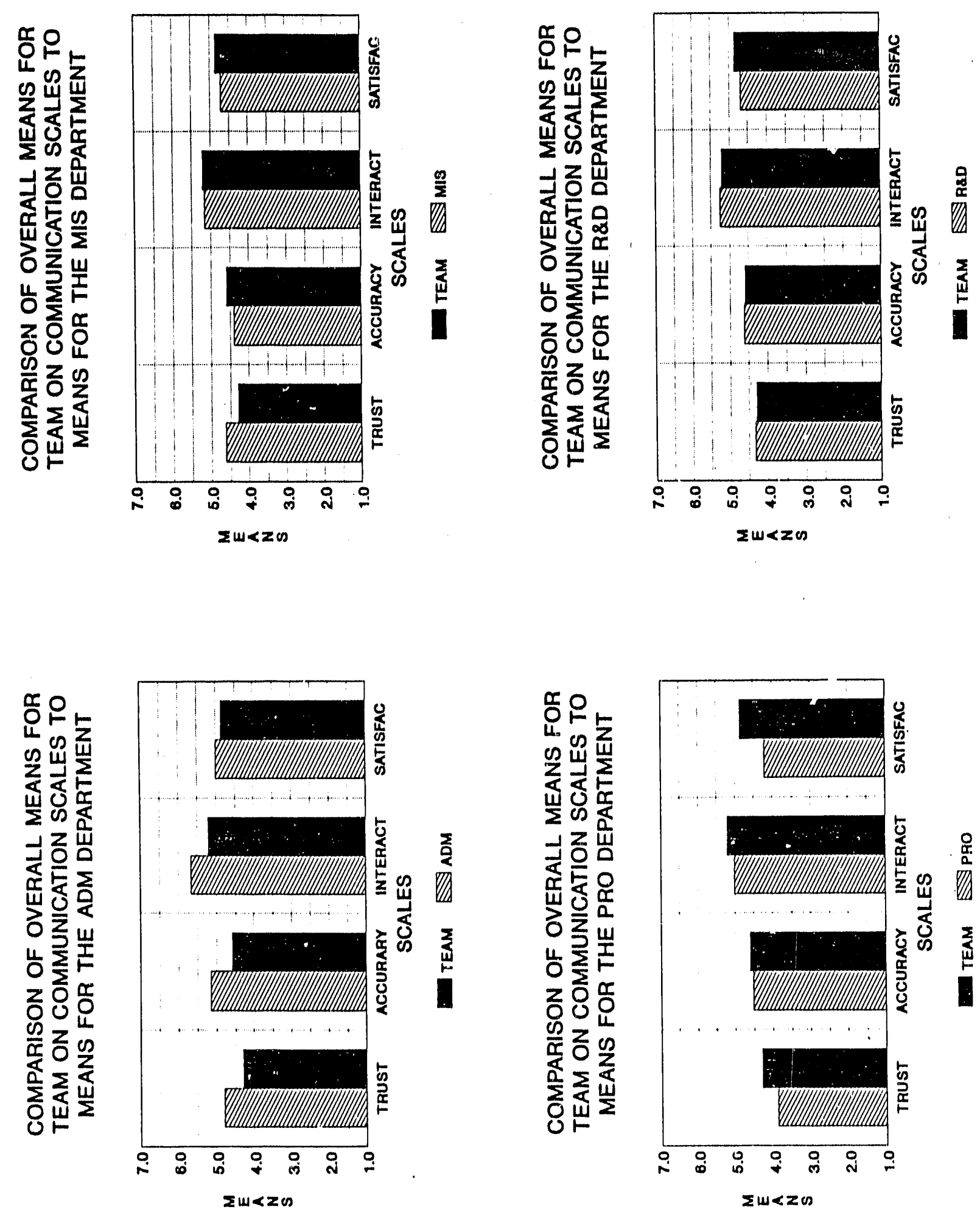

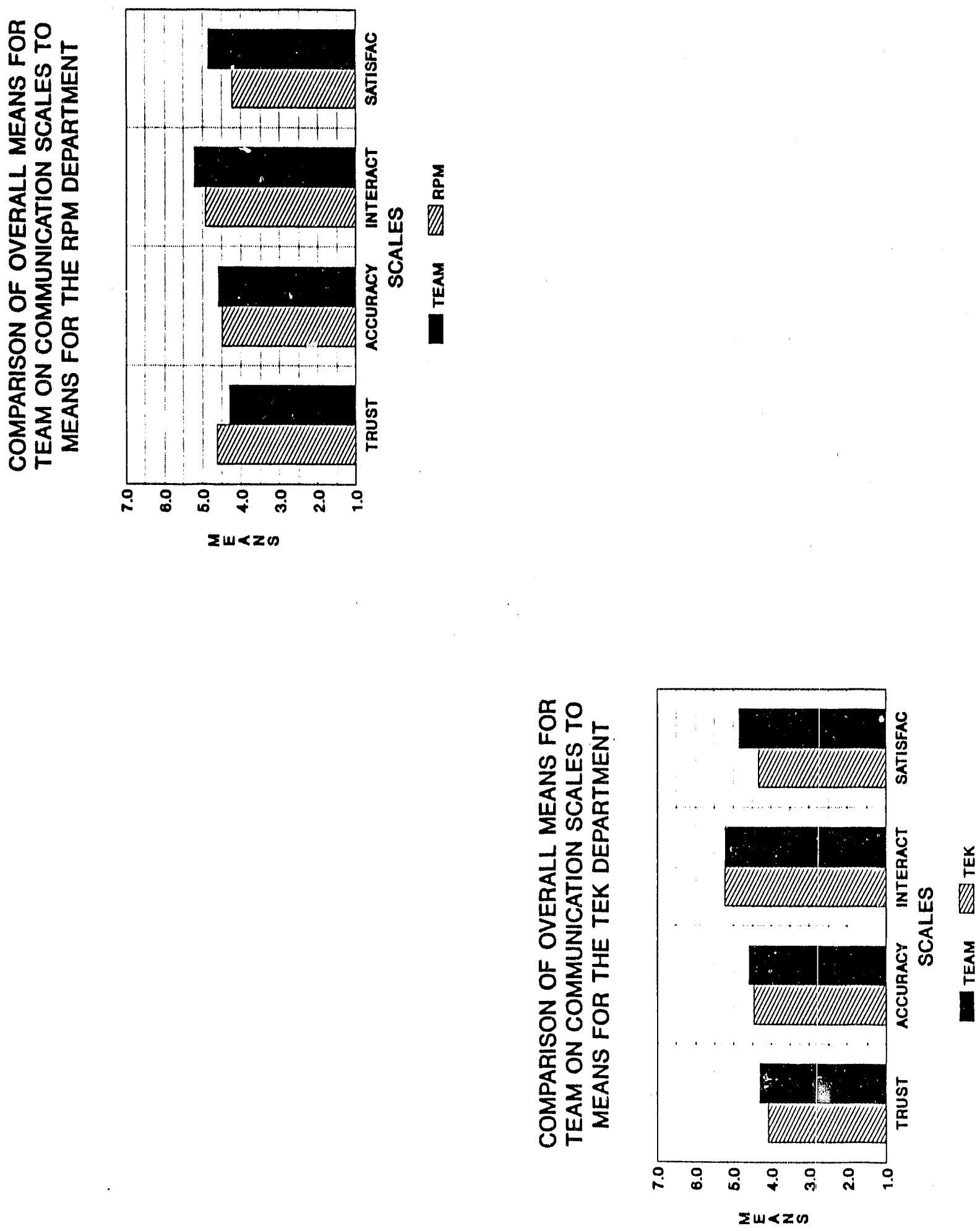
APPENDIX BB

COMPARISON OF ASI DEPARTMENTS TO THE OVERALL ASI MEAN VALUES

ON THE COMMUNICATIONS SCALES 


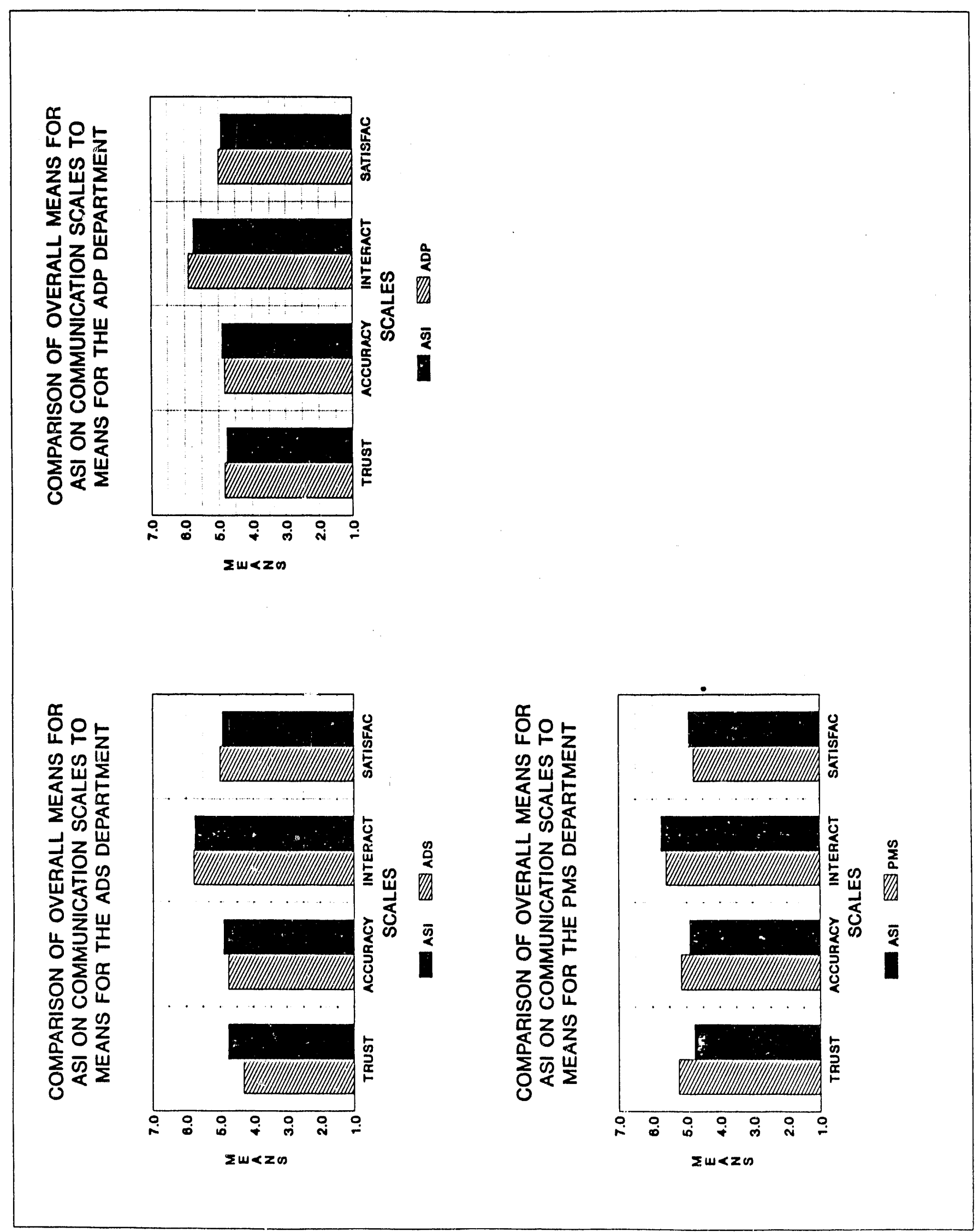

BB-1 


\section{APPENDIX CC}

COMPARISON OF DCI DEPARTMENTS TO THE OVERALL DCI MEAN VALUES ON THE COMMUNICATIONS SCALES 

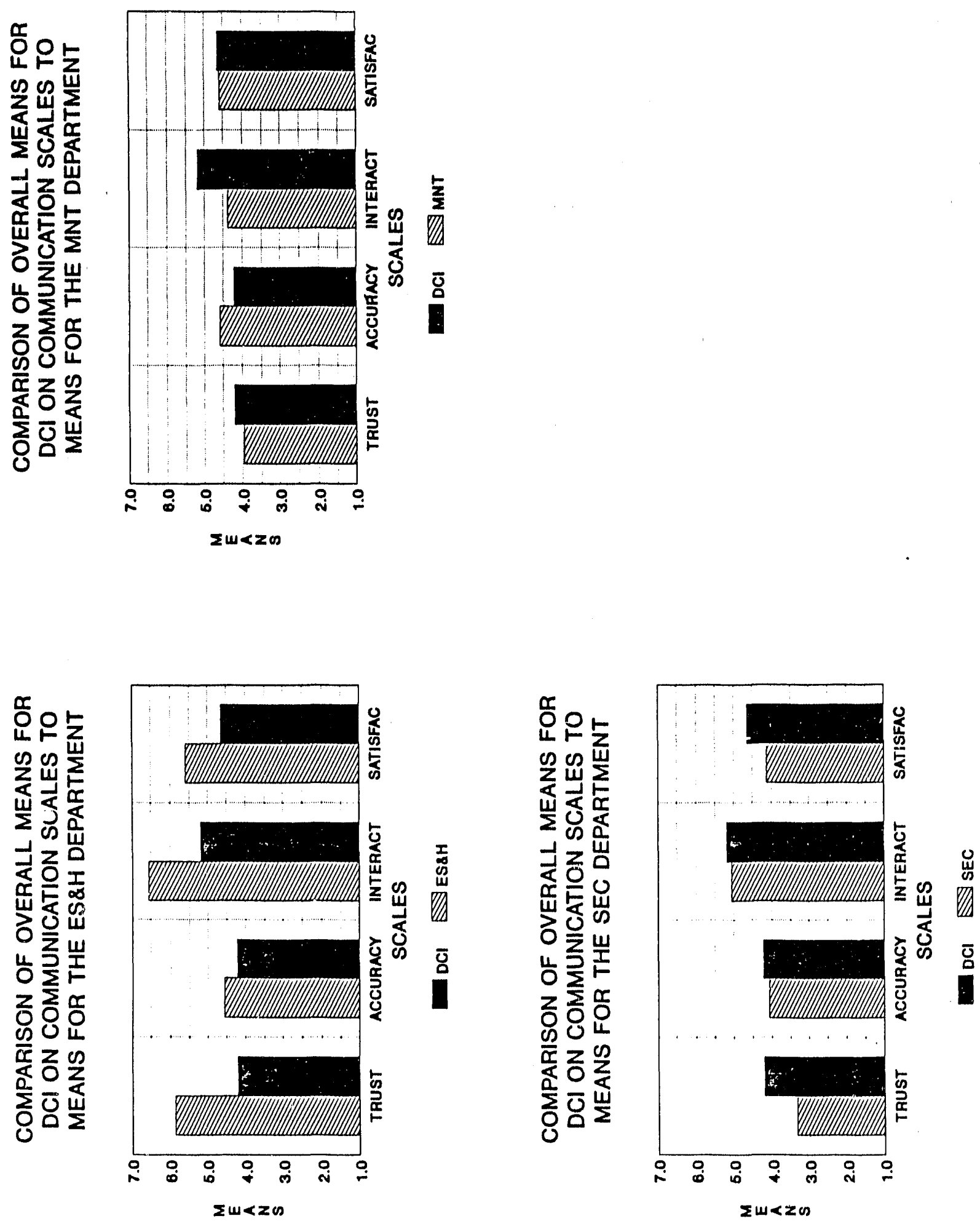


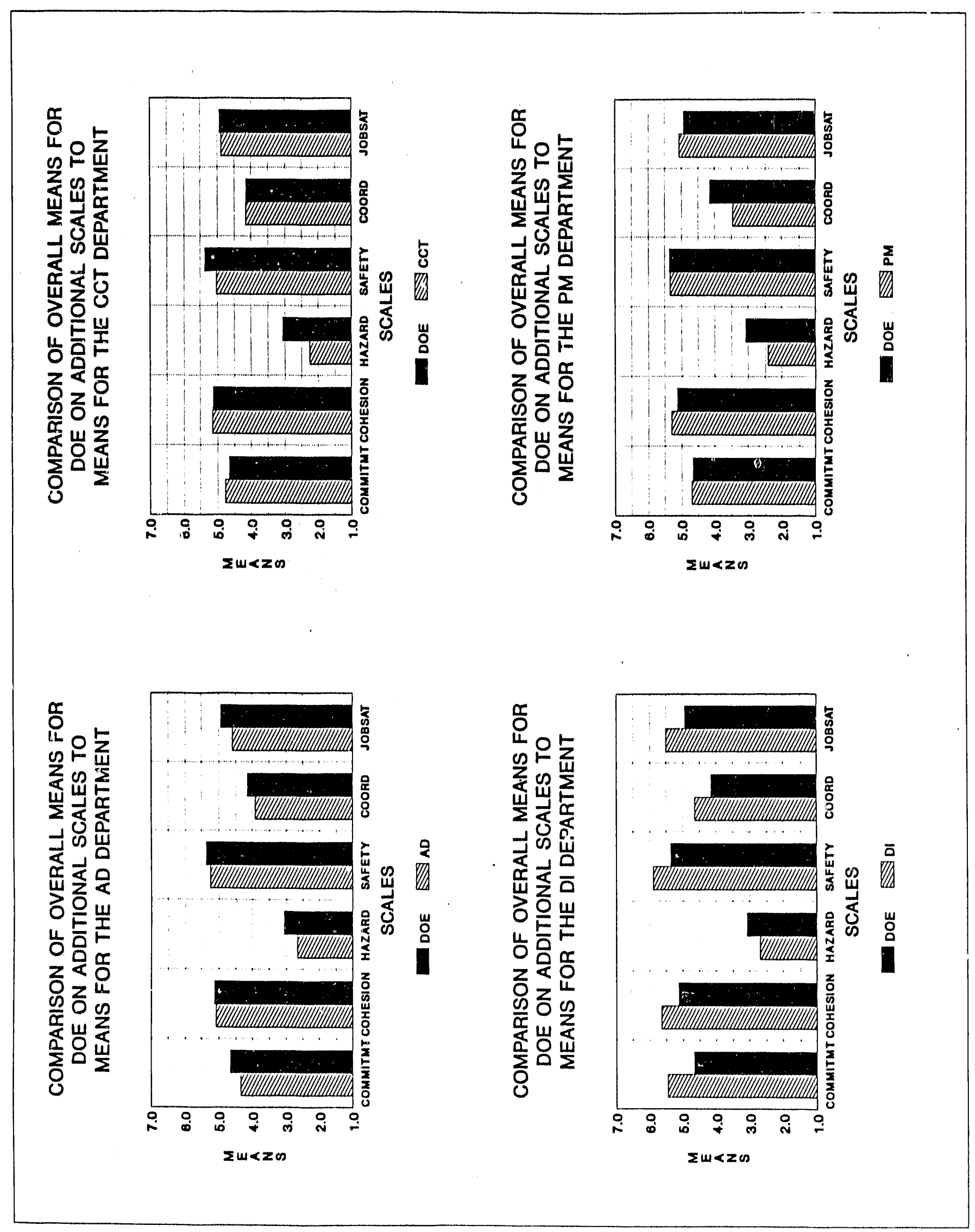

DD-1 


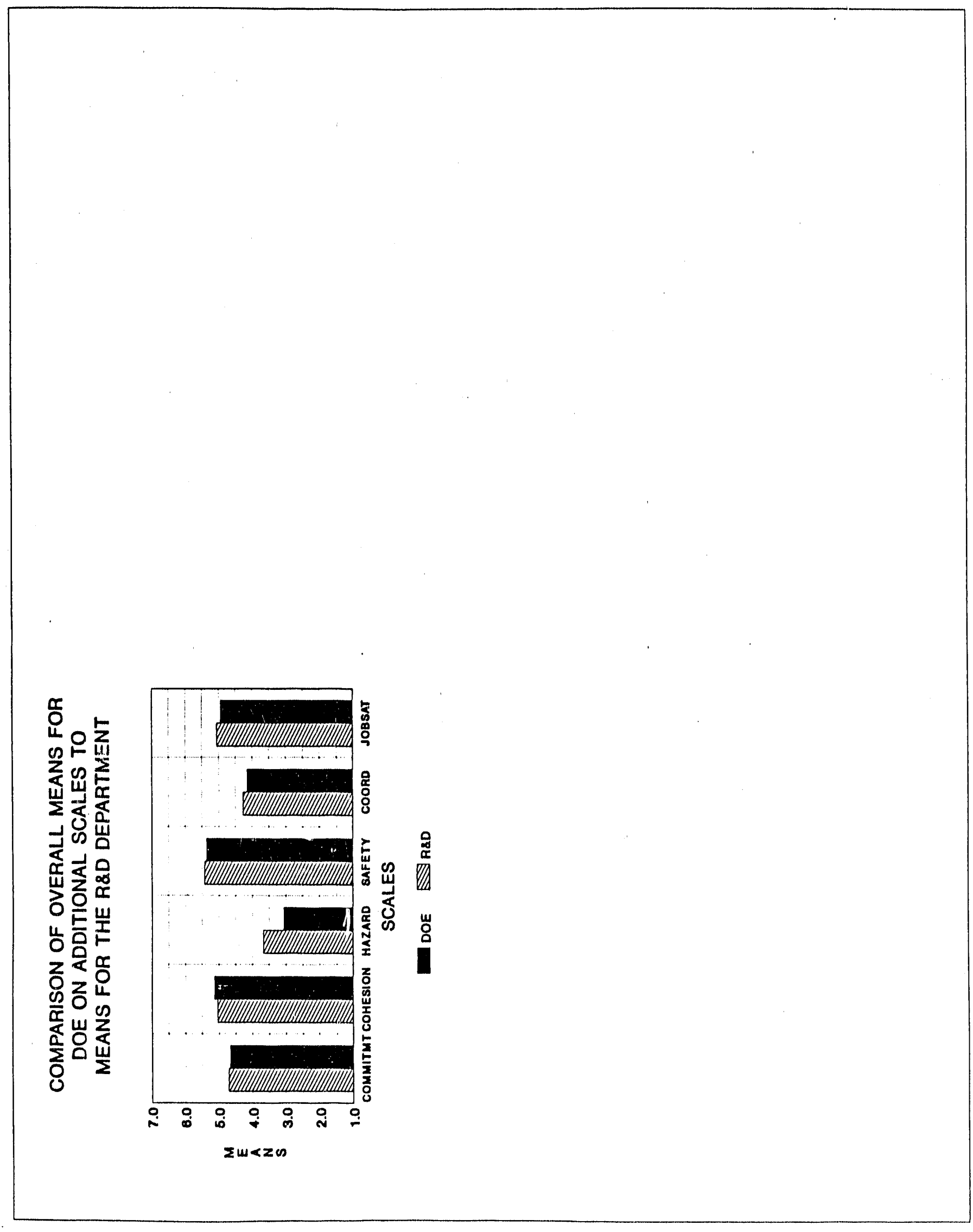


APPENDIX ER

COMPARISON OF TEAM DEPARTMENTS TO THE OVERALL TEAM MEAN VALUES ON THE ADDITIONAL SCALES 


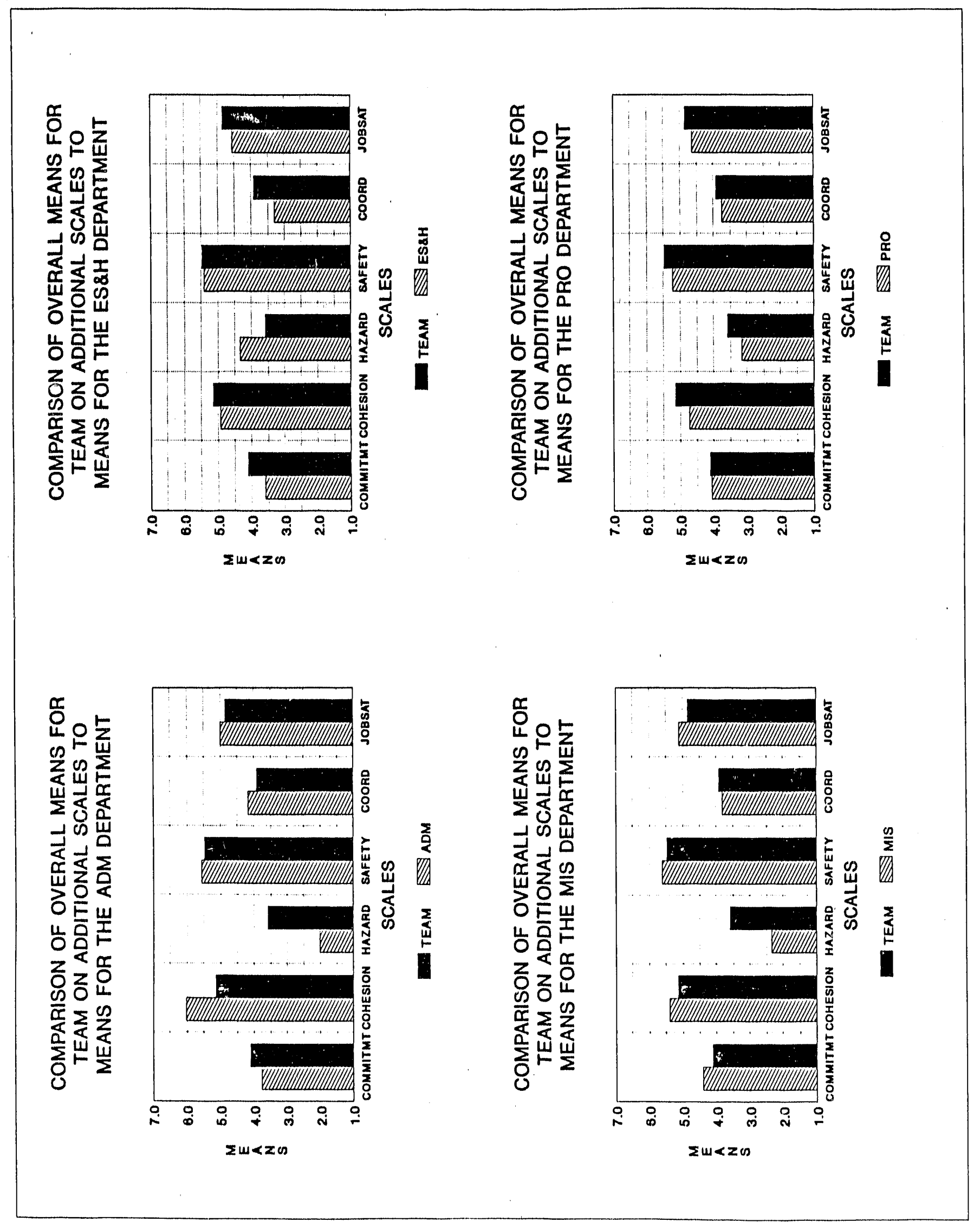

EE-1 


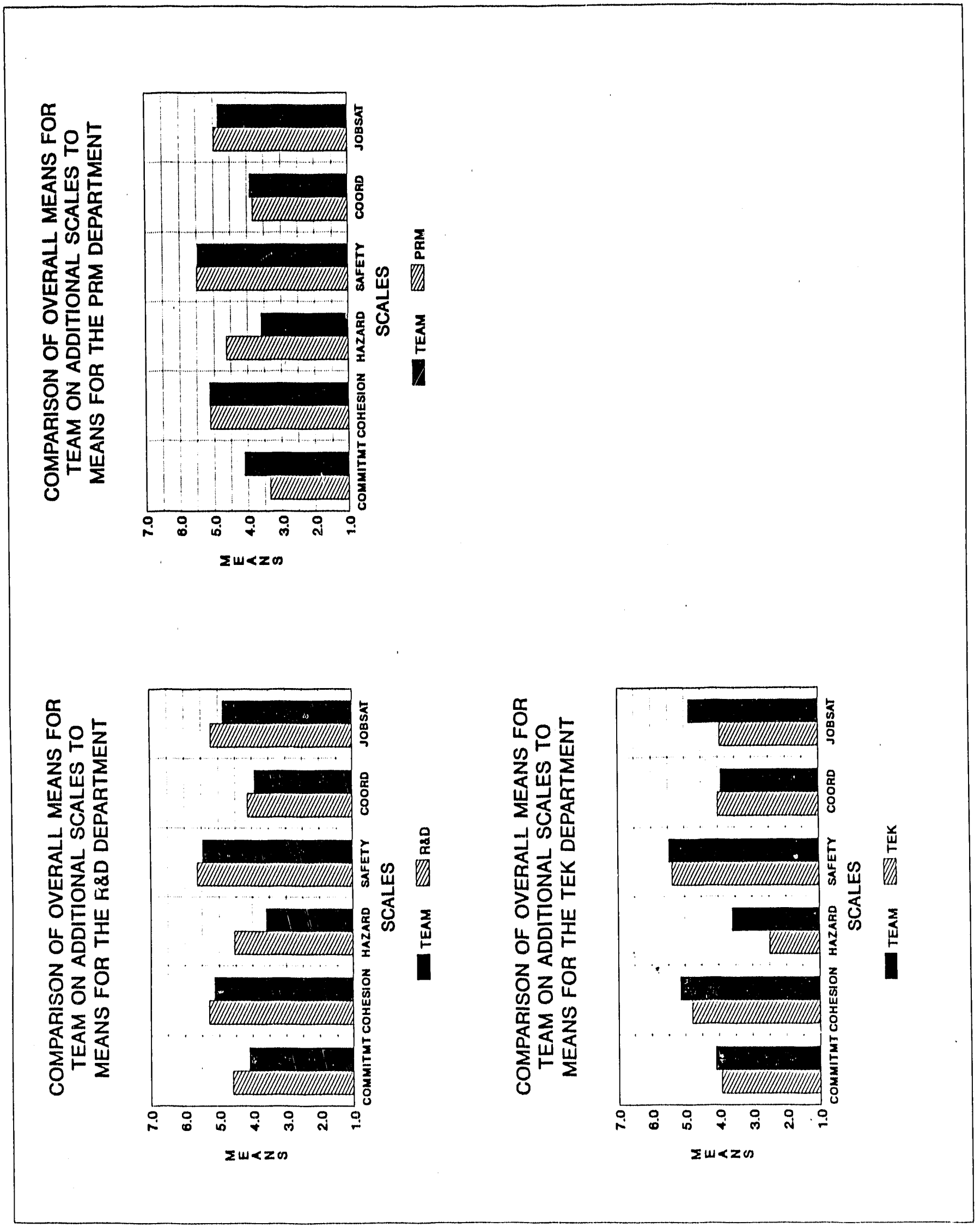




\section{APPENDIX FF \\ COMPARISON OF ASI DEPARTMENTS TO THE OVERALL ASI MEAN VALUES \\ ON THE ADDITIONAL SCALES}




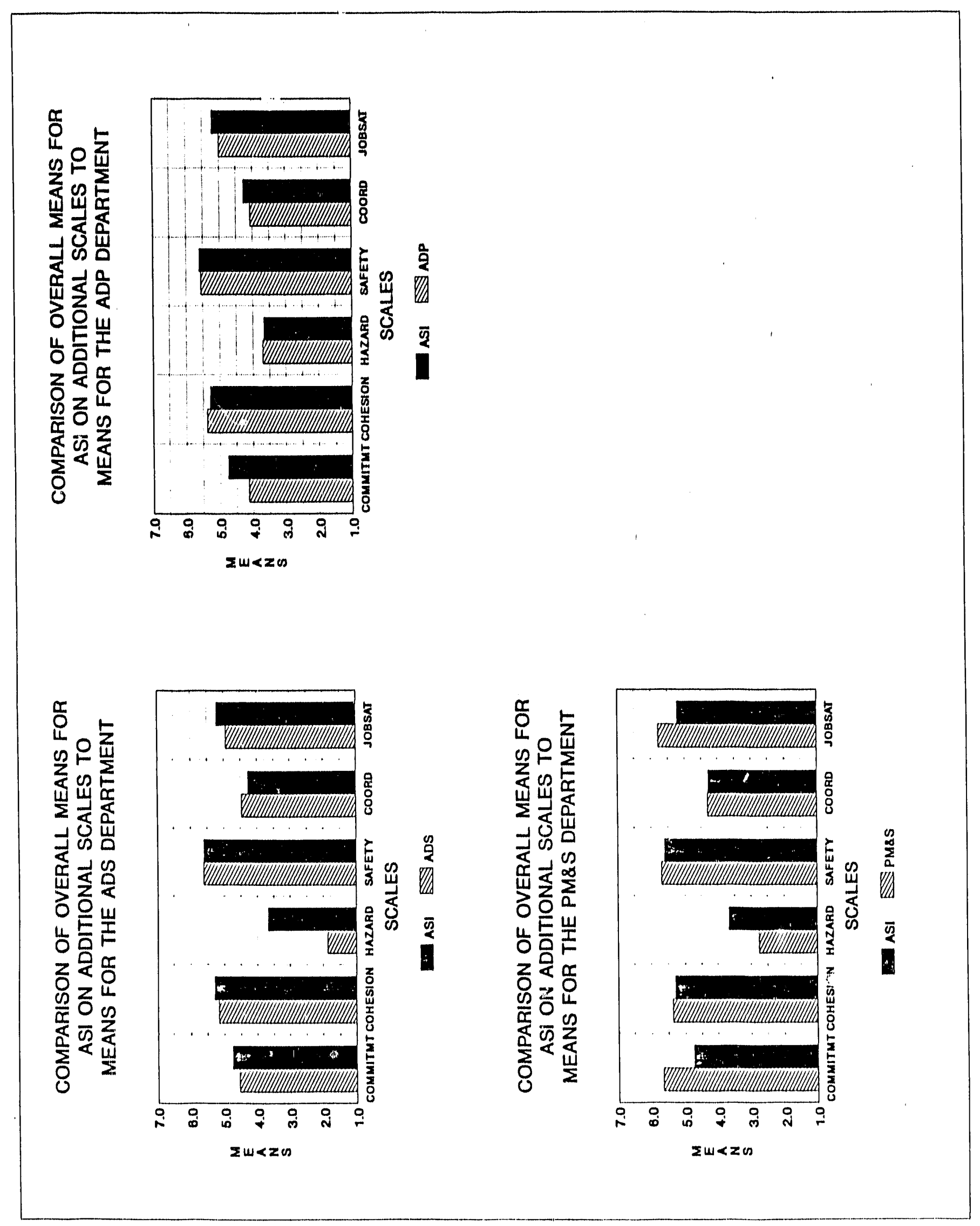




\begin{abstract}
APPENDIX GG
COMPARISON OF DCI DEPARTMENTS TO THE OVERALL DCI MEAN VALUES ON THE ADDITIONAL SCALES
\end{abstract}



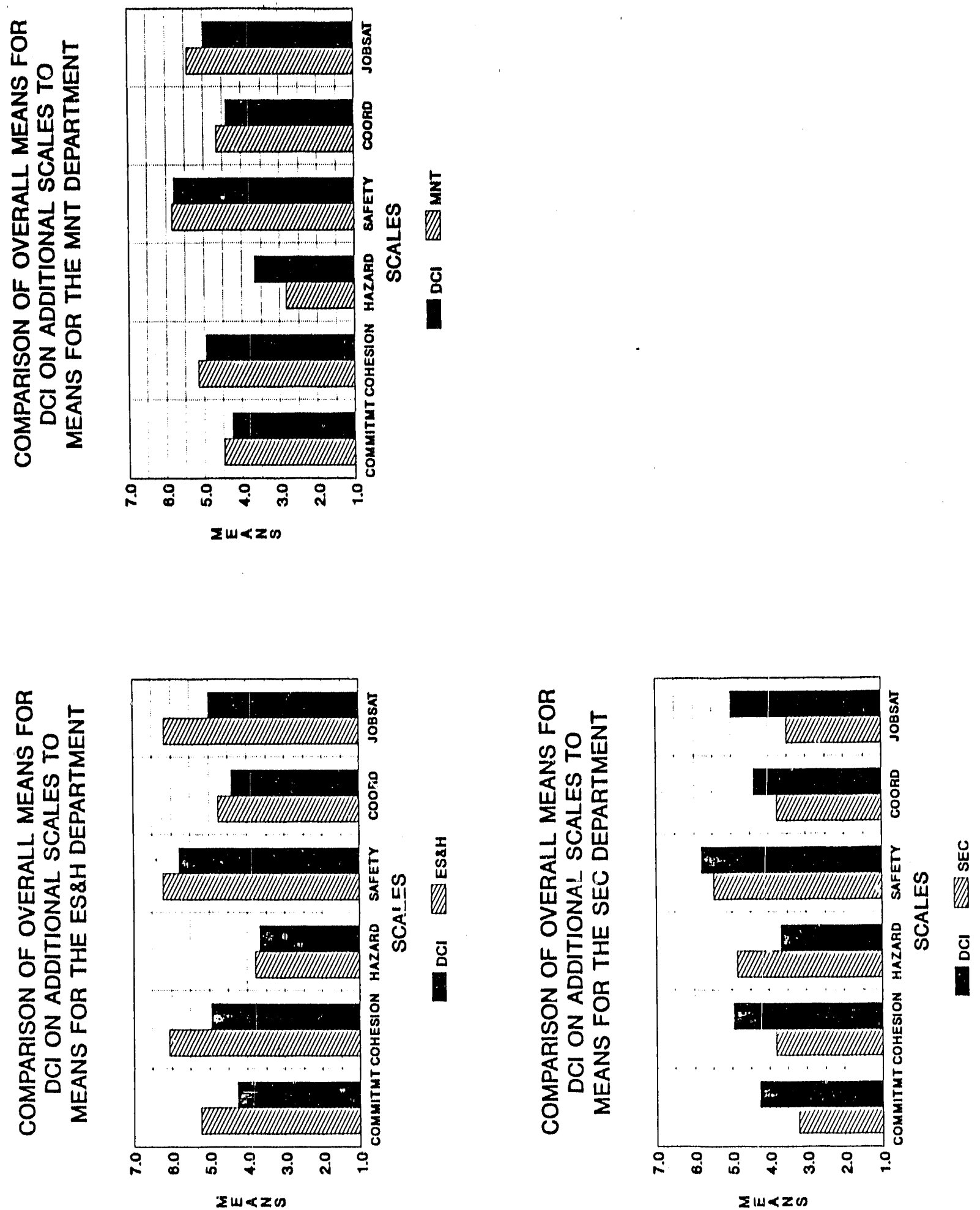

GG-1 


\section{APPENDIX HH}

COMPARISON OF DOE DEPARTMENTS TO THE OVERALL DOE MEAN VALUES

ON THE ENVIRONMENT, SAFETY, AND HEALTH QUESTIONS 


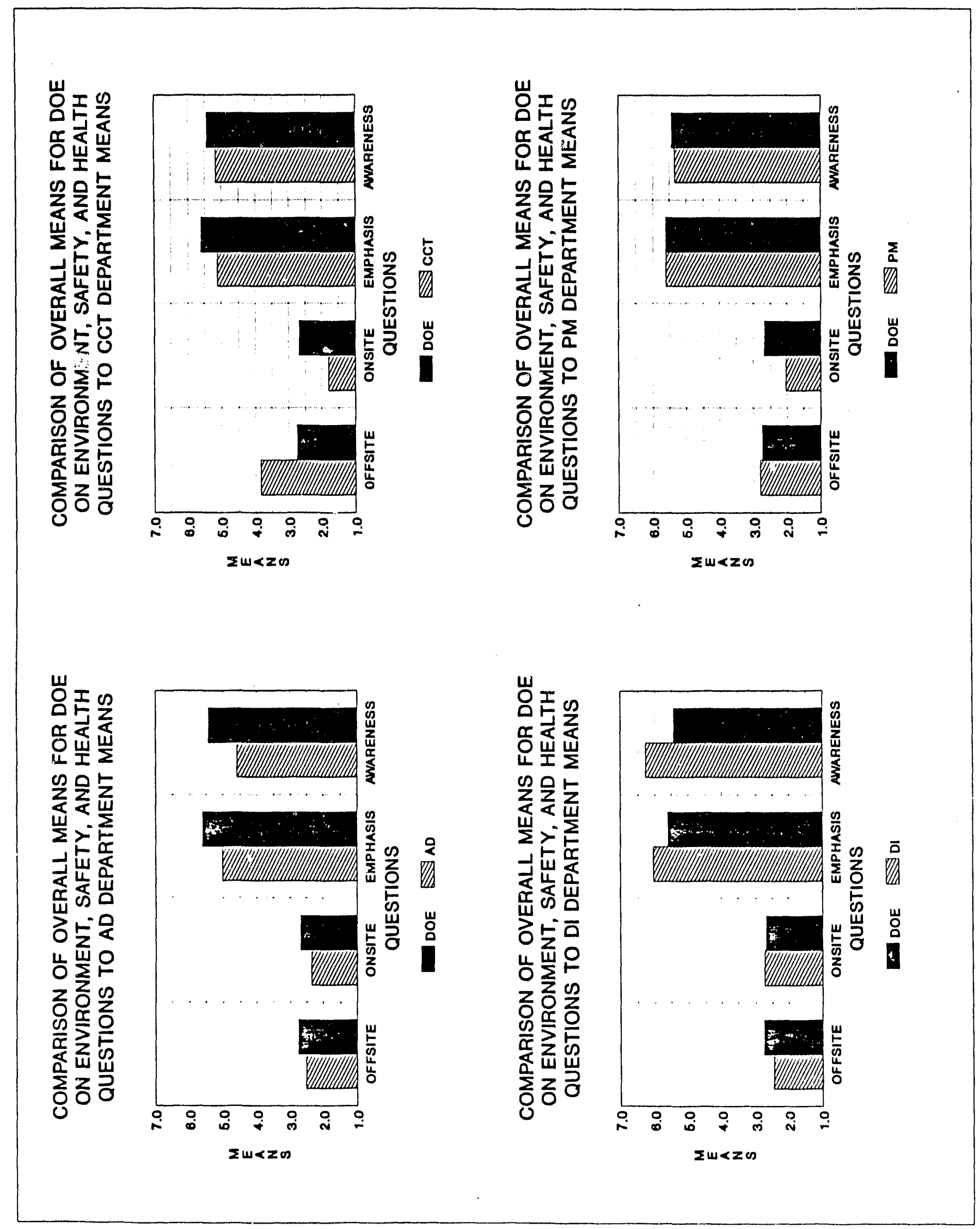




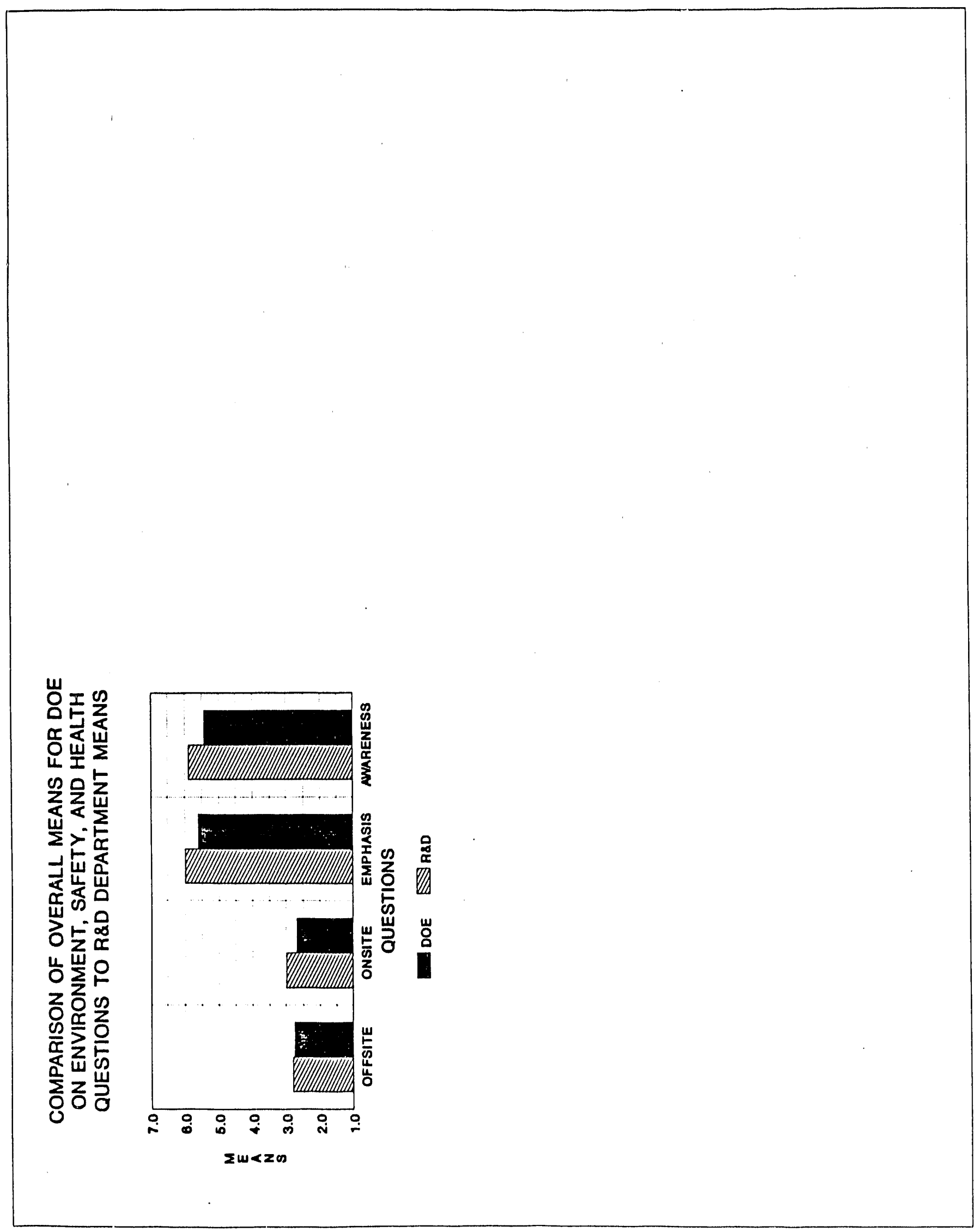


APPENDIX II

COMPARISON OF TEAM DEPARTMENTS TO THE OVERALL TEAM MEAN VALUES ON THE ENVIRONMENT, SAFETY, AND HEALTH QUESTIONS 


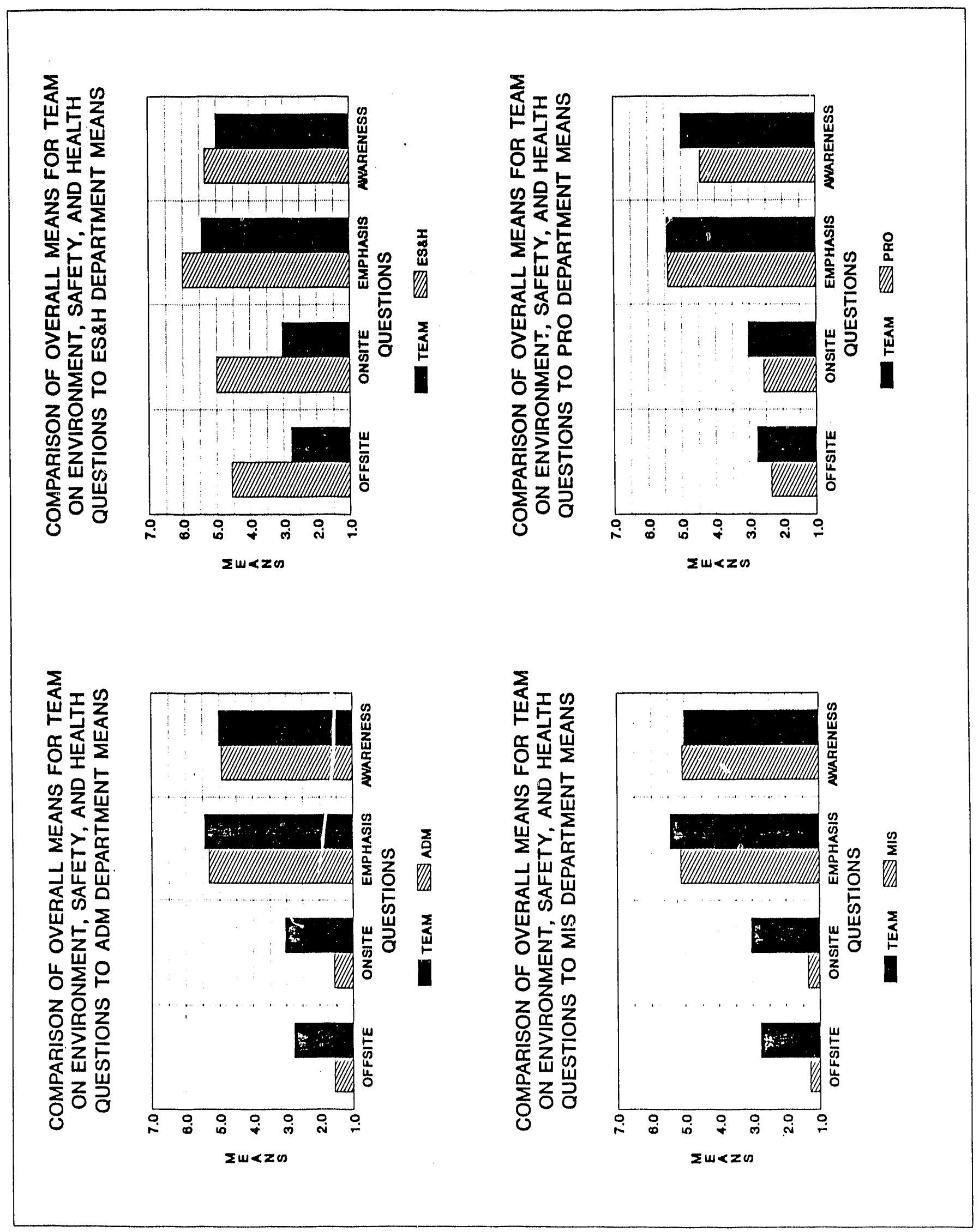




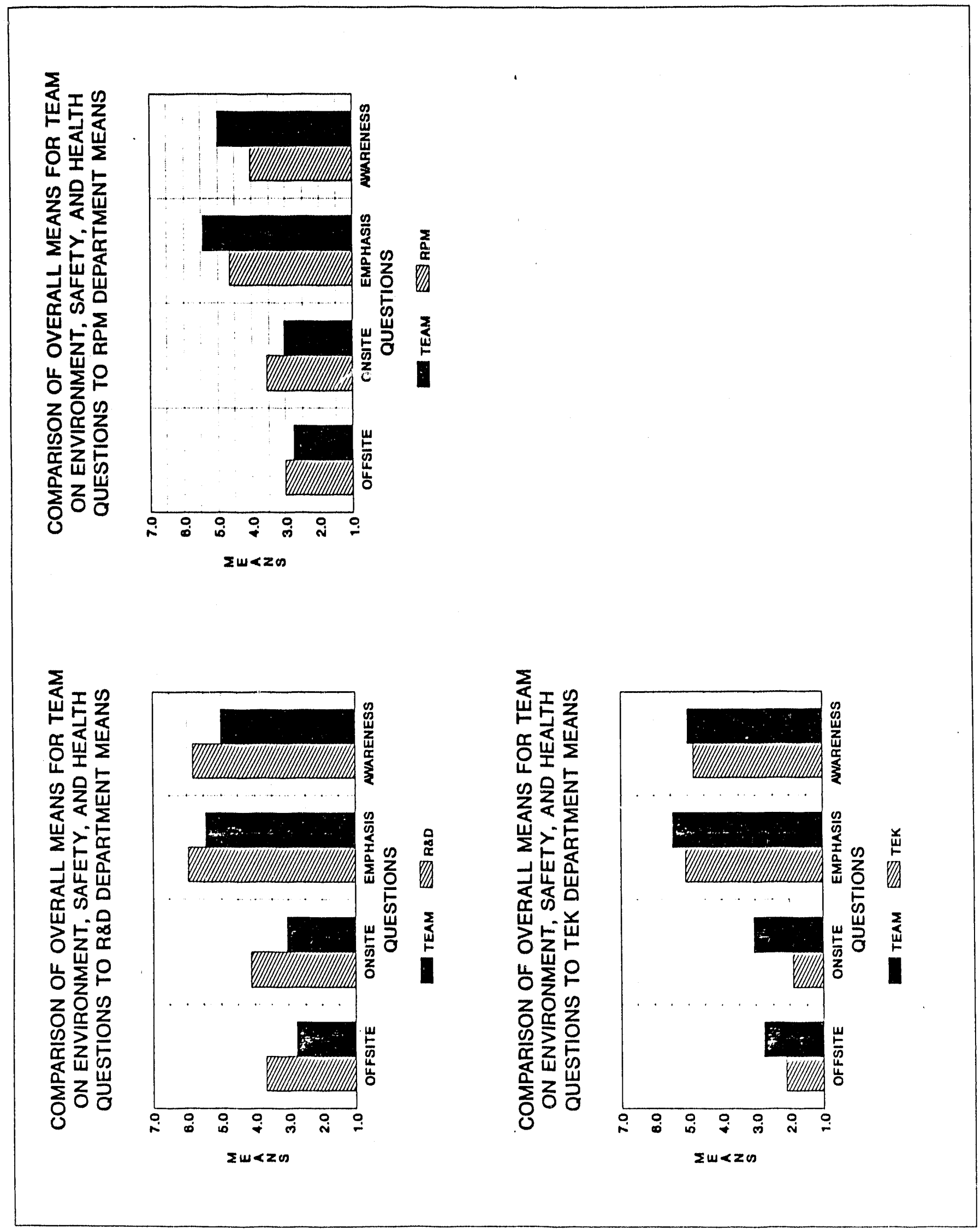




\section{APPENDIX JJ}

COMPARISON OF ASI DEPARTMENTS TO THE OVERALL ASI MEAN VALUES ON THE ENVIRONMENT, SAFETY, AND HEALTH QUESTIONS 


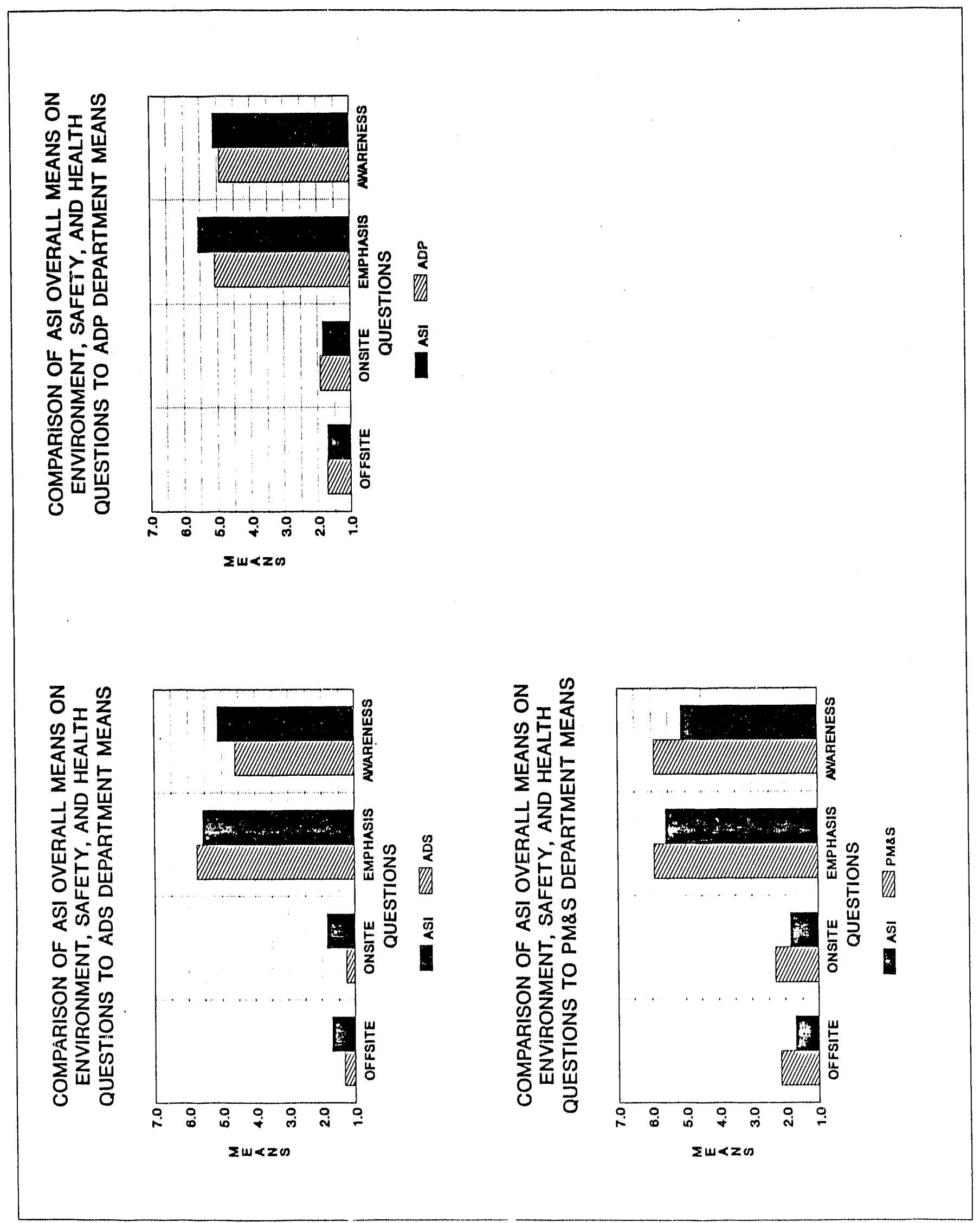




\begin{abstract}
APPENDIX KK
COMPARISON OF DCI DEPARTMENTS TO THE OVERALL DCI MEAN VALUES

ON THE ENVIRONMENT, SAFETY, AND HEALTH QUESTIONS
\end{abstract}



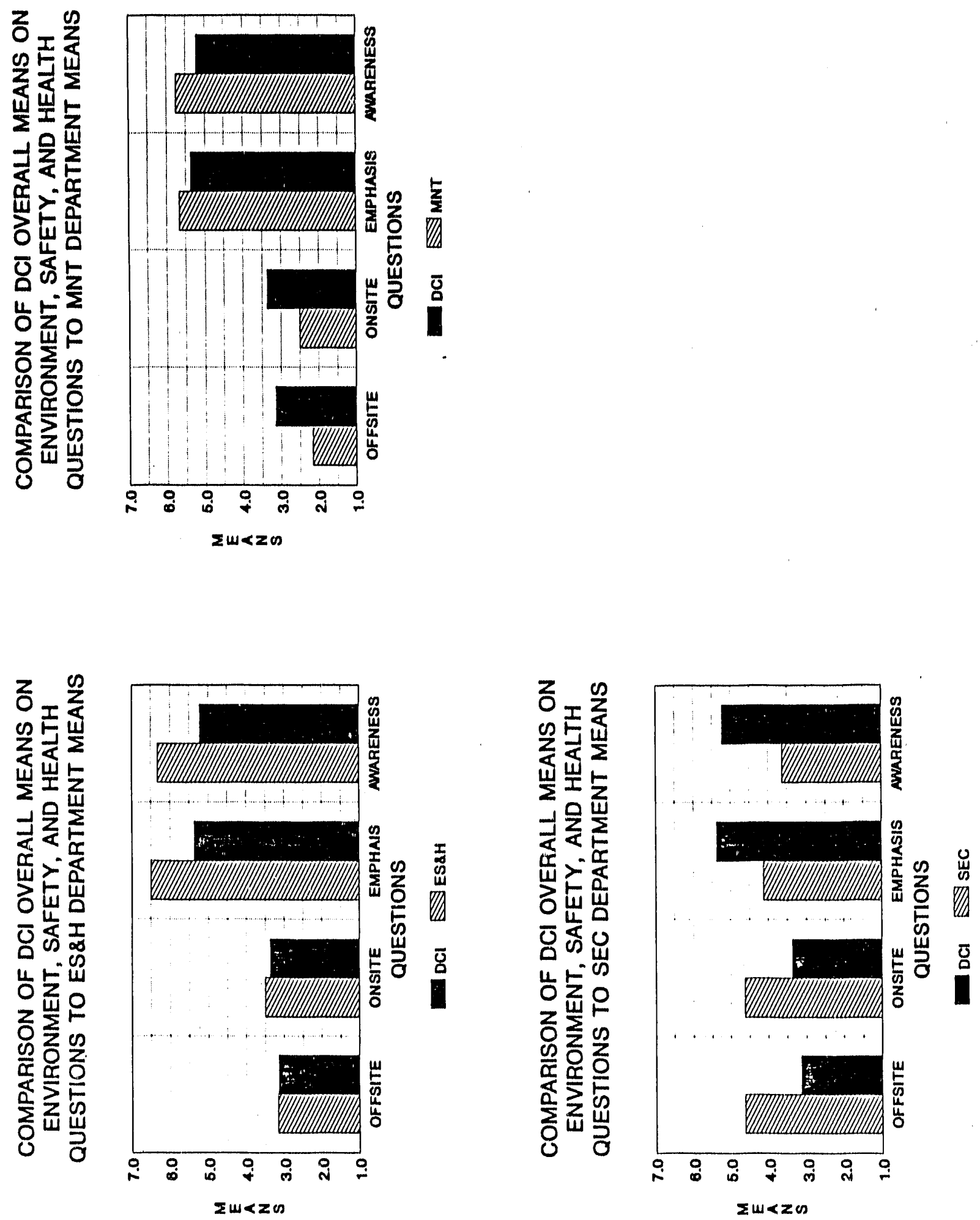

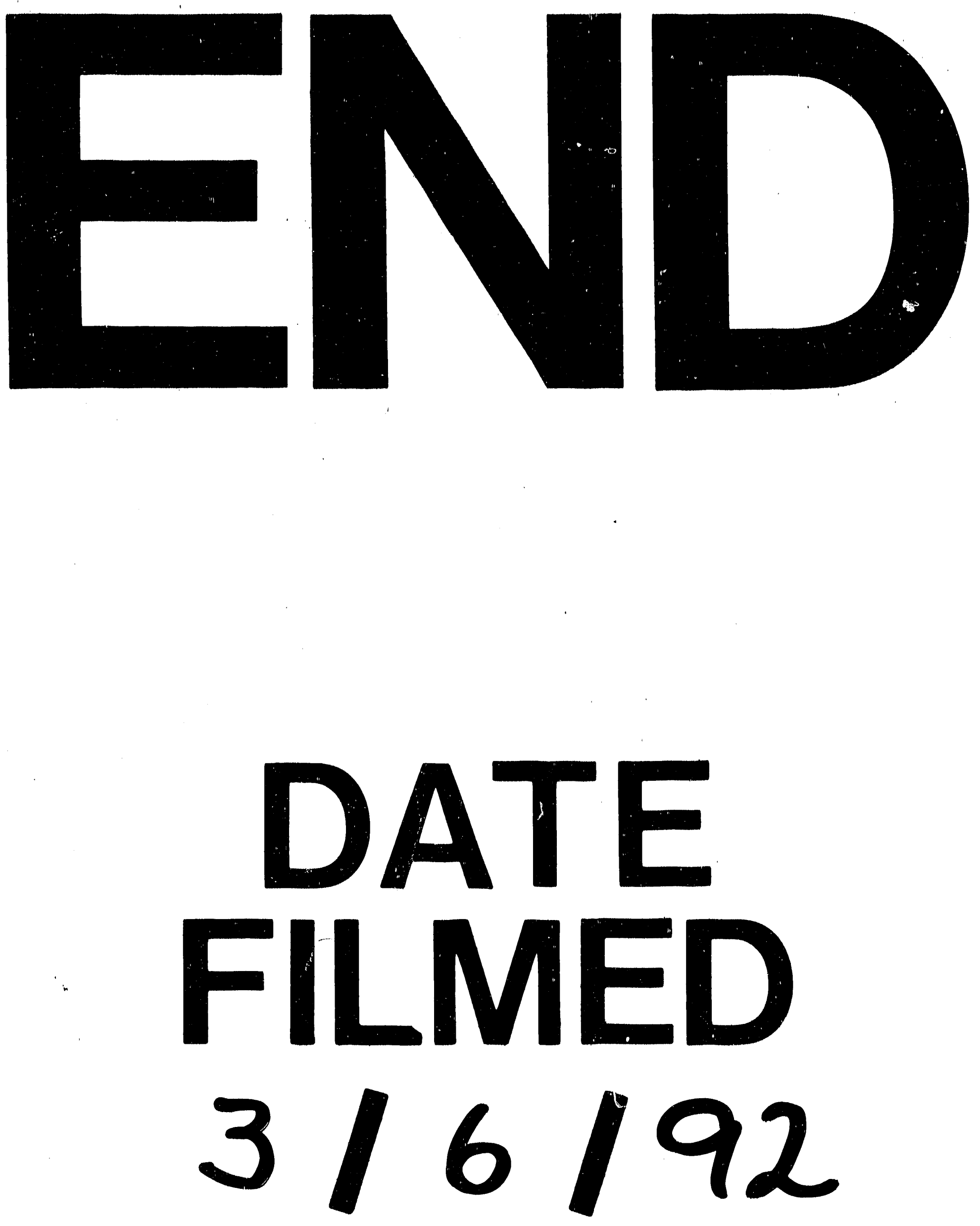

I 
